\title{
The evolution of the watering pot shells (Bivalvia: Anomalodesmata: Clavagellidae and Penicillidae)
}

\author{
Brian Morton \\ Department of Zoology, The Natural History Museum, Cromwell Road, \\ London SW7 5BD, United Kingdom \\ Email: prof_bmortonohotmail.co.uk
}

\begin{abstract}
Hitherto, the bivalve watering pot shells (Subclass Anomalodesmata) have been considered to be all contained within one superfamily - the Clavagelloidea - it too possessing but one family and generally comprising two functional clades: (i) the extinct Clavagella and the nestling/boring Dacosta and (ii) the endobenthic Brechites, Penicillus, Foegia, Kendrickiana and Nipponoclava (plus the fossil Pseudobrechites and Warnea), and Stirpulina. The cemented Pliocene-Recent Humphreyia can be derived from an endobenthic Brechites-like ancestor (Nipponoclava), making a third functional entity. The genus Dianadema also comprises species that are cemented. Recently, the endolithic Bryopa has been proposed as a fourth clade and a unique extension of the clavagellid line of evolution in which the anterior region of the right valve is dissolved as the animal bores deeper. The above studies, in broadening our understanding of the range of superfamilial functional diversity, however, raise questions with regard to the, as currently defined, taxonomic arrangement of the Clavagelloidea.
\end{abstract}

Species of the extinct genus Clavagella and their extant allies, notably Dacosta, have an internal ligament (but no lithodesma) located between chondrophores, both adductor muscles, a pallial line with a pallial sinus, and no pedal disc. Further, although Dacosta, Bryopa, Dianadema and Stirpulina cement their left valves to the wall of their crypt or adventitious tube, the right is free inside it. Conversely, both shell valves of Brechites and its allies, including the cemented Humphreyia, become surrounded by and united marginally with an adventitious tube and to which they are then fused by a calcareous secretion produced from the underlying mantle. Moreover, Brechites and Humphrevia have an external ligament (the latter with a lithodesma), are functionally amyarian as adults, have no pallial sinus and develop a watering pot anteriorly, internal to which is a highly muscular pedal disc. Most important, however, Humphreyia, at least, has a distinct post-planktonic life history stage in which a tree-living, typical bivalve juvenile, metamorphoses into a tube-dwelling adult. At this time, shell growth ceases and only the tube can be extended posteriorly and repaired. This is not the case with Clavagella and its allies although at some stage the juvenile does cement itself to its burrow wall but shell growth, especially of the free right valve, can continue.

All watering pot bivalves possess juvenile shells that in overall form and in the possession of distinct radial striae are reminiscent of representatives of the Lyonsiidae, suggesting a possible ancestry. The clavagellid fossil record shows that Clavagella and its allies (Dacosta, Bryopa, Dianadema and Stirpulina) arose in the Upper Cretaceous and are thus of Tethyan origin. Clavagellids have subsequently radiated into nearly all tropical waters. Conversely, the penicillid Brechites and its tube-dwelling allies, plus Humphrevia, arose at least 40 million years later, in the Oligocene, and have an Indo-West Pacific distribution.

It is argued, therefore, that the Clavagelloidea, as currently defined, comprises two families. Clavagella sensu stricto and sensu lato (including Dacosta, Bryopa, Dianadema and Ascaulocardium), with Stirpulina, belong to the Mesozoic and originally Tethyan Clavagellidae d'Orbigny, 1843. Brechites sensu stricto and sensu lato, with Humphreyia, belong, with the various endobenthic allies of the former, to the Cenozoic and Indo-West Pacific Penicillidae Bruguiere, 1789. Both families appear to have evolved at different times probably from lyonsiid ancestors. In such a scenario, they have both subsequently radiated into a wide range of marine habitats involving a considerable and remarkable degree of convergent evolution, for example, 
between the endobenthic tube-dwelling Stirpulina (Clavagellidae) and Brechites (Penicillidae) and the cemented Dianadema (Clavagellidae) and Humphreyia (Penicillidae). Only Dacosta and Bryopa (Clavagellidae), however, have adopted endolithic, nestling/boring life styles, with no penicillid counterpart. The burrow lining was thus essentially exaptive for the evolution of an adventitious tube (Stirpulina) in the Clavagellidae whereas that of the Penicillidae evolved, not just independently, but probably from a burrowing ancestor, like Nipponoclava.

Key words: Watering pot shells, Upper Cretaceous, Clavagellidae, Oligocene, Penicillidae, evolution of tube-dwelling, cementation, boring/nestling, neoteny, heterochrony, convergent evolution.

\section{INTRODUCTION}

It seems as if nature had taken precautions that her choicest treasures should not be made too common and thus undervalued' (A.R.Wallace, 1869)

Purchon (1968) considered the remarkable growth form of the watering pot shell Brechites penis (Linnaeus, 1758) to be the most bizarre in the whole class [Bivalvia].' Pojeta and Sohl (1987) described the Cretaceous anomalodesmatan clavagellid Ascaulocardium armatum and called it the ultimate variation on the bivalve paradigm'. As we shall see, however, $A$. armatum is just as bizarre as the endobenthic Brechites vaginiferus (Lamarck, 1818) and its allies but, arguably and as will be illustrated, not so amazing as the total spectrum of watering pot shell diversity. B.J. Smith (1998) described the Clavagellidae as 'the most aberrant of the bivalve families.' So bizarre (and generally rare) are fossil species of Stirpulina that the "Mysterious Fossils" pages of the Palaeontology Newsletter (Little, 2005) asked readers for help in identifying a species from the Plio-Pleistocene of Nicosia, Cyprus. Similarly if fossil watering pot shells are "rare", extant species are arguably, for so obviously amazing shells, among the rarest of living animals too. As this review will document, the original researches upon which it is based and that I have undertaken over a period of more than 20 years typically involved examination of single, preserved individuals scoured from museums worldwide. For example, the Japanese Stirpulina ramosa (Dunker, 1882 ) is known from only one or two specimens and has never (to my knowledge) been collected alive (Morton, 2006a).

The extinct and modern representatives of the, as currently defined, Clavagelloidea are also so strange that an obvious ancestral group is unknown. On the basis of an anatomy-based cladistic study, however, Harper et al. (2000) linked the superfamily to the predatory deep water septibranch families Verticordiidae, Lyonsiellidae, Poromyidae and Cuspidariidae as a sister group to the Lyonsiidae. Dreyer, Steiner and Harper (2003), on the basis of an 18S rRNA sequencing study of many anomalodesmatans, also concluded that the
Lyonsiidae constituted the closest relatives of the Clavagelloidea.

Carter (1978) suggested that the tube-dwelling Clavagelloidea evolved from deeply burrowing bivalves, probably representatives of the Pandoroidea although Pojeta and Sohl (1987) thought that they had evolved during the Jurassic Early Cretaceous from an ancestral representative of the Pholadomyidae. Morton (1985a) considered that the closest relatives of the Clavagelloidea were to be found among representatives of the Thracioidea, notably the Laternulidae (also with externally spinulose shells, Aller, 1974), with links back to the Pholadomyoidea (Morton, 1980). In the latter case this was because of an inferred common ability to take in interstitial water from sub-surface sediments via the pedal gape. This ability has now been demonstrated for Brechites vaginiferus and Foegia novaezelandiae (Morton, 2002a, 2004a).

The current level of knowledge with regard to the fossil record of the Clavagelloidea also hinders the identification of an ancestor, particularly as many details of the adventitious tube find similar structure and common function with other tubebuilding bivalves, for example, Eufistulana mumia (Spengler, 1783) (Gastrochaenidae) (Morton, 1983). Eames (1957) provided an example of the problem by describing a putative clavagelloid, Kitsonia eocina (Kitsoniidae), from the Eocene of Nigeria, but which with the presence of a distinct set of hinge teeth, is clearly not even an anomalodesmatan that generally lack them (Morton, 1981, 1985a). The accepted taxonomic classification, pattern of adaptive radiation and evolution of the Clavagelloidea have, thus, in this author's view, been misinterpreted.

Three recent studies suggest that the present location of all watering pot shells within one family may not be appropriate.

1. Savazzi (1999, pp. 231-232) stated: 'It cannot be excluded that the Clavagella and Brechites lineages [my italics] represent a case of parallel evolution, rather than successive evolutionary phases within the same phylogenetic lineage. In this scenario, Clavagella might have evolved from secondary borers, while Brechites might instead be a direct descendent from burrowers. 
A parallel evolution of the two lineages from ancestors with different life habitats (albeit belonging to the same taxonomic group) could explain their different morphological characters, which are too dissimilar to allow an unquestionable interpretation of Brechites as an offshoot of Clavagella.' Savazzi (2000, p. 324) continues with this theme, identifying Clavagella, Penicillus and Bryopa "groups", or clades, suggesting that they all represent monophyletic "lineages" and 'may justify the introduction of three subfamilies'. Most recently, Savazzi (2005, p. 80) states: 'The family Clavagellidae contains two separate adaptive (and most likely phylogenetic) lineages, called the Clavagella lineage and Penicillus lineage by Savazzi (2000)'.

2. A fourth cemented clavagelloid clade has been identified recently and is represented by two Australian genera, Humphreyia and Dianadema (Morton, 2002b, 2003a). Hitherto poorly studied, Humphreyia strangei (A. Adams, 1854) was considered by L.A. Smith (1962a, text-fig. 1) to represent a Recent offshoot of the Clavagella line. A study of $H$. strangei by Morton (2002b), however, has shown to the contrary that Humphreyia is most closely linked to the Brechites (or Penicillus) "lineage" (as Savazzi, 1999 and 2005 puts it). Moreover, Dianadema multangularis (Tate, 1887) has hitherto been placed in the genus Clavagella (B.J. Smith, 1971, 1976) but Morton (2003a) has shown that it is distinct in that it possesses a crown of tubules arising from the apex of the crypt, as also seen in the Indian Ocean D. mascarenensis recently described by Oliver and Holmes (2004) and the fossil Ascaulocardium armatum (Pojeta and Sohl, 1987).

3. Morton $(2005,2006 a)$ has studied the structure and method of formation of the adventitious tubes of the fossil clavagellid Stirpulina coronata (Deshayes, 1824) and the extant Stirpulina ramosa and showed that the process involved is fundamentally different from that of the penicillid Brechites vaginiferus, as elucidated by Harper and Morton (2004). Further, although representatives of both Brechites and Stirpulina have been considered closely related because of their common endobenthic lifestyles, the anterior watering pots of these two species are formed in wholly different manners.

The above observations have been preceded and superceded by more in-depth studies of the anatomies of Dacosta, Dianadema, Stirpulina and Bryopa (Morton, 1984a, 2003a, 2005a, 2005b), and Brechites and its various tube-dwelling relatives, Kendrickiana, Foegia, Nipponoclava, Penicillus and Humphreyia (Morton, 1984b, 2002a, 2002b, 2002c, 2005c), building on the cladistic analysis of the Anomalodesmata by Harper et al. (2000).

The overall aim of this review was thus to determine if there is a case for a division of the currently-perceived monophyletic Clavagelloidea not just into more than one "lineage", as most recently suggested by Savazzi (1999, 2000, 2005; see above), or subfamily/family as actually proposed by earlier authors (Gray, 1858a; Starobogatov, 1992) but subsequently ignored by, for example, L.A. Smith (1962b), Keen and L.A. Smith (1969), Runnegar (1974), B.J. Smith (1971, 1976, 1998), Morton (1981, 1985a) and Lamprell and Healy (1998). After reviewing the researches undertaken on the fossil and living watering pot shell genera and the conclusions thereby obtained, a redefined classification of the watering pots will be proposed. This, in turn, has allowed a picture of watering pot evolution and subsequent adaptive radiation to be constructed and one of the most remarkable patterns of convergent evolution elucidated.

\section{CURRENT TAXONOMY OF THE CLAVAGELLOIDEA}

Gray (1847) attempted the first classification of the watering pot shells, but the most authoritative, and still current, classification of the Clavagelloidea d'Orbigny, 1843 was provided by L.A. Smith and Keen (1969) who divided it and its sole family - the Clavagellidae - into the genera Clavagella Lamarck, 1818, Humphreyia Gray, 1858 and Penicillus Bruguiere, 1789. Clavagella was thought to comprise four subgenera, that is, Clavagella, Bryopa Gray, 1847, Dacosta Gray, 1858 and Stirpulina Stoliczka, 1870, as was Penicillus, that is, Penicillus, Foegia Gray, 1847, Pseudobrechites Magne, 1941 and Warnea Gray, 1858 (considered by B.J. Smith (1976) to be a junior synonym of Brechites Guettard 1770 ) - the latter two being extinct.

Prior to L.A. Smith and Keen (1969) and L.A. Smith (1962b), and subsequently B.J. Smith (1971, 1976), the notion of the Clavagelloidea as comprising but a single family continued to be accepted and I too have earlier followed this proposal (Morton, 1981, 1985a). B. J Smith (1998, p 412) most recently upheld this view by stating: "The superfamily Clavagelloidea comprises the single family Clavagellidae'. The classification of the Clavagelloidea accepted by most modern authors, for example, Vaught (1989), however, stems from B.J. Smith (1976) who considered, like L.A. Smith and Keen (1969), that the Clavagellidae comprised but three genera, that is, Clavagella (with Clavagella, Bryopa, Dacosta and Stirpulina as subgenera), Humphreyia (with Humphrevia and Nipponoclava B.J. Smith, 1976 as subgenera) and Brechites (with Brechites, Penicillus and Foegia as subgenera) (Table 1). Vaught (1989), however, 
Table 1 The present classification of the Clavagellidae (after B.J. Smith, 1976)

Family Clavagellidae d'Orbigny, 1844

(= Aspergillidae Gray, 1858)

Genus Clavagella Lamarck, 1818

Subgenus Clavagella

Subgenus Bryopa Gray, 1847

Subgenus Dacosta Gray, 1858

Subgenus Stirpulina Stolickzka, 1870

Genus Humphreyia Gray, 1858

Subgenus Humphreyia

Subgenus Nipponoclava Smith, 1976

Genus Brechites Guettard, 1770

Subgenus Brechites

Subgenus Penicillus Bruguière, 1789

Subgenus Foegia Gray, 1847

replaced Brechites by Penicillus (the former being considered non-binomial), with Foegia and Warnea only as sub-genera. Why the endobenthic, adventitious tube-dwelling Stirpulina should be ranked as a subgenus of Clavagella, alongside the endolithic Dacosta and Bryopa was, however, unexplained. As was the erection of a new subgenus, Nipponoclava, in place of Aspergillum gigantea (Sowerby, 1888) and the placement of this endobenthic, tube-dwelling species alongside the cemented Humphreyia. As more studies have been undertaken on what are very rare and bizarre watering pot shells, however, so taxonomic views have slowly changed and the time is appropriate to examine these animals, their origin(s), structure(s), relationship(s) and evolution more comprehensively.

\section{WATERING POT SHELL STRUCTURE AND ANATOMY}

\section{The shell and crypt or adventitious tube}

The valves of all watering pot shells comprise two layers, that is, a thin external layer of fine prisms covering a thicker inner layer of sheet nacre (Taylor et al., 1973) that may also be thin $(500 \mu \mathrm{m})$, for example in Brechites vaginiferus (Morton, 2002a). The generally equivalve shells of, again all, watering pot species is posteriorly elongate and anteriorly foreshortened, that is, slightly heteromyarian and thus inequilateral although usually equivalve. Typically too, the shells of all species are lyonsiid-like (Harper and Morton, 2004, figure $3 \mathrm{~A}$ ) and possess radiating rows of periostracal spinules (Aller, 1974; Carter and Aller, 1975; Prezant, 1979a). Both shell valves of $B$. vaginiferus and its adventitious tube-dwelling allies and the cemented Humphreyia strangei are united marginally into the fabric of an adventitious tube. In Dacosta australis (Sowerby, 1829) (Morton, 1984a) and its boring and cemented allies, that is, Bryopa aligamenta (Morton, 2005) and Dianadema multangularis (Morton, 2003a), respectively, and the adventitious tube-dwelling Stirpulina ramosa (Morton, 2006a) only the left valve is united marginally into the fabric of the crypt, the right remaining free within it. The adventitious tubes of both groups, however, comprises a highly organized microstructure of platy crystals $(\sim 10 \mu \mathrm{m}$ long and $0.5 \mu \mathrm{m}$ thick) arranged in chevron patterns with their long axes parallel to the walls of the tube. The tube of $B$. vaginiferus is covered by a thin $(\sim 1$ $\mu \mathrm{m})$ organic film that has attached to it larger clasts and extra-periostracal calcifications comprising bundles of hexagonal, aragonitic crystals $10 \mu \mathrm{m}$ long and $5 \mu \mathrm{m}$ wide and which are highly reminiscent of the "rice-grain-shaped crystals" reported from the sediment encrustations on the outside of two veneroid bivalves (Granicorium and Samarangia) (Taylor et al., 1999). It is generally considered, moreover, that the adventitious tube of species allied to the Brechites "lineage" is secreted but once (Gray, 1858b; B.J. Smith, 1978; Morton, 1984b, 1985b). Harper and Morton (2004) describe the mechanism of tube formation by $B$. vaginiferus and Savazzi (1982a, 2005) and Morton (2005a, 2006a) that of the fossil $S$. coronata and the extant $S$. ramosa.

Although all contemporary taxonomists, for example L.A. Smith (1962b), Keen and L.A. Smith (1969) and B.J. Smith (1971, 1976, 1998), link Clavagella and its allies with Brechites and Humphreyia in the Clavagellidae, the crypt of the former is actually very different from the adventitious tubes of the latter two genera. Figure 1 provides generalized pictures of (a) Dacosta australis and (b) Bryopa lata (Broderip, 1834) inside their crypts (note how the growth lines are from the anterior to the posterior in Clavagella, but in the opposite direction in Bryopa, as will be discussed). The internal ligament (PRL) of $D$. australis is shown in ventral and lateral views in Figure 1(c) and (d), respectively. It is located between chondrophores (C) and covered with "fused" periostracum (FP). The shell (SV) and saddle (SA) of the juvenile of Humphreyia strangei is illustrated from the right side in Figure 1(e) and internally in Figure 1(f) and showing the internal ligament (PRL) with a lithodesma (LI), fused periostracum (FP) and the absence of a pallial sinus (present in $D$. australis, Figure 2(b)) to the pallial line (PL). Anterior (AA) and posterior adductor (PA) muscle scars are of approximately equal size. A dorsal view of the adventitious tube of Brechites vaginiferus is shown in Figure 1(g), showing the minute shell valves (SV) and surrounding saddle (SA) and with the watering pot of the same species illustrated in Figure 1(h) from the anterior aspect.

Watering pot shell anatomy

Watering pot shells have always been of interest 

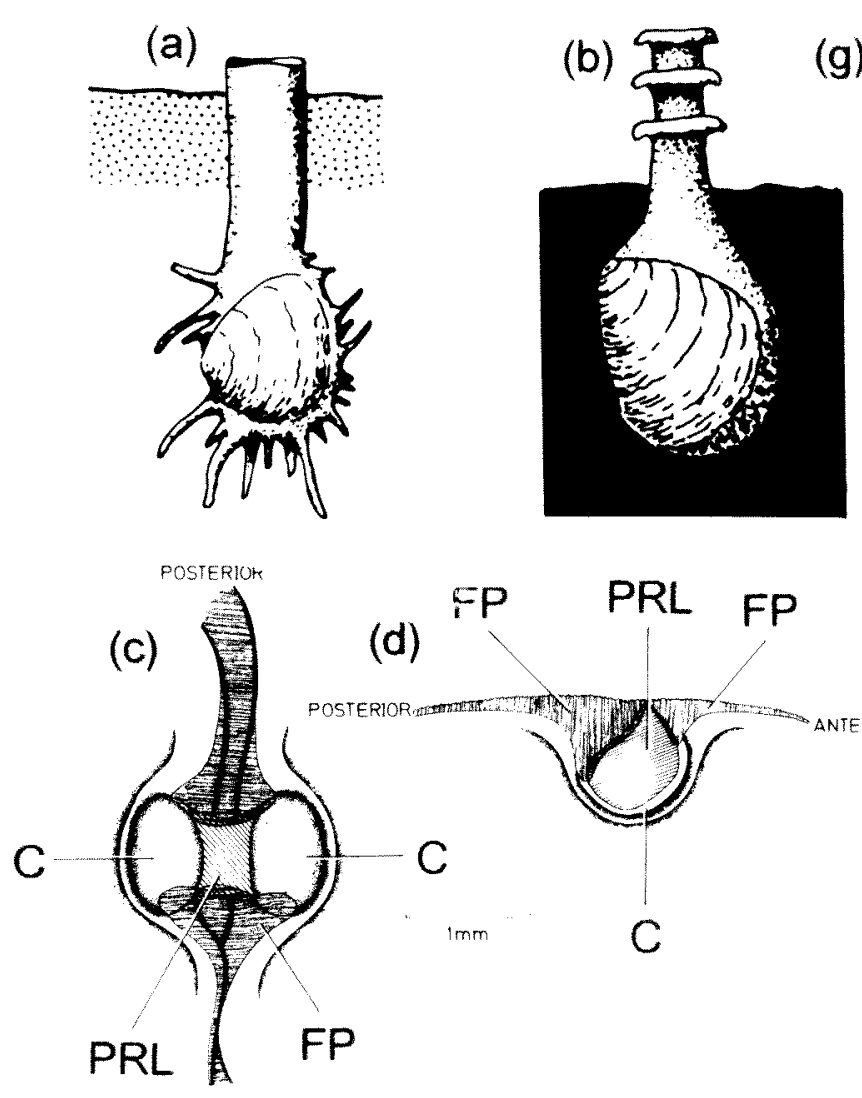

FP PRL FP
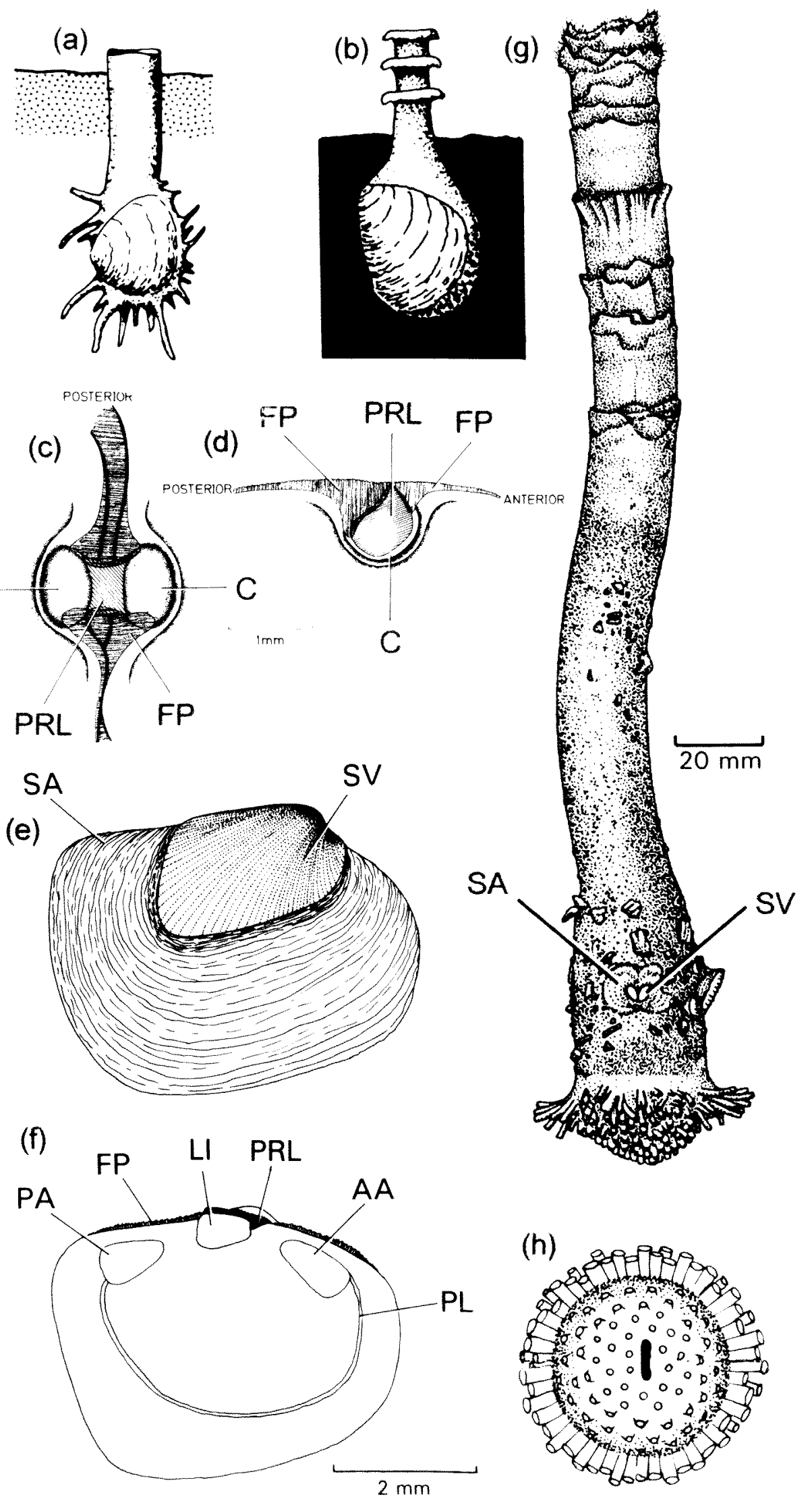

(h)

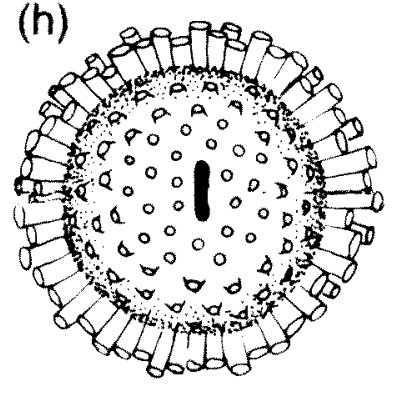

Figure 1 Views of a, Dacosta australis and b, Brvopa lata in situ in their crypts (redrawn after Savarzi, 1982a). Also) illustrated in ventral (c) and (d) side views is the hinge plate of Dacosta australis (redrawn after Morton, 1984a), the juvenile shell of Humphrevia strangei as seen from the right side (e) and internally (left valve) (f) (both redrawn after Morton, 1984b) and the adventitious tube of Brechites vaginiferus as seen (g) from the dorsal and (h), the anterior aspects (redrawn after B.J. Smith, 1998 and Morton, 1984b, respectively). (For abbreviations see Appendix). 
because of their strange structure and figure prominently in early malacological texts (Bruguiere, 1789; Chenu, 1843a, 1843b; Orbigny, 1843-1847; Reeve, 1860, 1873; Garner, 1860) and were similarly objects of great scientific interest in the $19^{\text {th }}$ century (Lamarck, 1818; Owen, 1835; Gray, 1852, 1858a, 1858b; Lacaze-Duthiers, 1870, 1883; Broderip, 1834, 1835).

Owen (1835), Chenu (1843a), Soliman (1971) and Kilburn (1974) have described the anatomies of species of Clavagella (actually all either Dacosta or Bryopa). Appukuttan (1974), Savazzi (2000) and Palazzi and Villari (2000) have studied species of Bryopa. Morton (1984a, 2003a, 2005) described Dacosta australis, Dianadema multangularis and Bryopa aligamenta. Among the Clavagellidae, therefore, only Stirpulina is undescribed anatomically, although shell and tube structure have recently been elucidated (Savazzi, 2005; Morton, 2005, 2006a, 2006b).

Garner (1860, plate 5, figs 1-4) illustrated the structure of Aspergillum (= Penicillus) javanum (Chenu, 1843). Similiarly, Lacaze-Duthiers (1870, 1883) and Purchon (1956, 1960) studied and described the anatomies of species of Penicillus, that is, P. (as Aspergillum) javanum (= $P$. philippinensis (Chenu, 1843)), $P$. (as Aspergillum) dichotomum (Chenu, 1843) (= P. penis) and $P$. (as Brechites) penis, respectively. Morton (1984b, 2002a, 2002b, 2004a, 2004b, 2004c, 2006c) described the anatomies of Brechites vaginiferus, Humphreyia strangei, Foegia novaezelandiae Bruguière, 1789, Nipponoclava gigantea Sowerby, 1888, Kendrickiana veitchi B.J. Smith, 1971 and Penicillus philippinensis.

An important point of distinction between Brechites and its allies and the extinct Clavagella and its surviving allies, however, is that the former has a distinct juvenile, strongly dimyarian juvenile stage that "metamorphoses" into an essentially amyarian adult when the adventitious tube is secreted. Conversely, Clavagella and its allies have a strongly dimyarian post-juvenile shell that continues to grow, retaining its musculature (Savazzi, 2000), and does not "metamorphose". This will be discussed in greater detail later.

The basic anatomy of all watering pot shells is typical of most representatives of the Anomalodesmata (Morton, 1981, 1985a). That is, extensive mantle fusion of the inner, middle and inner surfaces of the outer mantle folds, Type $C$ (Yonge, 1982), so that the periostracum occurs as a thick, continuous sheet around the mantle it overlies. The ctenidia of all watering pot shells are relatively large and comprise complete inner and the ascending lamellae only of the outer demibranchs and are thus of Type E (Atkins, 1937). The ctenidial labial palp junction is of Category III (Stasek, 1963) where the anterior ends of both demibranchs are inserted into the proximal oral groove between the inner and outer labial palps. The stomach (where studied) is of Type IV (Purchon, 1958a), that is, representative of the Gastrotetartika (Purchon, 1958b). The statocyst structure of all studied clavagelloids is of Type B3 (Morton, 1985c).

The above features, particularly of the organs of the mantle cavity clearly ally all watering pot shells with the Anomalodesmata. Notwithstanding, as will be described, there is a considerable range of loss of the adductor and pedal retractor muscles in the spectrum of the adventitious tube-dwelling watering pot shells in particular and, of course, a variety of adaptations to life within either a crypt or an adventitious tube. Similarly, some watering pot shells possess unique structures, such as pericardial proprioreceptors, first identified for Humphreyia strangei (Morton, 2002b) but also present (in simpler form) in others, for example, Dianadema multangularis (Morton, 2003a). Most significant characters separating watering pot shell genera, therefore, involve the shell. That is, shell form, ligament structure, muscle scars and the structure and formation of either the crypt or adventitious tube. This means, therefore, that the fossil record is extremely valuable in helping to determine patterns of evolution and adaptive radiation.

\section{THE FOSSIL RECORD}

L.A. Smith (1962a) considered that Clavagella and its allies first appeared in the Upper Cretaceous whereas Brechites and its allies first appeared in the Upper Oligocene. Savazzi (2005) suggests in relation to the Clavagellidae, that tube dwelling species of Clavagella, that is Stirpulina, are known since the Cretaceous, facultative borers (Clavagella sensu stricto) and tube dwellers since the Eocene (Cossmann and Pissarro, 1904-1913), with the facultatively coral-boring Bryopa arising in the Miocene (Savazzi, 2000).

Savazzi (2000) considered that Brechites and its allies probably appeared in the Early Oligocene of the northern Tethys although L.A. Smith (1962b) suggested that the various representatives of the Penicillidae have all arisen since the Late Oligocene.

A wholly accurate account of the fossil history of watering pot shells is not, however, possible because: (i) all species, like most anomalodesmatans, but especially extant taxa, are "rare"; (ii) the tubes of some are aragonitic, fragile and would not fossilize well, and (iii) adventitious tubes may be confused with, for example, those of polychaetes and gastrochaenid and teredinid bivalves. It is only very recently, for example, that the adventitious tube of a species of Stirpulina has been identified from Australia, indeed the southern hemisphere (Morton, 2006b). Savazzi (1999, p. 231) 
Table 2 The geographic distribution of representatives of the Clavagellidae and Penicillidae (in bold) from the Late Cretaceous to the Recent. (In part after L.A.Smith. 1962).

\begin{tabular}{|c|c|c|c|c|c|c|c|c|c|c|}
\hline & Age & $\begin{array}{l}\text { North } \\
\text { America }\end{array}$ & Europe & Africa & Red Sea & India & $\begin{array}{l}\text { Indo-West } \\
\text { Pacific }\end{array}$ & $\begin{array}{l}\text { Japan- } \\
\text { Philippines }\end{array}$ & Australia & $\begin{array}{l}\text { New } \\
\text { Zealand }\end{array}$ \\
\hline Recent & & & Bryopa & Dianadema & $\begin{array}{l}\text { Bryopa } \\
\text { Penicillus } \\
\text { Warnea }\end{array}$ & $\begin{array}{l}\text { Bryopa } \\
\text { Brechites }\end{array}$ & $\begin{array}{l}\text { Bryopa } \\
\text { Dianadema } \\
\text { Penicillus } \\
\text { Foegia }\end{array}$ & $\begin{array}{l}\text { Stirpulina } \\
\text { Bryopa } \\
\text { Brechites } \\
\text { Penicillus } \\
\text { Foegia } \\
\text { Nipponoclava } \\
\text { Warnea }\end{array}$ & $\begin{array}{l}\text { Bryopa } \\
\text { Dacosta } \\
\text { Dianadema } \\
\text { Brechites } \\
\text { Humphreyia } \\
\text { Penicillus } \\
\text { Foegia } \\
\text { Kendrickiana } \\
\text { Warnea }\end{array}$ & \\
\hline Pleistocene & 0.01 & & & & & & Penicillus & $\begin{array}{l}\text { Stirpulina } \\
\text { Nipponoclava }\end{array}$ & Kendrickiana & \\
\hline Pliocene & 1.0 & & $\begin{array}{l}\text { Clavagella } \\
\text { Stirpulina }\end{array}$ & & $\begin{array}{l}\text { Warnea } \\
\text { Penicillus }\end{array}$ & & $\begin{array}{l}\text { Warnea } \\
\text { Penicillus } \\
\text { Foegia }\end{array}$ & $\begin{array}{l}\text { Nipponoclava } \\
\text { Foegia } \\
\text { Warnea }\end{array}$ & $\begin{array}{l}\text { Dianadema } \\
\text { Kendrickiana } \\
\text { Humphreyia }\end{array}$ & \\
\hline Miocene & 6.5 & & & & & Clavagella & $\begin{array}{l}\text { Penicillus } \\
\text { Foegia }\end{array}$ & $\begin{array}{l}\text { Nipponoclava } \\
\text { Foegia }\end{array}$ & & Clavagella \\
\hline Oligocene & 23.0 & & $\begin{array}{l}\text { Bryopa } \\
\text { Clavagella } \\
\text { Stirpulina }\end{array}$ & & Stirpulina & & $\begin{array}{l}\text { Penicillus } \\
\text { Foegia }\end{array}$ & & $\begin{array}{l}\text { Clavagella } \\
\text { Penicillus }\end{array}$ & \\
\hline Eocene & 36.5 & $\begin{array}{l}\text { Clavagella } \\
\text { Stirpulina }\end{array}$ & $\begin{array}{l}\text { Clavagella } \\
\text { Stirpulina }\end{array}$ & & & & & & $\begin{array}{l}\text { Stirpulina } \\
\text { Dianadema }\end{array}$ & \\
\hline Palaeocene & 53.0 & & $\begin{array}{l}\text { Clavagella } \\
\text { Stirpulina }\end{array}$ & & & & & & & \\
\hline $\begin{array}{l}\text { Upper } \\
\text { Cretaceous }\end{array}$ & 65.0 & $\begin{array}{l}\text { Clavagella } \\
\text { Ascaulocardium } \\
\text { Stirpulina }\end{array}$ & $\begin{array}{l}\text { Clavagella } \\
\text { Stirpulina }\end{array}$ & Clavagella & & $\begin{array}{l}\text { Clavagella } \\
\text { Stirpulina }\end{array}$ & & & & \\
\hline
\end{tabular}


considered that the fossil record so far tells us little about the evolution of this family [the Clavagellidae]'. Despite the limitations of the fossil record, however, a review of the literature with regard to watering pot shells allows some general, but highly pertinent insights to be made about their evolutionary history, first reported upon by L.A. Smith (1962a). The information available on the fossil history of the Clavagellidae and Penicillidae is summarized in Table 2.

\section{The Clavagellidae}

The type species of Clavagella is C. echinata Lamarck, 1818, a fossil from the Paris Basin, France, and of which no type specimen has been found (B.J. Smith, 1971). Moreover, Lamarck (1818) did not illustrate this species, but it was by Brocchi (1814, plate XV, fig, 1) and Deshayes (1824, plate 1, figs 7 , 8 and 9) and subsequently a large number of fossil Clavagella species have been described, as will be discussed below.

Fossil Clavagella (see Keen and L.A. Smith, 1969, figure F32 -1) have a large shell surrounded by an adventitious crypt that incorporates the left valve into its structure. The crypt has a short siphonal tube projecting posteriorly and an anterior and ventral array of spiny tubules. Species of this genus appear to have been either nestlers or possibly endobenthic inhabitants of soft sediments. In his revision of the Recent species of the Clavagellidae, B.J. Smith (1976) assigned but two species, that is Clavagella (C.) torresi Smith, 1885 and C. (C.) multangularis (Tate, 1887) to this genus and subgenus. However, Morton (2003a) re-assigned these two species to a new genus, Dianadema, because they both possess, unlike fossil Clavagella species, an apical crown of tubules reminiscent of Ascaulocardium (Pojeta and Sohl, 1987). There are, thus, no extant species of Clavagella. As noted earlier, however, B.J. Smith (1976) identified three other subgenera of Clavagella, that is, Dacosta, Bryopa and Stirpulina. Subsequent authors have largely followed this arrangement. However, I consider that these three sub-genera should be considered to have generic status (plus Dianadema), because all their constituent species can and do (as will be illustrated) fit into distinct clades.

Fossil Clavagella and Stirpulina are mostly restricted to Europe (S. pliocenica, Mayoral, 1990) and North America (Stallwood, 1995), but also India (see below), Australia (Clavagella majorina, B.J. Smith, 1971; S. pallinupensis, Morton, 2006b) and from the early Late Miocene of New Zealand (Clavagella oamarutica Maxwell, 1978; Beu and Maxwell, 1990). Modern species also occur, for example, in the Mediterranean [but as Bryopa, not Clavagella] (Soliman, 1971; Savazzi, 2000), India [as Bryopa] (Appukuttan, 1974) and South Africa [as Dianadema, not Clavagella] (Kilburn, 1974),
Australia, for example, Dianadema multangularis (Tate, 1887) and Clavagella [as Dacosta] australis (Morton, 1984a), and Japan (Shikama, 1954) and southeast Asia [as Bryopa] (Savazzi, 2000; Morton, 2005)

L.A. Smith (1962b) and Stallwood (1995) provide lists of localities and ages for the fossil clavagellids discussed by them, and Stallwood (1995, p. 88) also provides a list of fossil species of Stirpulina. Species of the endobenthic, adventitious tube-dwelling Stirpulina have, in particular, been recorded from the Eocene of the Barton Beds, Sussex, U.K. (Dixon, 1878), the Paris Basin (Deshayes, 1824), and Sicily and Venice, Italy (Brocchi, 1814; Michelotti, 1861; Sacco, 1901, Savazzi, 1982b). Savazzi (1982b) described three species of Clavagella (Stirpulina) from the Tertiary of northeastern Italy and all comprised a crypt to which the left valve was cemented internally, while the right was free within it. In $C$. vicentina and $C$. veronensis there were also anterior tubules that were thought to achieve connection with the interstitial waters of the sediment, as in C. coronata from the Cretaceous of Southern India (Habe, 1977) and (reportedly the same species) from the Eocene of the Paris Basin, France (Savazzi 1999). Savazzi (1982a, figure 1A) illustrated Stirpulina coronata in a life position. Mayoral (1990) describes Stirpulina pliocenica from the Upper Neogene of Cuenca del Bajo Guad, Spain, while Lucoviæ (1922) described Stirpulina goldfussi from the Eocene of the Balkan Peninsula, between the Aral Sea and Lake Chalkar.

Nicol (1968) and Pojeta and Sohl (1988) describe species of Clavagella from Eocene rocks of Florida while Pojeta and Sohl (1987) describe species from Upper Santonian Cretaceous rocks of Mississippi and detail the Cretaceous distribution of the genus. They give a reported age range of Cenomanian to Holocene, with Cenomanian and Turonian occurrences restricted to Europe. Stallwood (1995) first described and reported upon Stirpulina saulae, the first fossil clavagellid recorded from the Pacific Province of North America and, specifically, from the Cretaceous, Late Turonian, Ladd Formation of the Santa Ana Mountains, California. With its left valve cemented to an adventitious crypt and the right free within it, this genus and species is clearly allied with Clavagella. Later, Pojeta and Johnson (1995) described a second clavagellid, Parastirpulina sohli, also from the Upper Cretaceous (Turonian) of North America. Today, Stirpulina only occurs alive in Japan, as Stirpuliniola ramosa (Habe, 1951, 1977). This generic name was erected by Kuroda and Habe (1971) to separate it from fossil taxa, although Vokes (1980) considered it to be a junior synonym of Stirpulina.

Pojeta and Sohl (1987) described Ascaulocardium armatum from upper Santonian to Maastrichtian 
rocks (Late Cretaceous) of the Gulf and Atlantic coastal plains of the U.S.A. With its left valve cemented to the adventitious crypt and the right free inside it, $A$. armatum is clearly allied with Clavagella, albeit of bizarre form, and especially Dianadema multangularis (Morton, 2002c).

In addition to Clavagella coronata, the small $(\sim 12$ $\mathrm{mm}$ ) C. semisulcata is recorded from the Valaudayur beds of Pondicherry, southern India (Forbes, 1846) that are Maastrichtian (Kossmatt, 1897; Sundaram, Henderson, Ayyasami and Stilwell, 2001). The species was illustrated as 'Gastrochaena' semisulcata (Forbes, 1846, plate 17, $1 \mathrm{a}$ and $\mathrm{b})$ and re-illustrated by Stoliczka (1870-1871, p. 31).

According to Savazzi (2000, p. 323), 'Clavagella and its allies probably appeared in the Upper Cretaceous of the Tethys' with early representatives described from the United States, including the Turonian of California (Stallwood, 1995), Europe, Africa and India. In the Palaeocene, the lineage became restricted to Europe. In the Eocene, it radiated westwards to Florida (Pojeta and Sohl, 1988; Jones and Nicol, 1989) and in the Oligocene eastwards into the Indo-Pacific, reaching Japan and the Philippines in the Miocene and Australasia in the Quaternary. According to Savazzi (2000), the obligate borer Bryopa appeared in the Late Oligocene of southern Europe (L.A. Smith, 1962a) and radiated subsequently to the tropical IndoPacific. It either survived the basal Neogene and Pleistocene Messinian Salinity Crises in the Mediterranean, or subsequently re-entered the Mediterranean on both occasions, its occurrence in this area being documented from the Miocene and Recent. In the Indo-Pacific, it is recorded from the Recent of several localities, principally the Red Sea (Soliman, 1971), southern India (Appukuttan, 1974), the Philippines (Savazzi, 2000) and Japan (Morton, 2005). Majima (1991) identifies four endemic Japanese watering pot shells that occur in Miocene to Holocene sediments. These are: the Holocene (and still extant) Nipponoclava gigantea (Sowerby, 1888), the Plio-Pleistocene Nipponoclava yokoyamai (Shikama, 1954), the Middle Miocene Nipponoclava kanazawaensis (Omura, 1969) and the late Pleistocene (but still extant) Stirpulina ramosa (Dunker, 1882). Originally identified as Bryopa lata by Nakamine and Habe (1980, plate 4), the Japanese species of this genus was described as new, that is, $B$. aligamenta (lacking a ligament) by Morton (2005). Other extant watering pot shells recorded from Japan include Foegia novaezelandiae (Nakamine and Habe, 1980, plate 5) and Clavagella japonica (Habe, 1981) but which (p. 190) is 'an ally to Clavagella torresi'and thus a species of Dianadema (Morton, 2003a).

The Clavagellidae is thus early Tethyan (B.J. Smith, 1976) and dates from the Upper Cretaceous.
New Zealand (Clavagella oamarutica: Maxwell, 1978; Beu and Maxwell, 1990) and southern Australian clavagellids (Clavagella majorina, B.J. Smith, 1971; Dianadema liratum, Tate, 1887b; Darragh, 1970) date from the Upper Oligocene, early Late Miocene and Pliocene-Pleistocene, respectively. Dianadema is recorded as a fossil from the Upper Eocene Blanche Point Marl, South Australia (Lamprell and Healy, 1998). B.J. Smith (1971) also records it from the Miocene Muddy Creek Formation, Torquay, also South Australia. Similarly, Cotton (1952) records D. [as Humphreyia] liratum and the penicillid Humphreyia strangei from the Lower Pliocene of the Adelaide Plains area of South Australia. Morton (2006c) recorded the first species of Stirpulina, $S$ pallinupensis, from southwestern Australia and the southern hemisphere. Stirpulina evolved in the Tethys and among the Late Eocene fossil assemblages from the Pallinup Formation at Walpole, southwestern Western Australia, most of the bivalve genera have a cosmopolitan distribution with either related or similar species occurring in New Zealand, Asia, Europe and America (Darragh and Kendrick, 1980, 2000). The Pallinup Formation of the Bremer Basin (Gammon, James, Clarke and Bone, 2000), whence S. pallinupensis was collected, was deposited on the shallow, inner continental shelf (Darragh and Kendrick, 1980). During the Late Eocene, Australia lay well to the south of its present position so that its southern coast was located in temperate waters, as it is today. At that time, it appears global climate was somewhat warmer and less latitudinally stratified than at present (Kemp, 1978). There was therefore neither polar glaciation nor a circum-Antarctic oceanic circulation, whereas an open seaway extended from the coast of northern Australia northwestwards into the Tethys and beyond, as far as what is now Western Europe, for example, the Paris and London Basins. At this time, some molluscan elements of the Tethyan Southwest Pacific fauna and other, more cosmopolitan, groups extended their ranges to southern Australian waters joining southern endemic species to form a distinctive blended fauna (Darragh and Kendrick, 1980, 2000) such as is found today in the Pallinup Formation. With the Oligocene, there was a general decline in sea temperatures (Shackleton and Kennett, 1975) and opening of the Drake Passage initiated the circumAntarctic circulation in the Southern Ocean. As a consequence, the warmer water molluscan assemblages of the Late Eocene in southern Australia, of which Stirpulina pallinupensis was a component, were succeeded by a cooler water Oligocene community (Darragh, 1985).

\section{The Penicillidae}

L.A. Smith (1962b) suggested that Brechites and 
its allies have all arisen since the Late Oligocene and have an essentially Indo-West Pacific distribution, including Japan (Habe, 1977), Southeast Asia (Dharma, 1992; Swennen, Moolenbeek, Ruttanadukal, Hobbelink, Decker and Hajisamae, 2001) and Australia (B.J. Smith, 1971; Morton, 2002a). Brechites and other genera are absent from North America and Europe, that is, the Atlantic and Mediterranean, although Magne (1941) describes Brechites (Pseudobrechites) leognanum from the Upper Oligocene of Aquitaine, France. Keen and L.A. Smith (1969), however, described this species as not possessing a pedal gape or slit in the anterior watering pot but both valves are illustrated (figure F32 [5]) as being incorporated into the structure of the adventitious tube. There is thus a poor fossil record for the Penicillidae save for the cemented, epibenthic Humphreyia. In reviewing the literature on Humphreyia, Morton (2002b), showed that the single extant species, $H$. strangei, has a Pliocene fossil record from southern Australia. There are fossil penicillids in the collections of the Western Australian Museum from the Pliocene Roe Calcarenite of southern Western Australia, for example Brechites vaginiferus, Kendrickiana veitchi and Penicillus philippinensis, but these remain hitherto unreported upon and are all extant species in Australian seas (Morton, 1984b, 2003a, 2004c, 2006b).

The genus Nipponoclava occurs as a fossil in the Miocene and Plio-Pleistocene of Japan, for example, N. yokoyamai (Shikama, 1954; Majima, 1991). The genus also occurs there as a single extant species, $N$. gigantea (B.J. Smith, 1976).

According to Savazzi (2000), Brechites and its allies probably appeared in the Early Oligocene of the northern Tethys (L.A. Smith, 1962b) and subsequently radiated into the Indo-West Pacific region, including Australia (L.A. Smith, 1962a), in which they have remained exclusively since the Neogene. Brechites dichotomus is the only living penicillid to be recorded from southern India (Hornell, 1921; Gravely, 1941; Satyamurti, 1956), but remains unstudied scientifically.

Table 3 A summary of the shell, adventitious tube and (known) anatomical characters of representatives of the Clavagellidae and Penicillidae (Anomalodesmata: Clavagelloidea). (For explanation and references see text).

\begin{tabular}{|c|c|c|}
\hline Character & Clavagellidae & Penicillidae \\
\hline Shell & Typical adult plus saddle & Juvenile plus saddle \\
\hline Shell valves & $\begin{array}{l}\text { Left valve cemented to } \\
\text { crypt/adventitious tube: } \\
\text { right valve free inside }\end{array}$ & $\begin{array}{l}\text { Both valves united into the } \\
\text { fabric of the tube }\end{array}$ \\
\hline Ligament & Internal & External \\
\hline Lithodesma & Absent & Present in Humphreyia juvenile \\
\hline Shell microstructure & $\begin{array}{l}\text { Prismatic outer layer: } \\
\text { sheet nacre inner layer }\end{array}$ & $\begin{array}{l}\text { Prismatic outer layer: } \\
\text { sheet nacre inner layer }\end{array}$ \\
\hline Shell spinules & Present & Present \\
\hline Periostracum & Two layered & Two layered \\
\hline Adventitious tube/crypt & Present & Present \\
\hline Adventitious tube & Free/cemented & Free/cemented \\
\hline Anterior tubules & Present/absent & Present \\
\hline Watering pot & Absent/present & Present \\
\hline \multicolumn{3}{|l|}{$\begin{array}{l}\text { Characters typical of } \\
\text { the Anomalodesmata }\end{array}$} \\
\hline Pallial fusions & Type C & Type C \\
\hline Fourth pallial aperture & Absent & Present \\
\hline Pedal gape & Present & Present \\
\hline Radial mantle glands & Present/absent & Present/absent \\
\hline Ctenidial ciliation & Type E & Type E \\
\hline Ctenidial/labial palp junction & Category 3 & Category 3 \\
\hline \multicolumn{3}{|l|}{$\begin{array}{l}\text { Unique watering pot } \\
\text { characters }\end{array}$} \\
\hline Adductor muscles & Present & Typically absent \\
\hline Pedal retractor muscles & Vestigial/absent & Vestigial/absent \\
\hline Pedal disc & Absent & Present \\
\hline Rectum & Penetrates kidneys & Passes over kidneys \\
\hline Statocysts & Type $\mathrm{B}_{3} /$ absent & Type $B_{3}$ /absent \\
\hline Pericardial proprioreceptors & $\begin{array}{l}\text { Present when posterior } \\
\text { pedal retractors present }\end{array}$ & $\begin{array}{l}\text { Present when posterior } \\
\text { pedal retractors present }\end{array}$ \\
\hline Suspensory muscles & Absent & Present in some \\
\hline
\end{tabular}




\section{THE WATERING POT GENERA}

\section{Clavagella and its allies}

A summary of the crypt and/or adventitious tube structure of the various extant representatives of the Clavagellidae is provided in Table 3. A more detailed and comprehensive comparison of the various genera of the Clavagellidae is given in Morton (2006a, table 1). All representatives of the Clavagellidae cement their left valve to the crypt (Clavagella), burrow wall (Dacosta and Bryopa) or tube (Stirpulina) (Savazzi, 1982a, 1982b, 1999, 2000, 2005 ) and the right valve, though free, is attached in the usual bivalve way to the other one by a ligament and anterior and posterior adductor muscles. Below is provided anatomical summaries of the various clavagellid clades and genera.

\section{(i) Nestling: Dacosta}

Dacosta australis lives in a burrow that is thought to have been occupied opportunistically by the juvenile and possibly then enlarged (Morton, 1984a). Figure 2(a) illustrates $D$. australis in its burrow with the free right valve (RV) and the heading perforated by tubules (TU). Ventrally, the mantle (VM) and the siphons (ES, IS) are covered in thick periostracum, although there is a pedal gape anteriorly (PG). Figure 2(b) shows the left valve (LV) attached to the burrow wall that is lined with calcified carbonate, except ventrally (UBW). Internally, there are distinct adductor and pallial retractor muscle scars and a deep pallial sinus. The ligament of $D$. australis is internal and located between vertically descending chondrophores, although the dorsal valve margins are united by a thickened pad of "fused" periostracum. The term "fused periostracum" was coined by Yonge (1978a) but is misleading because the periostracum covers the dorsal shell surface anyway: it is, thus, merely thickened to create, in Brechites and Humphreyia (and other bivalves including many other anomalodesmatans), a pad of "secondary" ligament. This has no elastic properties, however, and probably more importantly serves functionally, in the absence of hinge teeth, to effect valve alignment (Yonge and Morton, 1980). There is also a deep pallial sinus and the adductor muscles are large although pedal retractors are either absent or greatly reduced, as is the foot. In other respects, $D$. australis is a typical anomalodesmatan with the usual arrangement of ctenidia and labial palps in the mantle cavity and a complete intestine (Morton, 1984a); that is, it is a typical suspension-feeding bivalve. As will be seen and unlike penicillid watering pot shells, the anterior mantle is not formed into a pedal disc, although there is a pedal gape and tubules do invade the anterior end of the burrow. The long siphons are encased in periostracum and tipped apically by sand grains and other detritus held in place by secretions from arenophilic radial mantle glands described by Prezant (1979b) and Morton (1987). The siphons are formed by pallial fusions of Type C (Yonge, 1982) and apically the siphonal papillae of $C$. australis possess ciliated siphonal sense organs. As noted for "Clavagella"[no animal illustrated] melitensis by Pelseneer (1911), there is no fourth pallial aperture in D. australis (Morton, 1984a). In this respect, clavagellids are like species of Lyonsia, Laternula and Pandora (Pelseneer, 1911).

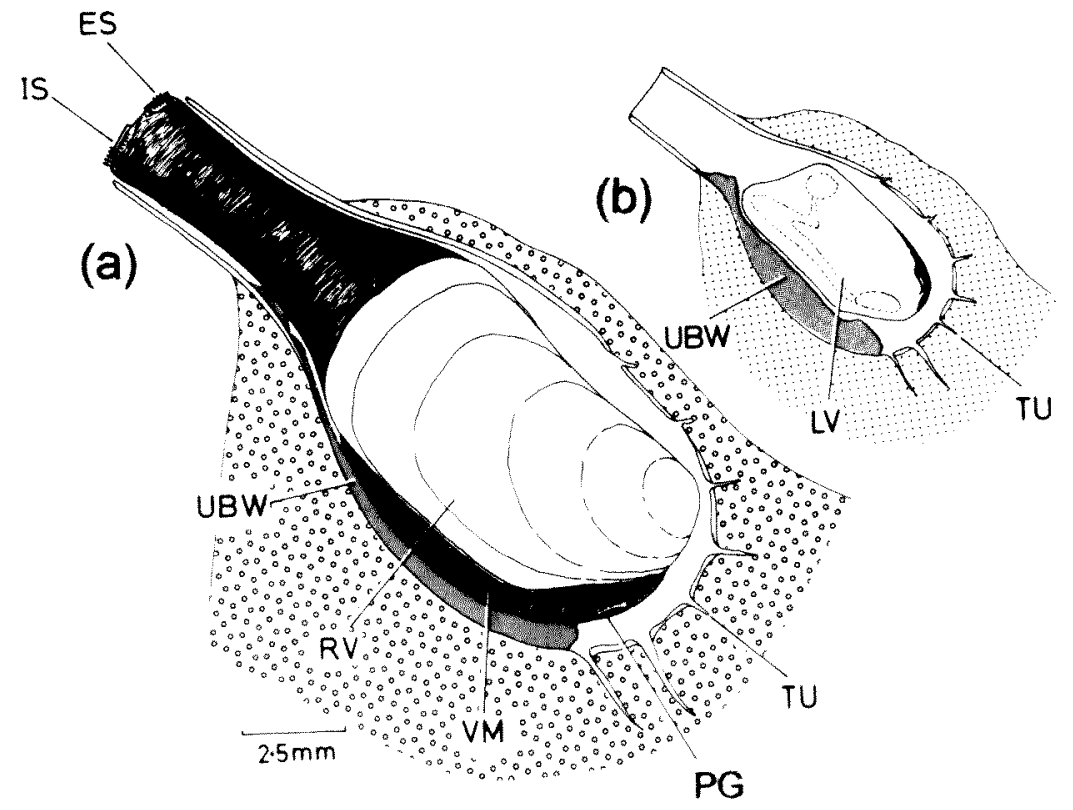

Figure 2 Dacosta australis. a, The animal inside its burrow as seen from the right side. $b$, The left shell valve attached to the burrow wall (redrawn after Morton, 1984a). (For abbreviations see Appendix). 


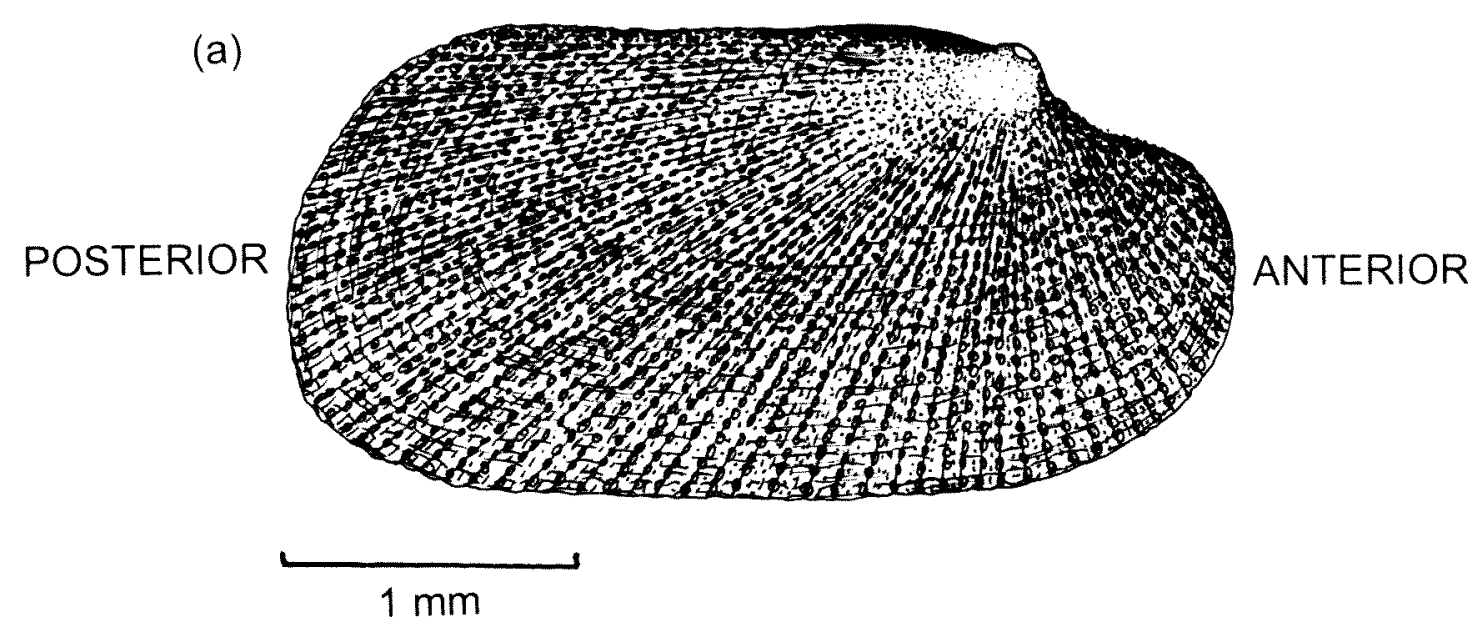

(b)

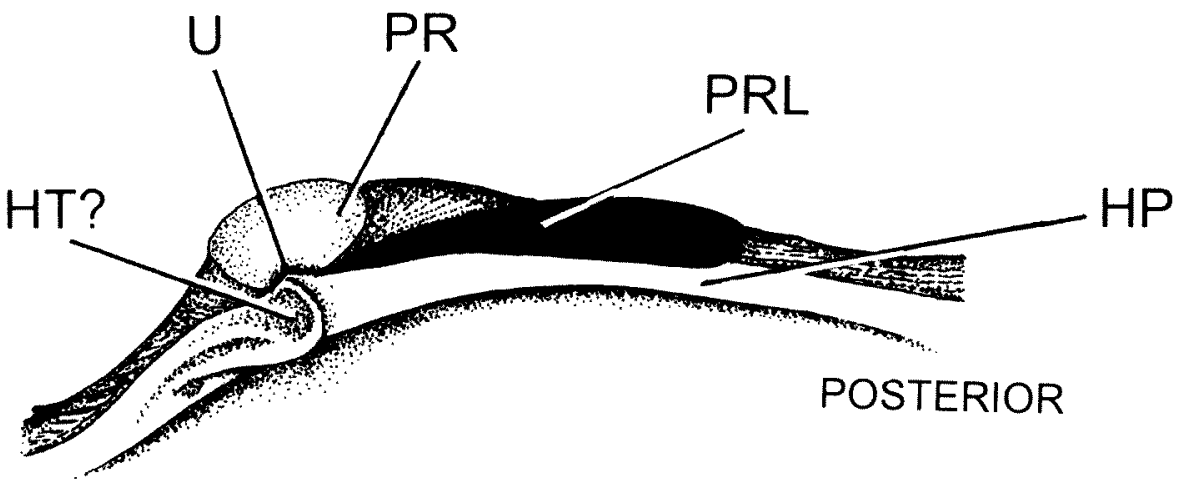

ANTERIOR

$250 \mu \mathrm{m}$

Figure 3 Bryopa lata. a, The juvenile shell as seen from the right side. $b$, An interior view of the hinge plate of the right valve (redrawn after Morton, 2005). (For abbreviations see Appendix).

(ii) Borers of living corals: Bryopa

Savazzi (2000) has described recently how Clavagella (Bryopa) lata (Broderip, 1834) occupies a burrow in dead corals that it enlarges by boring with dramatic consequences for shell form and structure. Bryopa aligamenta is also endolithic, but in living corals, in Japan, with the left valve cemented to the crypt wall (Morton, 2005). Figure $3(a)$ illustrates the right valve of the $B$. lata juvenile (redrawn after Palazzi and Villari, 2000) showing it to be anteriorly foreshortened and posteriorly elongate, creating a heteromyarian form, and radially spinulose as in Dacosta australis (Figure 1(e)). The hinge plate of the right valve of $B$. lata is illustrated in Figure 3(b). There is a distinct prodissoconch (PR) approximately $130 \mu \mathrm{m}$ in length, and umbo (U), an internal ligament (PRL) and there appears to be a small, ear-shaped hinge tooth (HT?) on the narrow hinge plate (HP). In this juvenile phase (see later), both valves are unattached and are posteriorly roundly elongate (like a lyonsiid shell) and the radiating cords of shell spinules are more obvious. Upon occupation of a crevice and later a burrow and cementation of the left valve to it, the right valve of the adult exhibits an unusual growth pattern, with commarginal lines seemingly arising from the posterior valve margin and extending towards the anterior (Figure 4(a)). In addition the outer shell layer is eroded dorsally to reveal the internal nacreous layer (NL) and calcareous material is laid down internally (IGI), especially anteriorly (AGI) as growth increments. Internally (Figure 4(b)), the right valve has a hinge plate (HP) and an eroded umbo (EU) with large adductor muscles (AA, PA) and a very thick pallial line (PL) and deep pallial sinus (PS). The same musculature is also seen in the internal surface of the left valve (Figure 4(c)) that is cemented to the crypt wall (CR) and the siphons are protectively encased with a siphonal channel (SC) laid down beyond the periostracum (PE) as a calcareous concretion. The unusual, remarkable, pattern of growth seen in the right valve will be described but essentially results from: (i), progressive anterior erosion of the umbones probably as a consequence of the boring process; (ii), the apparent migration posteriorly, as 
(a)
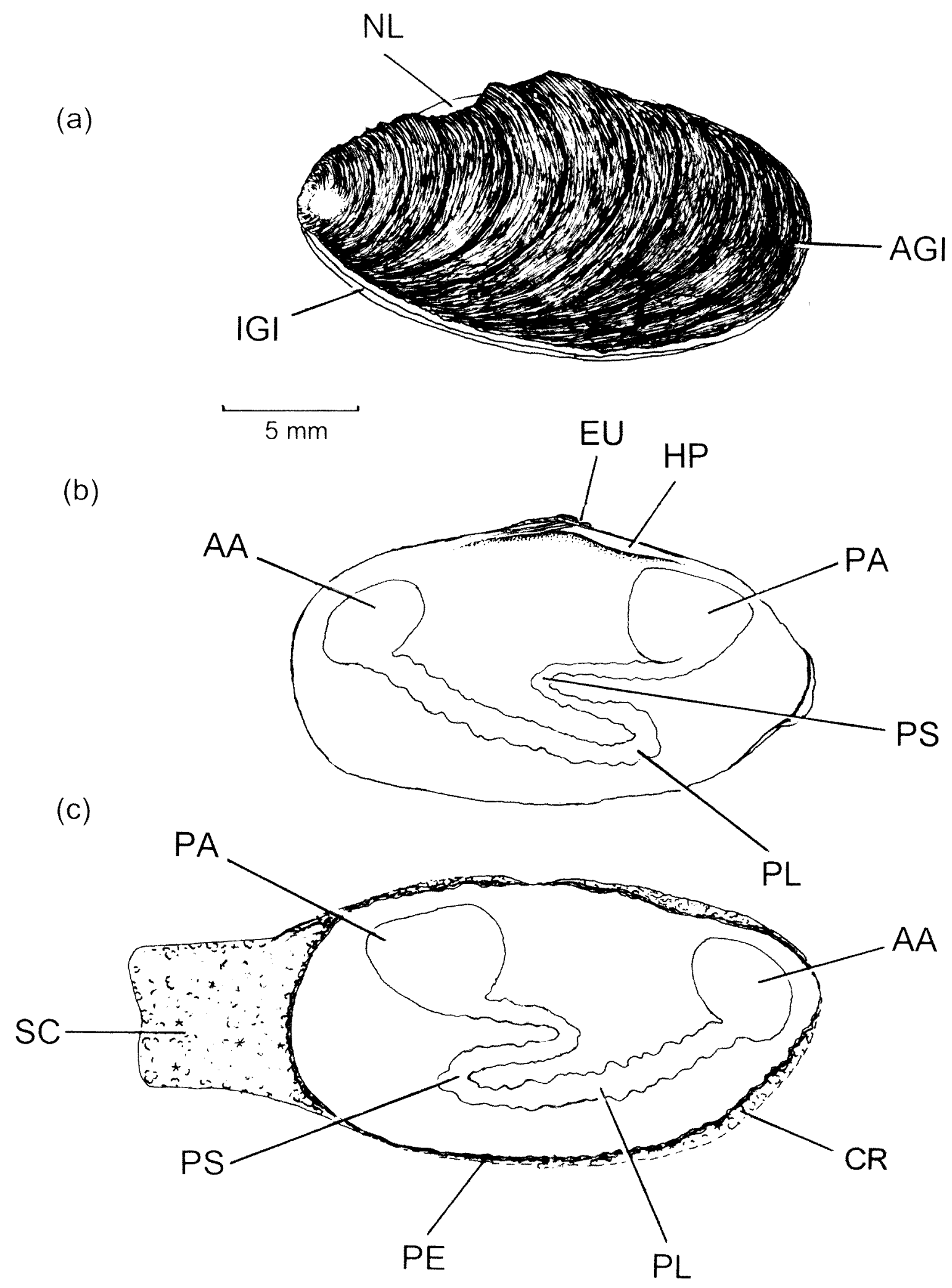

Figure 4 Bryopa aligamenta. a, The free right shell valve; $b$, an internal view of the attached left valve and $c$, an internal view of the free right valve (redrawn after Morton, 2005). (For abbreviations see Appendix).

the umbones are eroded, of the dorso-ventral growth axis of the shell and (iii), enhanced posterior inter-commarginal growth.

Appukuttan (1974, p. 20) and Savazzi (2000, p 316) assert that Bryopa lata has a prominent ligament' and that 'the ligament of $B$. lata is strongly prosodetic with reference to the umbones' respectively. This would not only be highly unusual for a bivalve, but is probably also not so. The juvenile of $B$. lata has an internal, opisthodetic ligament (Morton, 2005). A ligament was, however, either never present in B. aligamenta or has, more 
likely, been lost during the process of growth and chemical boring. It is possible, however, that if a juvenile ligament were present (as in B. lata, Savazzi, 2000), it too would be lost as a consequence of antero-dorsal erosion during boring. To retain valve alignment in the absence of a primary ligament and possibly upon reaching an adult size, the mantle lays down alternating layers of calcium carbonate and proteinaceous periostracum onto the interior surface of the shell to thicken it, most noticeably marginally and, especially, posteriorly. Thus, the space between the valves occupied by the body of the animal actually decreases with age and the valves probably thereby become progressively even less capable of parting. Because the two valves are united dorsally only by thin layers of

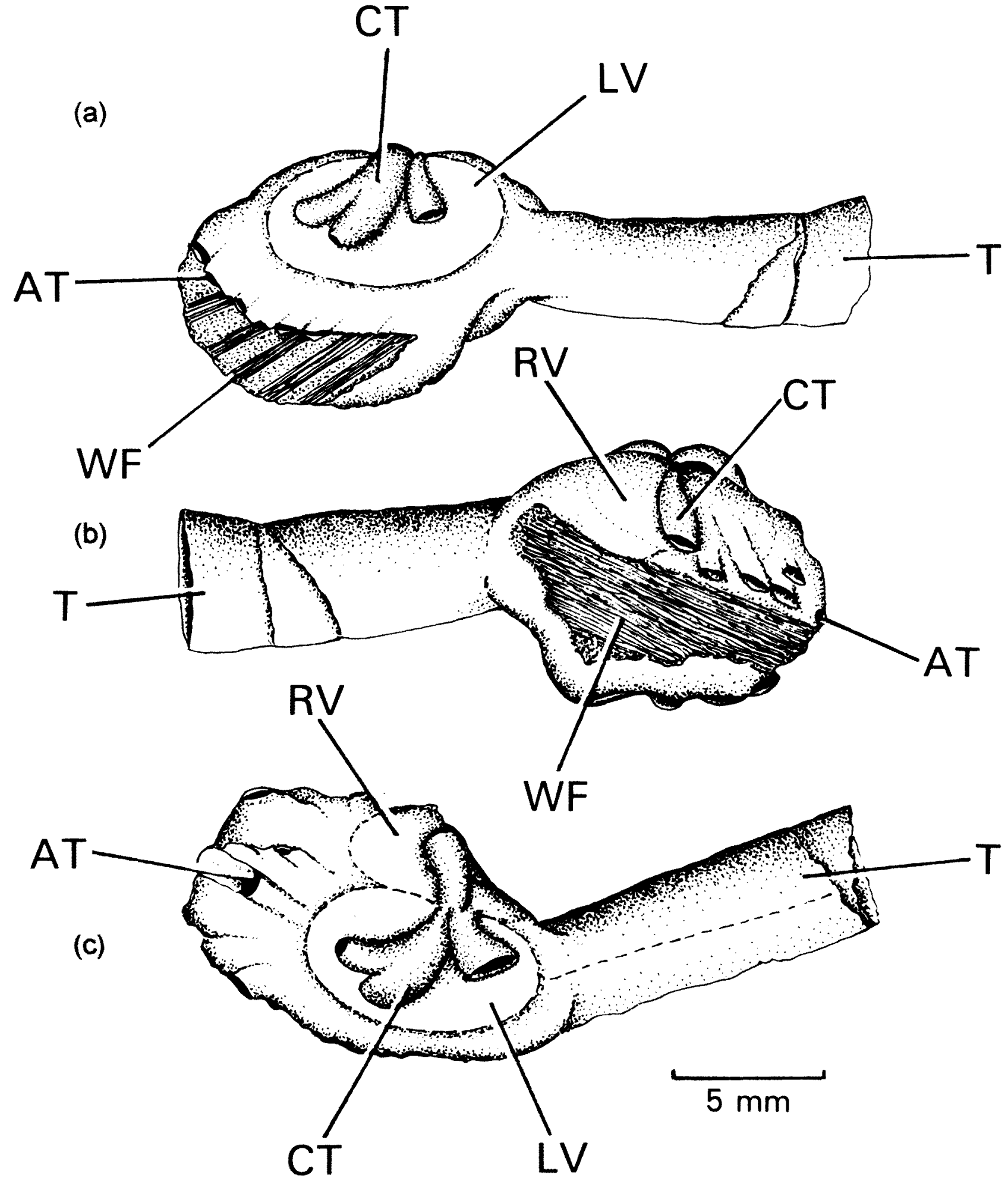

Figure 5 Dianadema multangularis. The adventitious tube as seen from $a$, the left; $b$, the right and $c$, dorsal perspectives. (For abbreviations see Appendix). 
periostracum too, there is little to create a valve opening force. $B$. aligamenta is further characterized by large adductor, pallial and siphonal retractor muscles, so that the entire animal is encased tightly within an internally strengthened shell within a crypt. Movement must therefore be minimal, blood being pumped into pallial haemocoels to push open the valves and extend the siphons. This suggests that $B$. aligamenta, and possibly B. lata, represents an extreme example of adaptation to an endolithic life style: that is, it internally strengthens its shell and the outer surface of the right valve and is probably capable of only limited movement even though it has relatively huge muscles to shut the shell, retract the siphons and seal the mantle cavity ventrally.

\section{(iii) Cementation: Dianadema}

Cotton (1961) and B.J. Smith $(1971,1976)$ reported upon an unusual species of Clavagella, that is, $C$. multangularis, from southern Australia first described by Tate (1887a, 1887b). Carter (1978) provides illustrations of the crypt and true shell of this species, noting the presence of periostracal spinules in the latter. Morton (2003a) further described this species but re-assigned it to a new genus, Dianadema. The left valve (LV) of $D$. multangularis (Figure 5(a)) is attached to the adventitious crypt that is, in turn, in this individual, cemented to wood fibres (WF) although attachment can be to other materials including shell fragments. The siphons are contained within an adventitious tube (T) and there are anterior (AT) and dorsal tubules (CT). The position of the internal right valve
( $R V$ ) is seen when the specimen is viewed from the right side (Figure 5(b)). The adventitious tube (T) that houses the siphons has breaks and repair marks. When seen from the dorsal perspective (Figure 5(c)), the dorsal tubules of the crypt are in the form of a crown (CT) arising from its right side and which arch over to fuse with the left valve (LV), although others recurve over the right (RV). Such a structure is reminiscent of Ascaulocardium armatum (Pojeta and Sohl, 1987). Little else is known about the biology of D. multangularis except that it attaches by [its] disc to rocks and shells [at] 2[00]-250 $\mathrm{m}$ depth or [is] unattached and partly embedded in substratum' (Lamprell and Healey, 1998, p. 220). 'A common habitat is on valves of dead bivalves and a number have been taken from between the large spines of Spondylus tenellus' Reeve, 1856 (B.J. Smith, 1976, p. 189). Hitherto only recorded from Australasia, Habe (1981) notes that his Clavagella japonica is like Dianadema torresi Smith, 1885 and specimens of C. minima (B.J. Smith, 1976, figs 6 and 7) from Mauritius (Indian Ocean) in the Natural History Museum, London, similarly have the dorsal crown of tubules characteristic of Dianadema (personal observations).

\section{(iv) Free living: Ascaulocardium}

Pojeta and Sohl (1987) assigned Clavagella armatum, a Late Cretaceous clavagellid fossil from Mississippi, to the new genus Ascaulocardium that is illustrated from the left side in Figure 6. In this taxon, there is a posterior adventitious tube $(\mathrm{T})$, four long anterior tubules (AT), right anterior tubules (RAT) and the crypt is united, also on the right side,

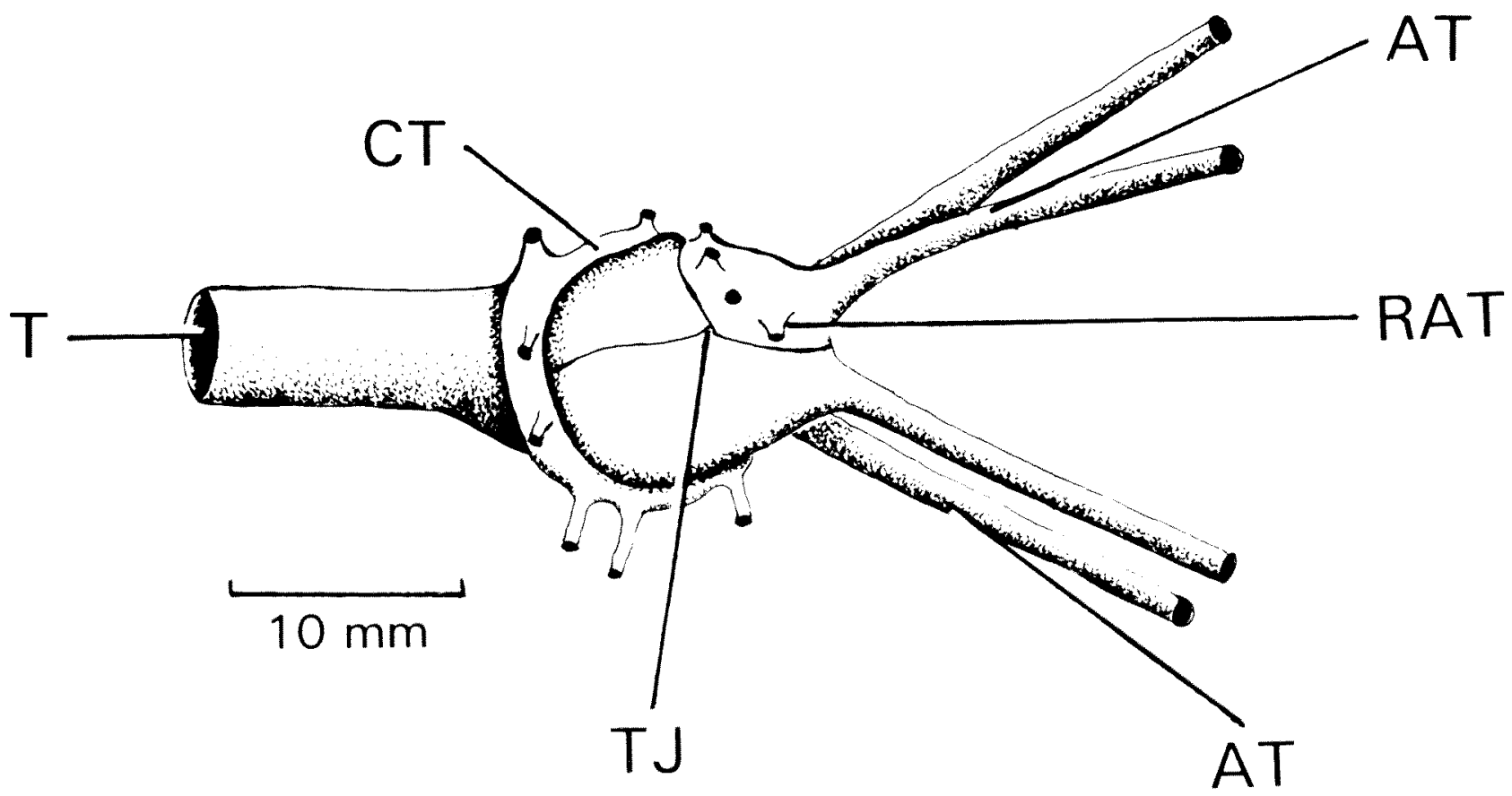

Figure 6 Ascaulocardium armatum. The adventitious tube as seen from the right side (redrawn after Pojeta and Sohl, 1987). (For abbreviations see Appendix). 
at a triple junction (TJ). As in Dianadema, there is a crown of tubules (CT) that encircle the crypt. Ascaulocardium armatum, like species of Clavagella, has the left valve fused to an adventitious crypt with the right free within it. On the right side, the crypt elements are fused at what was called a triple junction and there are right lateral tubules on the anterior plate and anterior tubules arising from the antero-ventral one (two on the right and left sides). Posteriorly, the siphons are enclosed within a tube. The crown of tubules in $A$. armatum is reminiscent of the situation in Dianadema multangularis, arising dorsally from the postero-dorsal plate and in the former but not the latter encircling and fusing with the crypt. Pojeta and Sohl (1987) believed $A$. armatum to be an endobenthic, free-living species.

\section{(v) Life in an adventitious tube: Stirpulina}

The only known living species of Stirpulina, that is, S. [as Stirpuliniola] ramosa occurs in Japan (Habe, 1951). Savazzi (1982a, text-fig.1) illustrated the fossil clavagellid $S$. coronata in life position as infaunally buried just like the penicillid Brechites (Morton, 2002a) and its allies. Savazzi (2005, figure 5) illustrates the tubes of the extinct $S$. bacillus (Brocchi, 1814) and S. coronata (Deshayes, 1824) and the extant S. ramosa. Morton $(2005,2006 \mathrm{a}, \mathrm{c})$ has described the tubes of $S$. coronata, $S$. pallinupensis and $S$. ramosa.

A specimen of Stirpulina ramosa is illustrated in dorsal view in Figure 7 . There is a long adventitious tube with break repairs (RE) and an array of branching tubules (TU) making up the anterior watering pot. Only the left valve (LV) is incorporated into the structure of the tube and on the right side there is a distinct pleat (PLE). The most important feature of Stirpulina, however, is that just like Clavagella, Dacosta, Bryopa, Ascaulocardium and Dianadema, the left valve is united with the crypt which is here formed into an adventitious tube, whereas the right is free inside it (Savazzi 1999, text-fig.17. 13D). Nothing else is known of the anatomy of Stirpulina although Morton (2006a) has explained how the adventitious tube and watering pot of $S$. ramosa are formed. Both are secreted from the mantle margin and surface surrounding and extending from the left shell valve so that only it is incorporated into its structure. A dorsally derived mantle element is progressively extended over to the right side of the body meeting a ventrally derived counterpart that passes beneath it forming a pleat in the calcareous structure of the right side of the tube that they secrete. This pleat extends into the complex of watering pot tubules and forms the pedal gape. The watering pot is thus $\Omega$ shaped. The ventrally derived mantle element forms a sinusoidal crest on the right hand base of the watering creating a pedal gape sinus scar on the right valve.

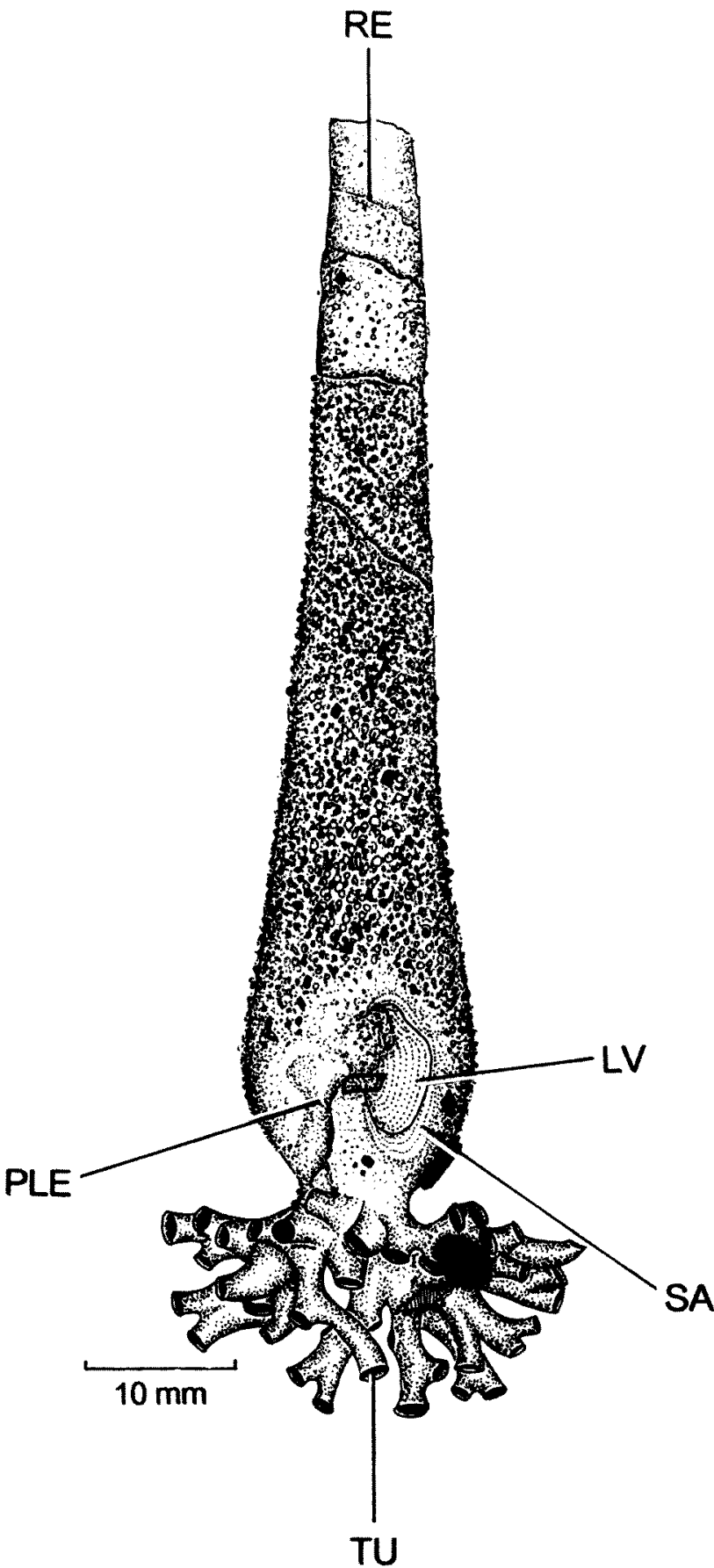

Figure 7 Stirpulina ramosa. The adventitious tube as seen from the dorsal aspect. (For abbreviations see Appendix).

\section{Brechites and its allies}

(i) Life in an adventitious tube: Brechites

A summary of the structure of the shell and adventitious tubes of the genera of the Penicillidae is provided in Table 3. Morton (2006c, table 1) provides a more detailed and comprehensive comparison of the various representatives of the Penicillidae. Chenu (1843b), Lacaze-Duthiers (1870, 1883), Jousseaume (1888), Lamy (1923) and B.J. Smith $(1971,1976)$ have described the anatomies of 


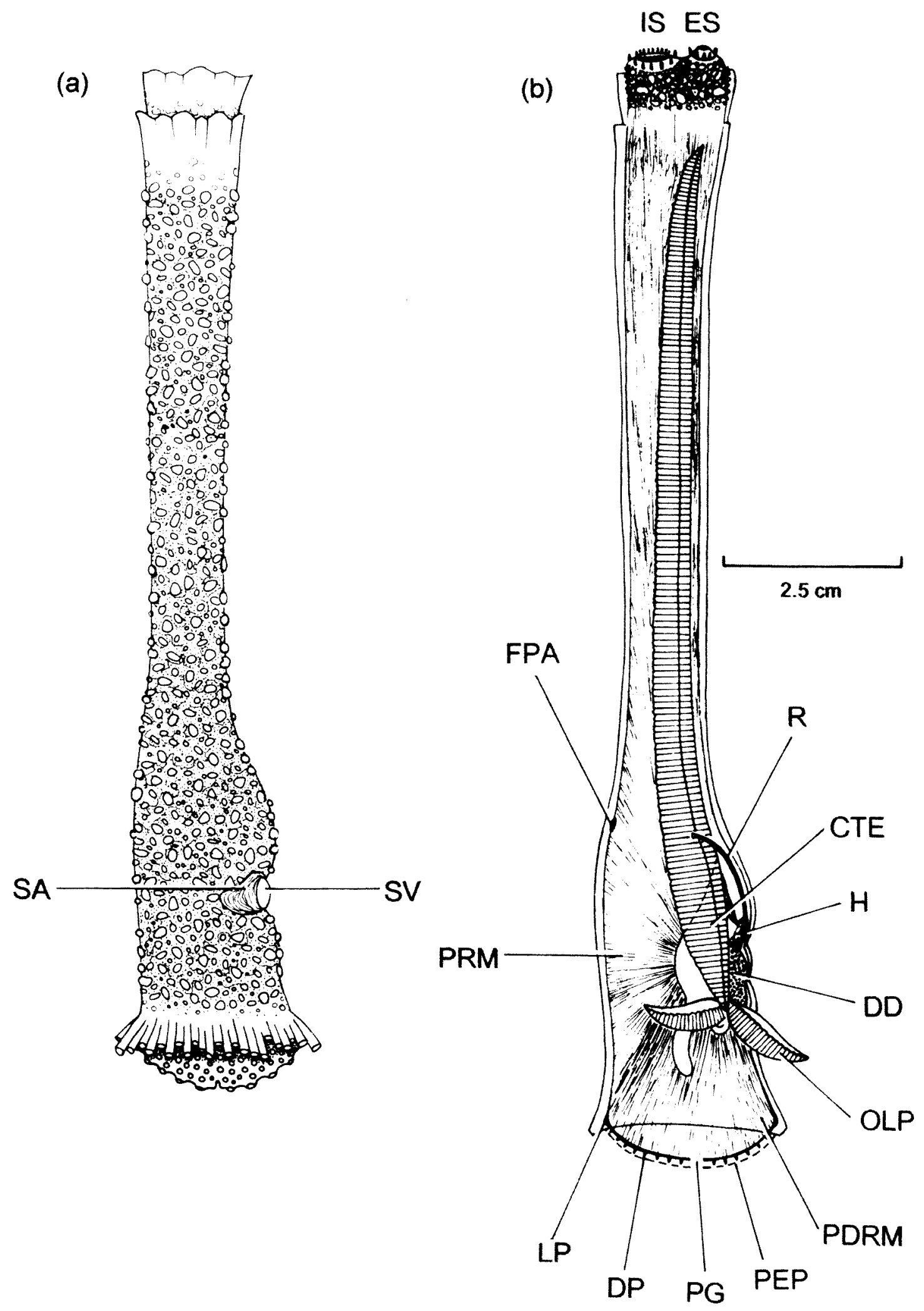

Figure 8 Brechites vaginiferus. a, The adventitious tube as seen from the right side and $b$, the organs of the mantle cavity also seen from the right side (redrawn after Morton, 1984b). (For abbreviations see Appendix).

a number of species of Brechites and their allies. The most recent accounts of living individuals of Brechites penis and $B$. vaginiferus are by Purchon (1956, 1960) and Morton (1984b, 2002a), respectively. No juvenile of any species of Brechites and its allies, other than Humphreyia strangei (E. A. Smith, 1909; Morton, 1984b, 2002b), is known. Because of the adult similarity between Brechites and its adventitious tube dwelling allies and the cemented Humphrevia, however, it is postulated 
that the former suite of species does have a juvenile stage similar to the latter.

Morton (1984b, 2002a) has described the adult adventitious tube of Brechites vaginiferus. The tube (Figure 1(g) and 8(a)) comprises a juvenile shell (SV) surrounded by a saddle (SA) the margin of which is encompassed by the adventitious tube and further united internally by layers of calcium carbonate secreted by the dorsal surface of the mantle. Anteriorly, as noted earlier (Figure 1(h)), the tube is formed into a watering pot with many, open tubules and an open pedal slit. The siphons (Figure $8(\mathrm{~b})$, ES, IS) are housed within the posteriorly elongate tube that can be added to progressively, as so-called "plaited" (probably a spelling mistake for "pleated") ruffles, as the animal grows, which is only possible in the posterior direction. The greatly elongate ctenidia (CTE) extend up to the apices of the siphons separating supra- from infra-branchial chambers. The labial palps (OLP) are large. There is a small visceral mass and the pericardium, with a heart $(\mathrm{H})$, is located beneath a swollen region of the tube, posterior to the shell valves. Muscle fibres extend posteriorly as siphonal retractors and ventrally and anteriorly as pallial (PRM) and pedal disc retractor muscles (PDRM), respectively. There is a pedal gape $(\mathrm{PG})$ in the pedal disc (PEP), a small foot and a fourth pallial aperture (FPA). On the pedal disc, there are lateral (LP) and disc papillae (DP) corresponding with the arrangement of tubules on the watering pot (Figure 1(h)).

It is believed that the main component of the tube is produced only once (Gray, 1858b; LacazeDuthiers, 1883; Jousseaume, 1888; Lamy, 1923; B.J. Smith, 1978; Morton, 1984b, 2002a). In the tips of the siphons are arenophilic radial mantle glands which occur in some other watering pot species and in some other anomalodesmatans and which in them all serve to stick detritus to the apices of the siphons and thus camouflage them (Morton, 2000a, 2002b, 2002c). Brechites vaginiferus occupies a range of intertidal and subtidal habitats and in sand the tube is long and thin whereas in rocky crevices and cobble habitats it is cemented to the encompassing substratum and is short and squat (Morton, 2002a), resulting in the erection of a distinct sub-species, Brechites vaginiferus australis (Chenu, 1843), for the latter growth form (Lamprell and Healey, 1998).

Scanning electron micrographs of the true shell of Brechites vaginiferus (Figure 9(a), arrow) show the presence of a prodissoconch ( $150 \mu \mathrm{m}$ in length) confirming that, as in every other bivalve, there is a typical larval stage, as first proposed by Jousseaume (1888) and suspected by B. J Smith (1978), even though it is still unknown if development is direct
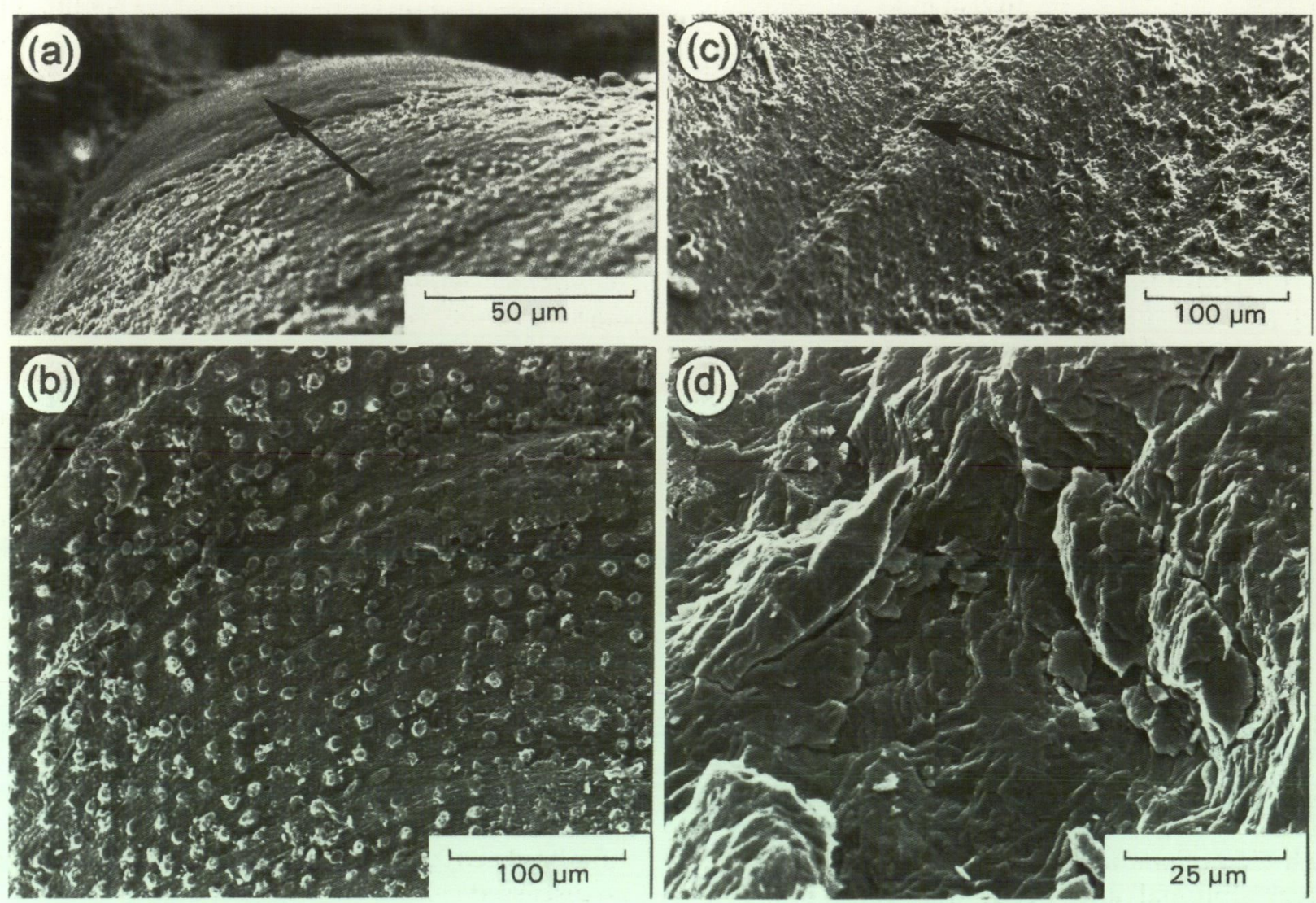

Figure 9 Brechites vaginiferus. Scanning electron micrographs of $a$, the prodissoconch (arrow); b, the surface of the juvenile shell; $\mathrm{c}$, the saddle with (arrowed) the junction between it and the juvenile shell and $\mathrm{d}$, the tube fractured and comprising plate crystals. 
or indirect. The juvenile shell is quadrate and its surface is finely spinulate (Figure $9(b)$ ), as is that of Humphreysia (= Humphreyia) strangei (Taylor et al., 1973) and Dianadema multangularis (Morton, 2003a). The junction between the true shell and saddle is illustrated in Figure 9(c) (arrow). The saddle material is of a homogeneous structure that is laid down internal to the nacreous layer of the shell. It comprises a series of marginal growth rings produced at an unknown frequency to create the unusual structure between shell and tube. The tube comprises a single-layered structure (Figure 9(d)) comprising stacks (Taylor, Kennedy and Hall, 1973) of flat platy crystals except at the posterior, siphonal end where it comprises a number of layers laid down as either growth or repair increments and between which are held clasts of sand grains and organic material (Harper and Morton 2004).

Internally, the body of Brechites vaginiferus occupies the swollen anterior end of the adventitious tube under the shell and saddle that are all fused by calcareous cement secreted by the dorsal mantle. Greatly elongate siphons occupy the remainder of the tube. The adult $B$. vaginiferus is amyarian although there are a remnant pair of anterior, but no posterior, pedal retractor muscles (Morton, 1984b, 2002a). In most other anatomical respects, $B$. vaginiferus is a typical representative of the Anomalodesmata. The ctenidia and labial palps function in the usual bivalve manner for collecting siphonally inhaled food. Brechites vaginiferus can, however, also collect potential food (bacteria, dissolved organics and mineral salts) from the interstitial water of the sediments in which its watering pot is embedded (Morton, 2002a). There is also an intestine of the usual anomalodesmatan bivalve form to process ingested material, but there are no pericardial proprioreceptors described for Humphreyia strangei (Morton, 2002b), because there are no posterior pedal retractor muscles.

\section{(ii) Foegia}

Foegia novaezelandiae is known only from the Holocene of Western Australia and Japan (Morton, 2004a) and is thus possibly very modem (Figure $10(a))$. Like Brechites vaginiferus, F. novaezelandiae has been shown to use its muscular pedal disc to pump interstitial water into its mantle cavity via the pedal gape, and hence the pedal slit and tubules of the anterior watering pot component of the adventitious tube (Morton, 2004a)

Foegia novaezelandiae is similar to Brechites vaginiferus in being amyarian except for minute anterior pedal retractor muscles in the latter. As with $B$. vaginiferus also, pallial retractor muscles effect siphonal and pedal disc retraction. The adventitious tube of $F$. novaezelandiae is more complex in that the shell valves are recessed and largely hidden externally by additional bulbous concretions of tube material secreted from anterior and posterior pallial crests. Although the interstitial water $F$. novaezelandiae pumps into the mantle cavity probably contains interstitial bacteria and dissolved organic material which serve as nutritional supplements, this species, unlike $B$. vaginiterus, has an agglomeration of organic material and bacteria adhering to its highly convoluted periostracum anteriorly, particularly that of the pedal disc and thus inside the adventitious tube. Morton (2004a) speculated that such bacteria might help detoxify the hydrogen sulphide contained in the interstitial water of the hypoxic sediments that, unlike other penicillids, $F$. novaezelandiae inhabits. However, $F$. novaezelandiae has a full complement of mantle cavity and intestinal organs for the processing of food filtered from the seawater above.

\section{(iii) Penicillus}

Lacaze-Duthiers (1870, 1883) and Purchon (1956, 1960) studied the anatomy of species of Penicillus (Figure 10(b)), that is, P. (as Aspergillum) javanum (= P. philippinensis), $P$. (as Aspergillum) dichotomum (=P. penis) and $P$. (as Brechites) penis, respectively. The Indo-West Pacific watering pot shell Penicillus philippinensis (Penicillidae) is essentially amyarian, that is, the posterior adductor and pedal retractor muscles are lost, their anterior equivalents vestigial (Morton, 2006c). In addition to a small group of pallial retractor muscles arising from the pallial line, as is typical of other penicillids, $P$. philippinensis is connected to its adventitious tube dorso-laterally by a saddleshaped array of papillae that previses the more elaborate system in the southern Australian Kendrickiana veitchi. This species and $P$. philippinensis are different from other penicillids too in that the siphons are capable of only limited retraction into the adventitious tube. Their extension in both species is largely by hydraulic means, the complex pallial musculature acting antagonistically with extensive blood-filled haemocoels. Penicillus philippinensis can also be separated from other penicillids in a number of anatomical respects. For example, some species such as $K$. veitchi and Nipponoclava gigantea (but not Foegia novaezelandiae) have vestigial posterior pedal retractor muscles and associated pericardial proprioreceptors but $P$. philippinensis does not. Like other penicillids, however, $P$. philippinensis has a muscular pedal dise whereas $K$. veitchi does not. A trend in the Penicillidae towards greater and greater specialization for life inside an adventitious tube has been identified by Morton (2006a) and will be discussed below

\section{(iv) Kendrickiana}

The largest ( $>30 \mathrm{~cm}$ tube length) extant species of 

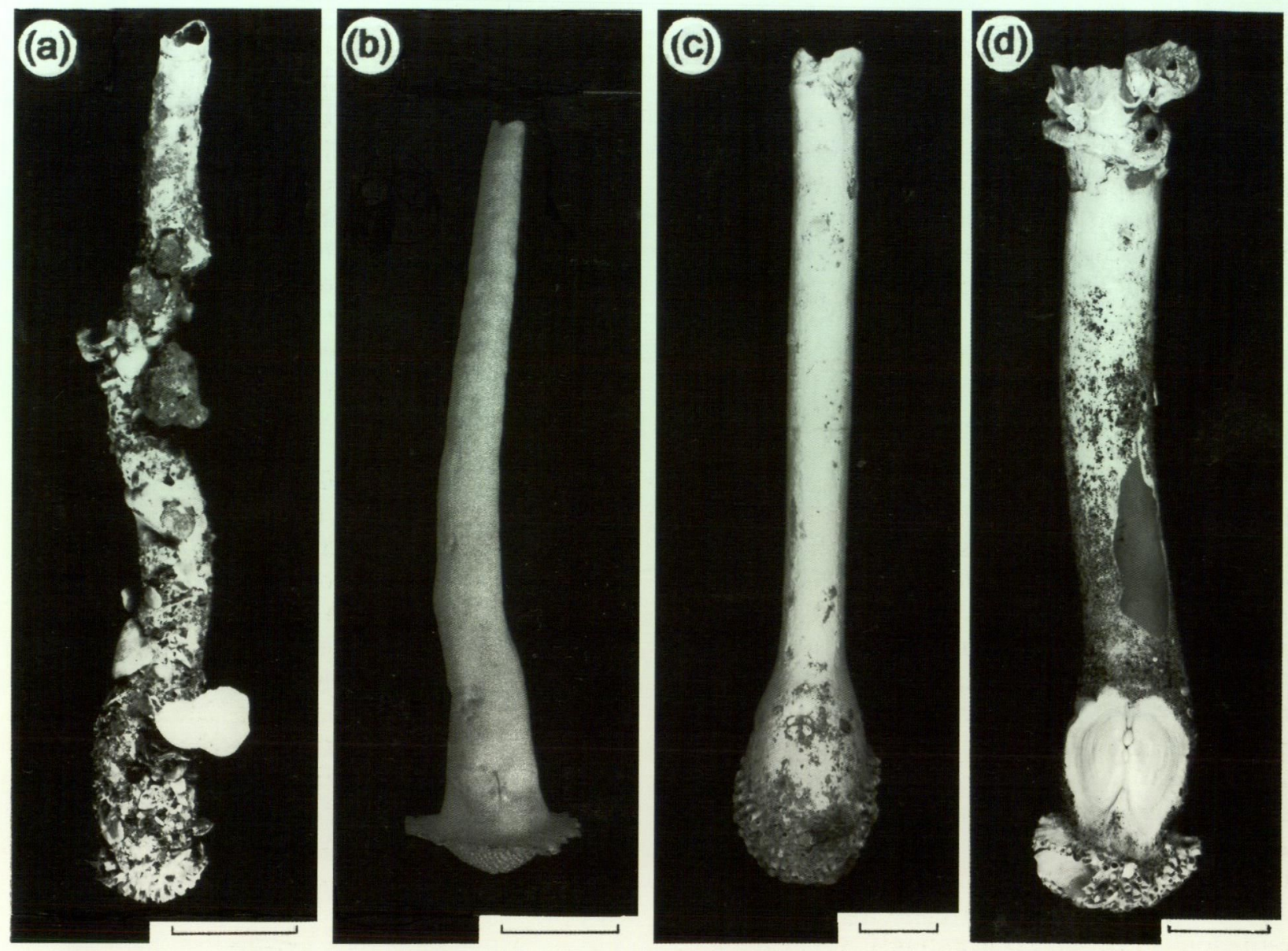

Figure 10 The adventitious tubes of a, Foegia novaezelandiae; b, Penicillus philippinensis; c, Kendrickiana veitchi and d, Nipponclava gigantea, as seen from the dorsal aspects (scale bar $=20 \mathrm{~mm}$ ).

the adventitious tube-building watering pot shells was placed in the genus Foegia (itself formerly a subgenus of Brechites), the type species of which is $F$. novaezelandiae. Following examinations of and comparison with $F$. novaezelandiae, the southern Australian $F$. veitchi was placed in its own new genus Kendrickiana (Morton, 2004c) (Figure 10(c)). Anteriorly, the adventitious tube does not end in a watering pot "rose" as in other penicillids, but is egg-shaped with the tubules arranged more randomly.

Both Foegia novaezelandiae and Kendrickiana veitchi are essentially amyarian in terms of adductor and pedal retractor muscles but the latter species is connected to its adventitious tube dorsally by an unique horseshoe-shaped array of muscular papillae which are inserted into holes in the tube. Kendrickiana veitchi is similar to Penicillus philippinensis in that the siphons are capable of only limited retraction into the adventitious tube and their extension in $K$. veitchi is almost certainly exclusively by hydraulic means. Kendrickiana veitchi does not possess pedal retractor muscles and thus there are no pericardial proprioreceptors. Similarly, unlike all other penicillids $K$. veitchi does not possess a muscular pedal disc inside the watering pot and apparently lives exclusively in subtidal (to $-12 \mathrm{~m}$ ) Posidonia sea grass beds.

The peculiar dorsal horseshoe-shaped crescent of muscular papillae facilitates secure attachment to the tube (but not shell valves) and can be considered to represent a neomorph, that is, a secondarily derived structure replacing the lost adductor muscles. As such, it does not serve to close the shell valves, since these are tiny $(\sim 3 \mathrm{~mm}$ long) and immovably fused into the fabric of the adventitious tube but does re-create one of their functions, that is, to generate the muscular forces which assist in effecting exchange with the water column above and, probably, interstitial waters in the burrow heading below. As noted above, the elaborate saddle-shaped array of papillae connecting the animal to its adventitious tube dorso-laterally is foreshadowed by the simpler system in Penicillus philippinensis (Morton, 2006c). In all other anatomical respects, however, $K$. veitchi is typical of the other endobenthic penicillids.

\section{(v) Nipponoclava}

Nipponoclava gigantea is restricted to the tropical Western Pacific waters of southern Japan at depths 
of between $5-70 \mathrm{~m}$ and lives in coarse sand and gravel (Figure 10(d)). In many respects, $N$. gigantea appears similar to other endobenthic penicillids in that there is a true shell, the margins of which, via the intermediary of a narrow saddle, are united with an adventitious tube. This has a large watering pot anteriorly and pleated ruffles, representing either growth or repair events, posteriorly. Nipponoclava gigantea differs from other penicillids, however, in that its true shell is large, that is, $\sim 20 \mathrm{~mm}$ in height as compared to $2-3 \mathrm{~mm}$ and the angle of valve splay is but $\sim 80^{\circ}$ as opposed to $\sim 180^{\circ}$ in other endobenthic penicillids. Internally too, the post-juvenile shell has a wide pallial line and shallow pallial sinus and there are anterior adductor muscle scars. There are possibly also posterior adductor muscle scars. These are not present in the adult animal, however, although the anterior adductor is. Also present are paired anterior and (possibly) posterior pedal retractor muscles, the latter having a nervous union with the visceral ganglia to create simple stretch or tonus proprioreceptors.

Morton (2004b) argued that Nipponoclava gigantea provides clues as to how the tube-dwelling lifestyle has evolved in the various taxa of the Penicillidae. It is suggested that through a process of heterochrony in which the animal produces its adventitious tube at progressively earlier and earlier developmental stages, the true shell has become actually and relatively smaller and smaller and, hence, more splayed in more derived penicillids. Nipponoclava gigantea is thus an important link between an hypothetical lyonsiid ancestor and the more specialized penicillids.

\section{(vi) Cementation: Humphreyia}

The genus Humphreyia is represented in southern Australia by H. strangei (A. Adams, 1852). Cotton (1961) identified a second species, $H$. incerta Chenu, 1843b, from southern Australia but this was not recognized by subsequent authors, for example, B.J. Smith (1971, 1976, 1998) and Lamprell and Healey (1998) and is actually a specimen of Kendrickiana veitchi (Morton, 2004c). Fossil tubes of $H$. strangei have been obtained from Late Pliocene sediments, also only from southern Australia (Gray, 1852, 1858a; E. A. Smith, 1909; L.A. Smith, 1971, 1976; Morton, 2002b).

Morton (2002b) described the anatomy of Humphreyia strangei. This study was of special interest because there is a specimen of a juvenile (Figure 11) available for examination so that it was possible to investigate how this species "metamorphoses" from a free-living individual to a cemented adult. The juvenile shell of $H$. strangei is subquadrate, slightly heteromyarian, equivalve (Figure 11(a), SV) and possesses an external ornamentation of radially arranged spinules. There are relatively large anterior and posterior adductor muscles, but no obvious pedal retractor muscles, and a deep pallial sinus. The long siphons and body are contained within a periostracal sheath (Figure 11(b), PE) dotted with adhering sand grains (SAG) and within which there is a pedal gape (PG) and a fourth pallial aperture. Internally, the juvenile shell of $H$. strangei, with an external opisthodetic primary ligament that also has a ventral lithodesma (Figure 1(f), LI), is overlain by thick fused periostracum and cemented to the adventitious tube by further secretions from the dorsal mantle, as in Brechites vaginiferus (Morton, 2002a) and all other penicillids.

The adult of Humphreyia strangei is very different (Figure 12) from the juvenile (Figure 11) in that it is cemented. When seen from the right side (Figure 12), there is a shell (SV) like that of the juvenile, but this has been expanded by secretion of the saddle (SA) and anteriorly by formation of a primary (PWP) and then secondary (SWP) watering put, with marginal tubules (TU). The adventitious tube $(\mathrm{T})$ arises as a posterior extension (EAT) from the watering pot (ESWP) and shows signs of subsequent growth (STG). Laterally, the tube has a ridge (LR) defining dorsal exhalant from ventral inhalant siphons. The adult of $H$. strangei (unlike

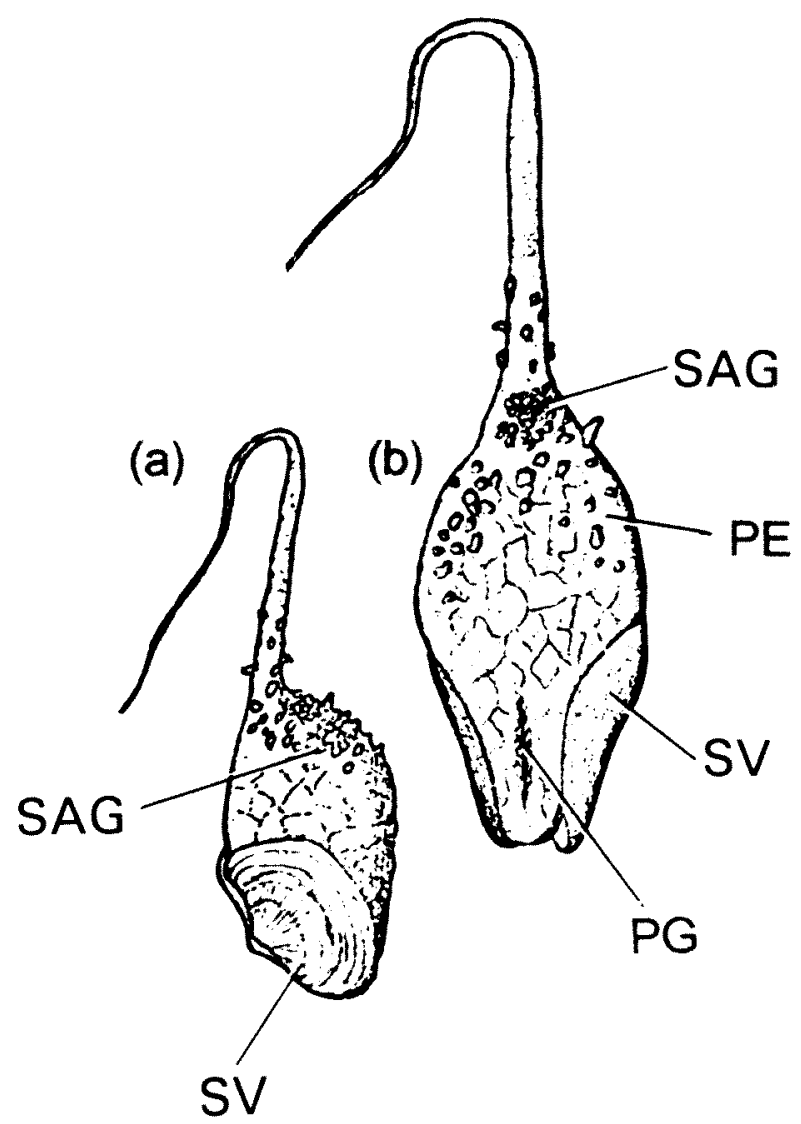

Figure 11 Humphreyia strangei. The juvenile as seen in (a), side and (b), dorsal views (redrawn after E. A. Smith, 1909). (For abbreviations set Appendix). 


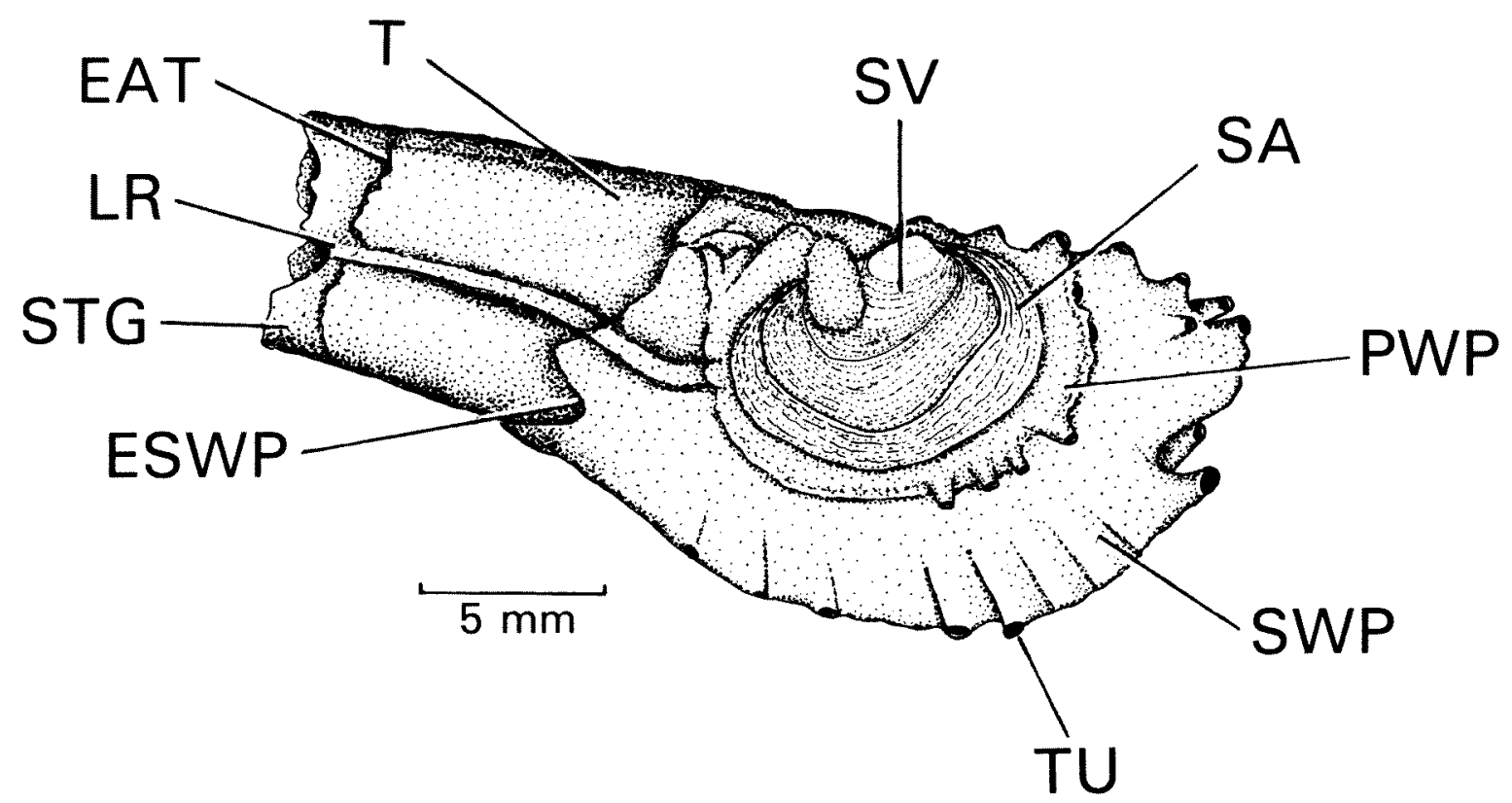

Figure 12 Humphreyia strangei. The adult as seen from the right side (redrawn after Morton, 2002b). (For abbreviations see Appendix).

the juvenile) is essentially amyarian. Anatomically, there is a typical anomalodesmatan bivalve suite of ctenidia, labial palps and associated ciliary currents related to suspension feeding, and a complete intestine. Morton (2002b) identified a pair of tiny pedal retractor muscles (Figure 13, PM) within the distal limbs of the kidneys arising from the dorsal mantle (M) and thus attached to the adventitious tube (T), or internal saddle, and extending downwards and attaching to the ventral surface of the pericardium (PEC). Ventrally, each muscle block is in intimate contact with a large $(100 \mu \mathrm{m})$ ganglion (PRG) which, because of its position, is not one of the fused and distinctive visceral ganglia but a specialized structure with nervous connections, albeit via the cerebro-pleural-visceral connective (CP-V-CONN), posteriorly, to these and, anteriorly, the cerebral ganglia. Lateral to each ganglion is what is believed to be a sensory structure that comprises hollow sacs some $100 \mu \mathrm{m}$ in horizontal diameter with thickened $(8 \mu \mathrm{m})$ internal epithelial linings. These structures are considered to be a pair of specialized proprioreceptors (PSS). Each one resembles a disc to which dorsal and ventral proprioreceptor muscles attach, so that as they either contract or relax, the hollow sensory sacs adjacent to each proprioreceptor ganglion will either compress or expand, respectively, and so stimulate it and thence, the cerebro-pleural and visceral ganglia. They probably monitor rectal tonus in relation to the discharge of faeces into the long exhalant siphon and thus to the exterior (Morton, 2002b).

The foot of the adult Humphreyia strangei is reduced relative to its size in the juvenile and it is proposed that, at some point in time, possibly at maturity, and when a site suitable for adult occupation is found, the hitherto mobile juvenile cements itself to the substratum (Morton, 2002b). How the secretion that covers the animal and cements it to the substratum is produced is unknown, but is possibly secreted in the same way as in Brechites vaginiferus (Harper and Morton, 2004) from the outer surface of the mantle but without the template of a burrow wall.

\section{DISCUSSION}

An adventitious tube is produced by the representatives of a number of bivalve lineages, for example, the wood-boring Teredinidae (Turner, 1966) and the Gastrochaenidae, that is, Cucurbitula cymbium Spengler, 1783 and Eufistulana mumia (Carter, 1978; Morton, 1982, 1983). In both, this is associated with the great elongation of the siphons and some elements of the mantle cavity, for example, the ctenidia and visceral mass, beyond the confines of the shell. In teredinids, the shell is reduced because it functions largely as a rasping file. Gastrochaenids more closely resemble the anomalodesmatan watering pot shells in that some are borers (Gastrochaena), others inhabit a crypt (Cucurbitula) and Eufistulana creates a long adventitious tube (Carter, 1978; Morton, 1983). In gastrochaenids, however, the shell is always free within its crypt (or tube) and, though small, still grows continuously with age, for example, Cucurbitula (Morton, 1982). This is not so with the various representatives of the Clavagellidae and Penicillidae, however, where the shell is either partly or wholly united, respectively, with a much larger crypt or adventitious tube, again 


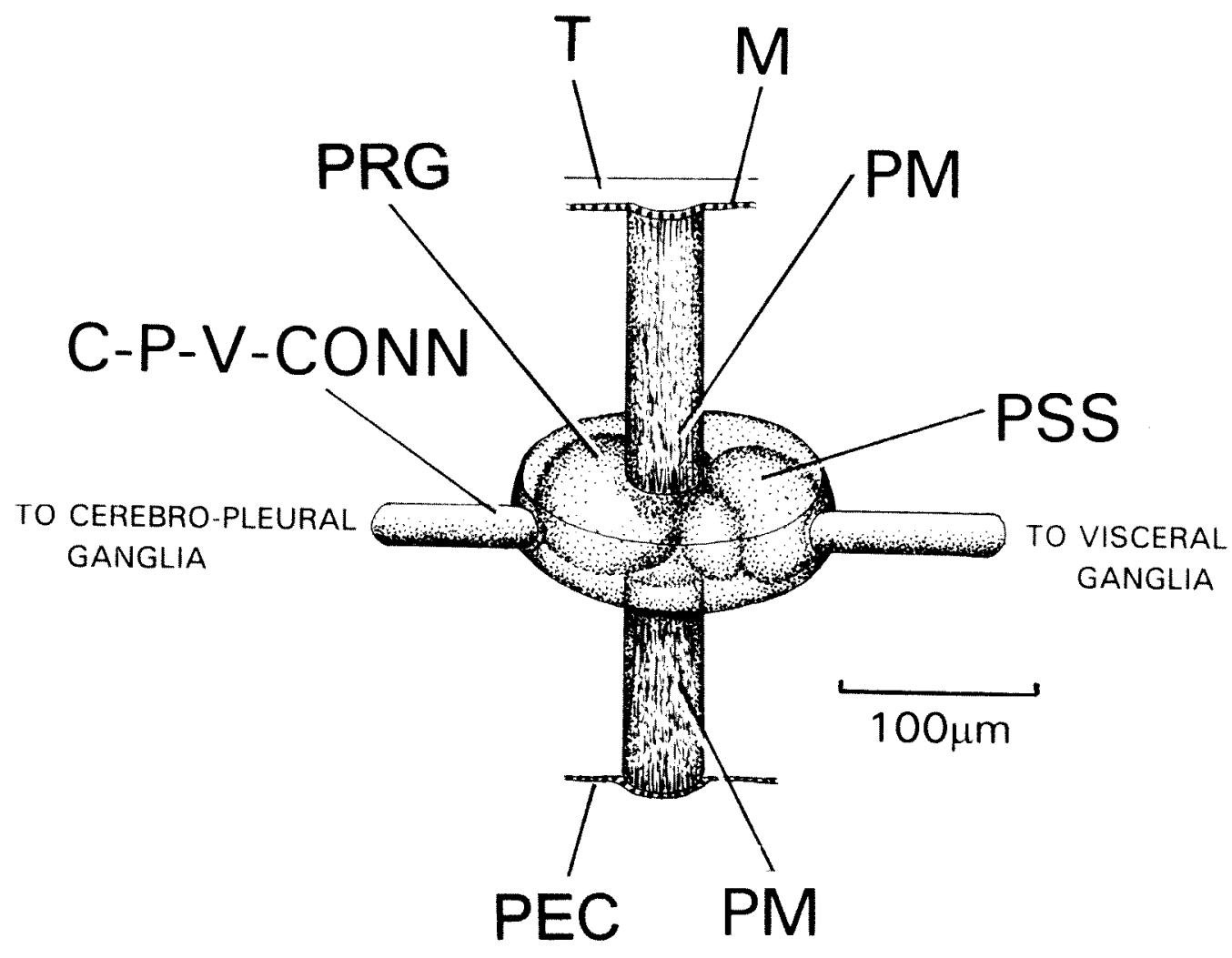

Figure 13 Humphreyia strangei. An interpretation of the structure of a pericardial proprioreceptor (redrawn after Morton, 2002b). (For abbreviations see Appendix).

respectively. Further, in representatives of the former the shell is typical of an adult whereas in the latter it is a juvenile.

As this paper argues, what has been regarded as the monophyletic Clavagelloidea, as presently understood, actually comprises two families and is thus diphyletic. Both herein identified families, though different in terms of shell and tube characters, are similar in terms of their general anatomies and, thus, clearly have an anomalodesmatan body plan (Morton, 1981, 1985a). The structures of the crypts/adventitious tubes and the anatomical characteristics of representatives of the Clavagellidae and Penicillidae are compared in Table 3. It is argued that from morphologically simpler anomalodesmatans, probably representatives of the Lyonsiidae, a crypt or adventitious tube has evolved twice, suggesting an ancestral predisposition towards progenesis and the advantages accrued from such derived structures in facilitating the occupation of highly specialized marine niches. Although the nestling/boring mode of life is seen only in the Clavagellidae (Dacosta and Bryopa), the cemented and endobenthic modes of life have, it is argued, evolved twice. It will be further argued that neoteny, particularly in the Penicillidae, has favoured precocious sexual maturity at progressively earlier stages of shell growth and that hypermorphosis has resulted in the formation of enormously enlarged siphons, particularly in Stirpulina (Clavagellidae) and Brechites and its allies (Penicillidae) that become protected by subsequently secreted adventitious tubes. Unfortunately, there is little evidence in support of neoteny because no juveniles of any taxa, save one, have been identified. The exception to this is the single preserved juvenile of Humphreyia strangei (Morton, 1984b, 2002b). This juvenile individual had anterior and posterior adductor muscles and the foot had a byssal groove. If, as seems possible, "true" shell growth of such an individual were to be arrested in favour of enhanced "adventitious" tube growth at precocious sexual maturity, this would constitute evidence for post-neotenous hypermorphosis.

\section{Function and origin of the clawgellid crypt}

The crypts of representatives of the Clavagellidae probably serve a number of functions. For example, species of the oldest genus Clavagella encase themselves in a crypt. Dacosta australis is a nestler that possibly enlarges its borehole (perhaps made initially by another borer) and tubules penetrate its base. What their function is, however, is unknown. Dacosta australis also secretes a posterior tube to protectively enclose its siphons and lines its burrow bevond the margins of the left shell valve that is cemented to the crypt wall. In basic structure, 
therefore, the crypt of the numerous extinct species of Clavagella and the simple burrow of $D$. australis serve largely for protection of the contained animal.

Species of Bryopa inhabit corals. Savazzi (2000) thought that $B$. lata bores into dead corals, whereas Morton (2005) showed that B. aligamenta occupies living corals but, unlike $D$. australis, does not develop a tubular network into the host skeleton. Bryopa aligamenta too produces a posterior siphonal extension, as does $B$. aperta, that of the latter being flared apically and ruffled (Morton, 2005). Bryopa aligamenta has evolved surprisingly complex ways to protect itself. In addition to the siphonal extension, it lines its burrow beyond the margin of the cemented left shell valve (as in $D$. australis) and lays down sheets of calcium carbonate to the inner surface of the, free, right valve to thicken it. As the burrow is dissolved anteriorly so too is the shell, creating a highly unusual growth form described first by Savazzi (2000) but resulting in the only known (adult) bivalve, $B$. aligamenta, without a primary ligament (Morton, 2005). Again, such adaptations seem to be for protection.

\section{(i) Growth of the Bryopa shell}

The pattern of growth exhibited by Dacosta australis is typical of the Bivalvia, with commaginal growth lines arising from the umbones (Morton, 1984a). The pattern of shell growth exhibited by Bryopa lata is, however, different with the growth lines seemingly arising from the posterior edge of the shell. Savazzi (2000) interpreted growth in this unusual animal. Subsequently, this was reinterpreted by Morton (2005). In the Bivalvia, growth in size is typically at the shell margin resulting in the sequential production on each valve of commarginal growth lines. In an equilateral, isomyarian bivalve, for example species of Circe (Figure 14(a)), such lines radiate out equilaterally from the umbones about the dorso-ventral growth axis of the shell (D-V). In an inequilateral bivalve, such as the posteriorly elongate borer Barnea (Figure 14(b)), growth ceases to be radially uniform about the dorso-ventral axis that now extends posteriorly and the distances between successive commarginal growth lines become greater on the posterior slope and restricted anteriorly. The opposite of this is seen in species of rapidly burrowing Donax (Figure 14(c)), that is, the dorsoventral growth axis of the shell extends anteriorly and hence the anterior slope of the shell becomes larger through enhanced inter-commarginal growth in this direction. Such variations in the patterns of growth demonstrated by the many representatives of the Bivalvia create the diversity of the class.

In Brypoa aligamenta, as suggested by Savazzi (2000) for Bryopa lata, there is erosion of the anterodorsal regions of the shell as the animal chemically etches out its burrow anteriorly so that the juvenile primary ligament is progressively lost. Importantly, however, so too is the umbo. This, as the focal point of valve union and whose position determines the dorso-ventral growth axis of the shell, thus appears to migrate posteriorly (as the umbones are progressively etched backwards). The commarginal growth lines thus appear to arise on the posterior slope of the shell and to extend towards the anterior. In addition to the apparent posterior 'migration' of the umbones, there is proportionally greater inter-commarginal growth of the posterior slope of the shell valve. This means that the posterior slope expands faster relative to the anterior, enhancing the effect created by the posteriorly migrating growth axis. The shapes of $B$. lata and $B$. aligamenta thus progressively change ontogenetically from a juvenile free-living stage (Palazzi and Villari, 2000) to the adult (Figure 14(d), i-v). A similar situation to that of Bryopa is also seen in the South American freshwater unionid Acostaea rivoli. Yonge (1978b) described the remarkable shell form of this species, as did Taylor, et al. (1969) for the Unionoidea in general. Yonge (1978b) explained that a pallial epithelium can secrete as well as resorb shell material and that secretion begins again (following growth) but at a point distant from the original ligament, so that a new one is formed posterior to it and the original umbones and ligament are progressively lost. The observations by Taylor et al. (1969) on this subject are restricted to the statements (p. 111) that 'During the process of regeneration the epithelial cells of the general mantle surface, change their size and morphology to resemble those of the outer fold of the mantle edge' and (p. 114) that this 'is a response by the mantle to some stimulus resulting from the abrasion and solution of the shell from the umbonal region'. In $A$. rivoli, the epithelium secreting the anterior outer layer of the ligament must be responsible for the decalcification of this region of the upper (right) valve (Yonge, 1978b). Similarly it is also the right valve in $B$. lata.

Interestingly, the growth form of the shell in Bryopa aligamenta does not influence the orientation of the animal within it. That is, the positions of the remnant umbo and the hinge plate in the free right valve are still dorsal and the body tissues, including the main adductor musculature, have not been affected by the ontogenetic changes in shell form. A similar situation is also seen in the coiled and similarly cemented anomalodesmatan Cleidothaerus maorianus. In this bivalve, the form of the body (Morton, 1974) is uninfluenced by the extreme coiling of the shell that results, for example, in the lithodesma growing around the ligament through $>360^{\circ}$ (Yonge and Morton, 1980). A second interesting point about the unusual growth form of Bryopa lata and B. aligamenta, however is that if it 


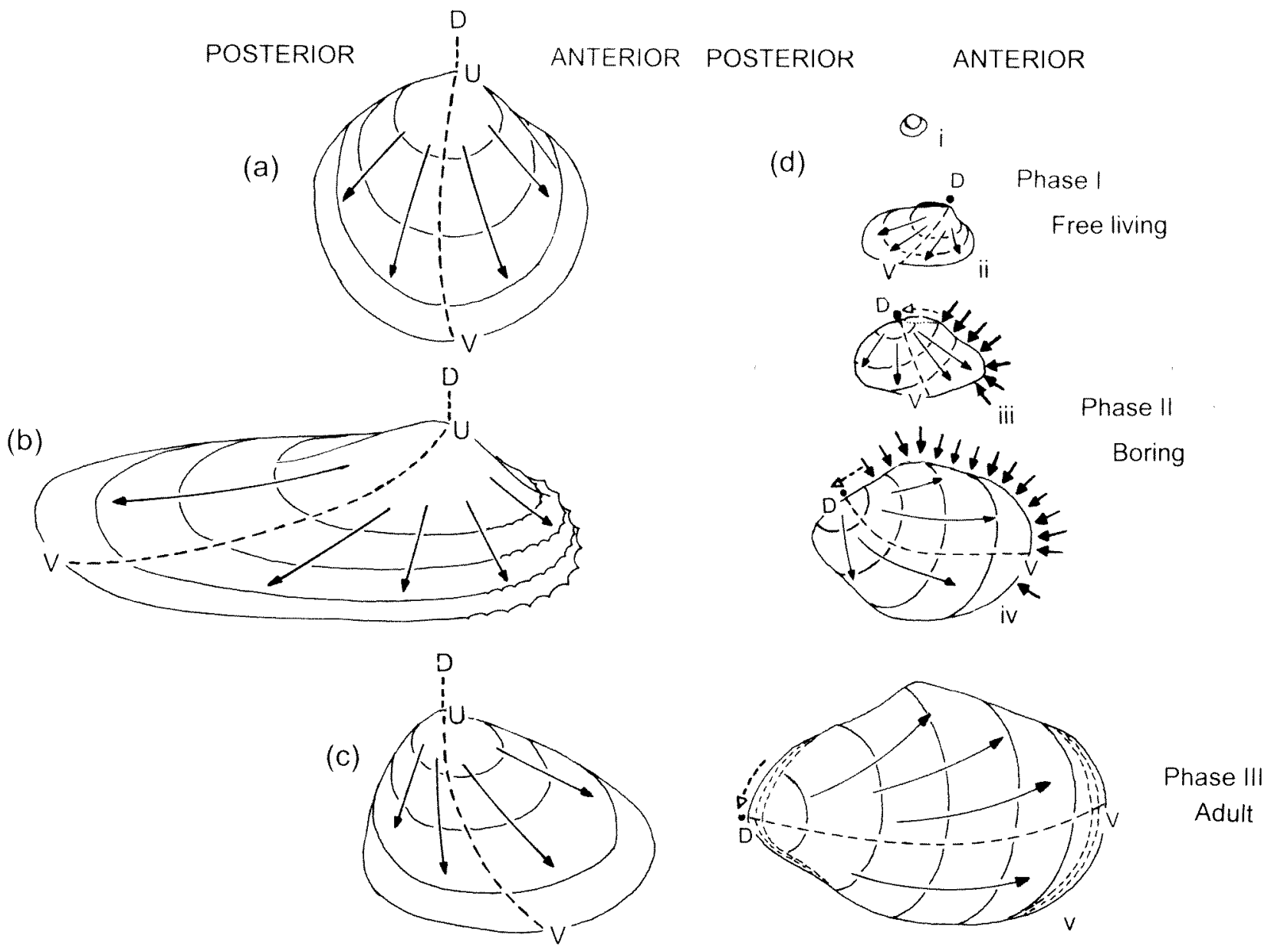

Figure 14 The pattens of commarginal growth as seen in (a), an approximately isomyarian bivalve, Circe: (b), the posteriorly elongated borer, Barnea and (c), the anteriorly elongated burrower, Donax. These are compared with (d), the pattern of commarginal growth in Bryopa aligamenta illustrated as a succession of hypothetical ontogenetic growth stages (i-v) (redrawn after Morton, 2005). (For abbreviations see Appendix).

is a consequence of anterior boring, then the absence of a similar pattern in Dacosta australis suggests that it does not bore.

(ii) The life history of Bryopa

With the above interpretation available, it is possible to characterize the life history phases in the pattern of growth expressed by Bryopa aligamenta, as follows:

Phase I. Each post-settlement individual of Bryopa aligamenta commences life with "the appearance of Thracia or Lyonsia " (Fischer, 1887; Palazzi and Villari, 2000), as a free-living juvenile that is further described by Palazzi and Villari as thin, flat, brittle, shiny and internally nacreous (Figure 14(d), i and ii). This juvenile presumably now finds a crevice in a coral head to lodge itself into and commences boring. To achieve this it, again presumably, has mechanisms to protect itself against the coral's nematocysts, as in species of coral-boring Lithophaga (Morton and Scott, 1980).

Phase II. Once a borehole is established, it is presumably enlarged chemically in a downward direction, that is, anteriorly, since there are no physical attributes of the shell that could effect mechanical boring. During this active boring phase (Figure 14(d), iii and iv), the right valve architecture is progressively modified as the bivalve bores deeper into its substratum, the ligament, umbo and the antero-dorsal margin of the shell are eroded and the dorso-ventral growth axis of the shell appears to migrate posteriorly. Eroded material is probably redistributed over the right valve to strengthen it externally and to form the siphonal canal as in species of coral-boring Lithophaga (Morton and Scott, 1980). It is not, however, laid over the surface of the left valve suggesting that this is at all times firmly adpressed against the burrow wall and to which it becomes cemented, possibly when the boring process slows as the animal approaches maturity.

Phase III. By the time boring ceases, the dorsoventral growth axis of the shell has moved to a posterior position and now the shell valves are further strengthened internally by the production of alternating layers of calcium carbonate and 
proteinaceous periostracum (Figure 14(d), v). The calcareous layers are obvious anteriorly but especially so posteriorly as the animal now further protects itself in this direction, for example, from surface roving predatory gastropods (Morton, 1990). The layers of periostracum serve as a "secondary ligament" (Yonge, 1978a) to keep the valves aligned in the absence (probably loss) of a primary ligament - in the latter case due to anteriordorsal erosion - and function as a simple hinge allowing the valves to part within the narrow, protective, confines of the crypt, probably by adjustments to the haemocoelomic tonus of the various body organs. More calcareous material is probably also deposited posteriorly so that this vulnerable end of the shell fits closely up against the similarly lined and strengthened siphonal tube.

\section{(iii) Cementation: Dianadema}

Species of Dianadema cement themselves into crevices or to pieces of wood or shell. There is thus no burrow to line or substratum onto which they can cement their left shell valves. Instead, an adventitious tube is produced and into the fabric of which is incorporated the left valve. Species of Dianadema, for example D. multangularis, have tubules emerging from the ventral base of the tube and possess apically a dorsal crown of tubules that is suggested to function in the aeration of the crypt (Morton, 2003a). This is in itself of great interest but, more importantly, such a structure links Dianadema with the Late Cretaceous clavagellid Ascaulocardium armatum and which also had a medial circlet of tubules and right anterior tubules arising dorsally from between the beaks (Pojeta and Sohl, 1987, figure 23). The identification of Dianadema and the separation of it from Clavagella sensu stricto (without a dorsal crown of tubules) thus helps us understand the lifestyle of Ascaulocardium, that is, it was probably not a burrower/borer and was not cemented like $D$. multangularis but was an endobenthic species much more like $D$. torresi. The tubule arrangement of the Late Cretaceous Ascaulocardium was possibly thus also an adaptation to improving the aeration of its crypt, as suggested for Dianadema (Morton, 2003a).

(iv) Functioning of the Dianadema aeration system

How the aeration system of the crypt tubule system in Dianadema multangularis (and probably Ascaulocardium armatum) might function is illustrated in Figure 15 (Morton, 2003a). The shell is here shown in transverse section with the left valve (LV) attached to and the right (RV) free within the crypt. The crypt possesses anterior and ventral tubules (AT/VT), connected to the dorsal crown of tubules (CT) and the whole structure is cemented to a solid substratum (S). Except at the small pedal

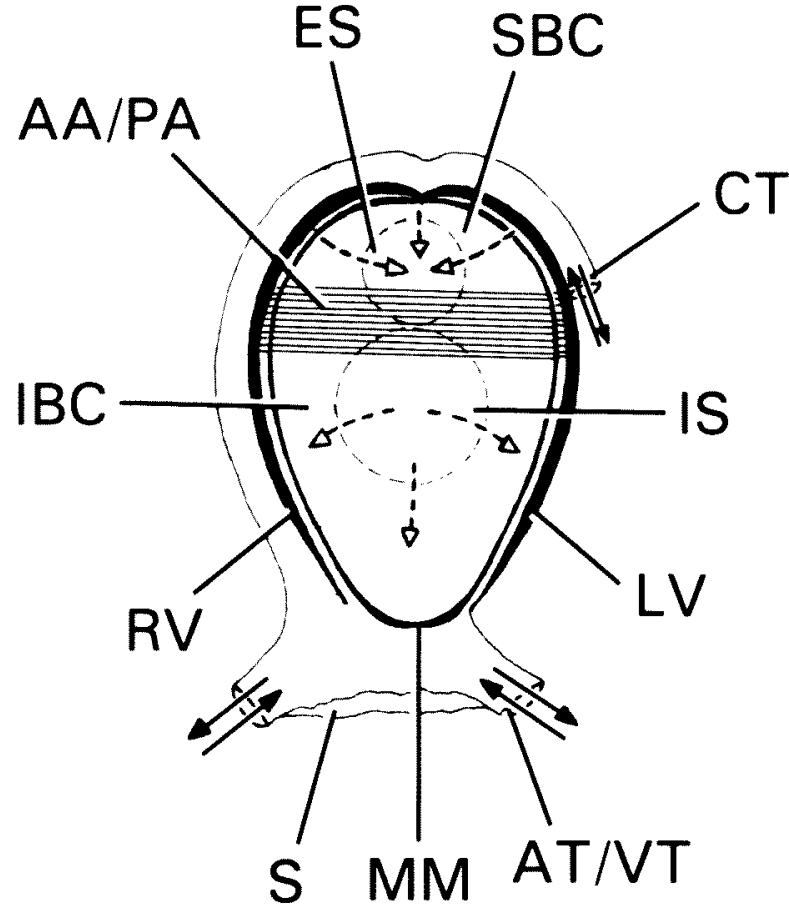

Figure 15 Dianadema multangularis. A transverse section through the shell and adventitious tube showing how water is pumped through the tubule system (redrawn after Morton, 2003a). (For abbreviations see Appendix).

gape, the whole of the ventral mantle margin (MM) is sealed. Water thus flows into the infra-branchial chamber (IBC) via the inhalant siphon (IS), through the ctenidia, and out of the supra-branchial chamber (SBC) via the exhalant siphon (ES), as in a typical bivalve. This movement will be facilitated in part by the lateral cilia on the ctenidia but also by the pumping action created by the contraction and relaxation of the anterior and posterior adductor muscles (AA/PA). However, when the adductor muscles relax, the ligament will also relax and so the internal right valve will move towards the wall of the crypt, the left being fused to it and thus immobile. This will push water within the crypt out of the tubule orifices. When the adductor muscles contract, the right valve will be pulled inwards creating a suction pressure within the crypt and water will be pulled into it at the tubule orifices. Clearly, the functioning of the adductor muscles in controlling the flow of water into and out of the mantle cavity via the siphons and into and out of the crypt chamber via the tubules must be coordinated but, it is argued, this remarkable structure and system has been evolved in Dianadema (and in Ascaulocardium) as a means of more effectively aerating the protective crypt. It also means that the animal could aerate its crypt even if the siphons were non-functioning and retracted, that is, the tubules also constitute an accessory defense mechanism. 
(a)

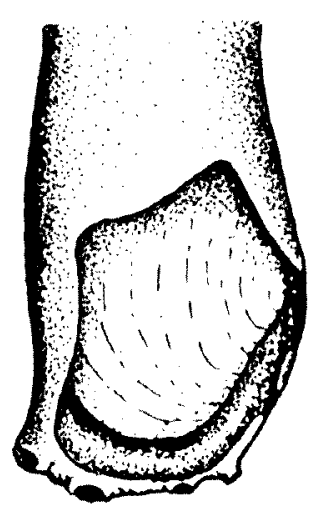

(b)

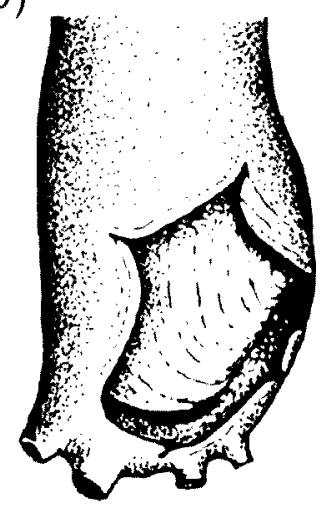

(c)

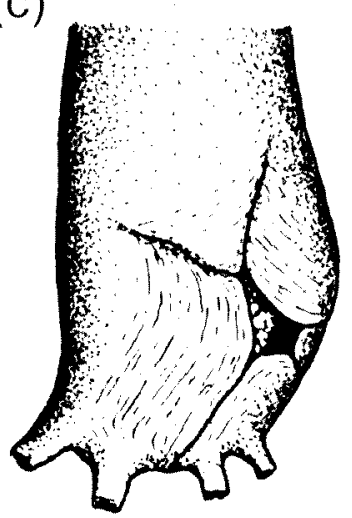

$10 \mathrm{~mm}$

Figure 16 Three stages $(a-c)$ in the construction of the adventitious tube of Stirpulina coronata. (redrawn after Savazzi, 1999)

(v) Adoption of an endobenthic lifestyle

Both Clavagella and Stirpulina evolved in the Upper Cretaceous but the latter can be viewed as the ultimate refinement of the simpler crypt first produced by the former. In Stirpulina, a free-living adult animal living vertically in sediments secretes an adventitious tube against the template of the occupied burrow wall so that it encases the siphons and body - again protectively. Anteriorly, however, tubules are produced that allow either aeration of the burrow heading or, possibly more likely, as in endobenthic penicillids, the sucking of interstitial water and nutrients into the mantle cavity. If this is true, then the watering pot of the adventitious tube of Stirpulina is convergent with that of Brechites and its endobenthic allies, as will be discussed.

\section{(vi) Formation of the Stirpulina adventitious tube}

The fossil Stirpulina bacillus (Clavagellidae) from the Pliocene-Pleistocene of Palermo, Sicily, Italy, was, like the extant Stirpuliniola[=Stirpulina] ramosa, endobenthic with a long adventitious tube and anterior watering pot. The watering pots of the fossils $S$. coronata, $S$. vicentina and $S$. bacillus, moreover, are formed in a different manner to that of penicillids, by progressive encasement of the right valve inside the tube (Figure 16, after Savazzi, 1982a, figure 17.13). The tube is formed first, with the left valve united into its fabric. Folds of mantle tissue secrete calcium carbonate at their leading edges (Figure 16(a)) and gradually form into five units (Figure 16(b)) that eventually coalesce but leave a pleat extending from the also enlarged watering pot tubules (Figure 16(c)). Such a process mirrors the situation described for S. coronata and, thus, eventually creates a watering pot that is not a symmetrical disc as in penicillids, but is $\Omega$-shaped (Figure 17) (Morton, 2006c). A very similar pattern of tube formation has been described for the extant
Stirpulina ramosa (Morton, 2006a). In clavagellids, therefore (i), a burrow lining and the development of tubules to better aerate a protective crypt have led to (ii), the evolution of cementation (Dianadema) and (iii), facilitated the colonization of soft sediments (Ascaulocardium) and (iv), thereby resulted in the evolution of the vertically endobenthic genus Stirpulina. The burrow lining was thus essentially exaptive for the evolution of an adventitious tube in the Clavagellidae.

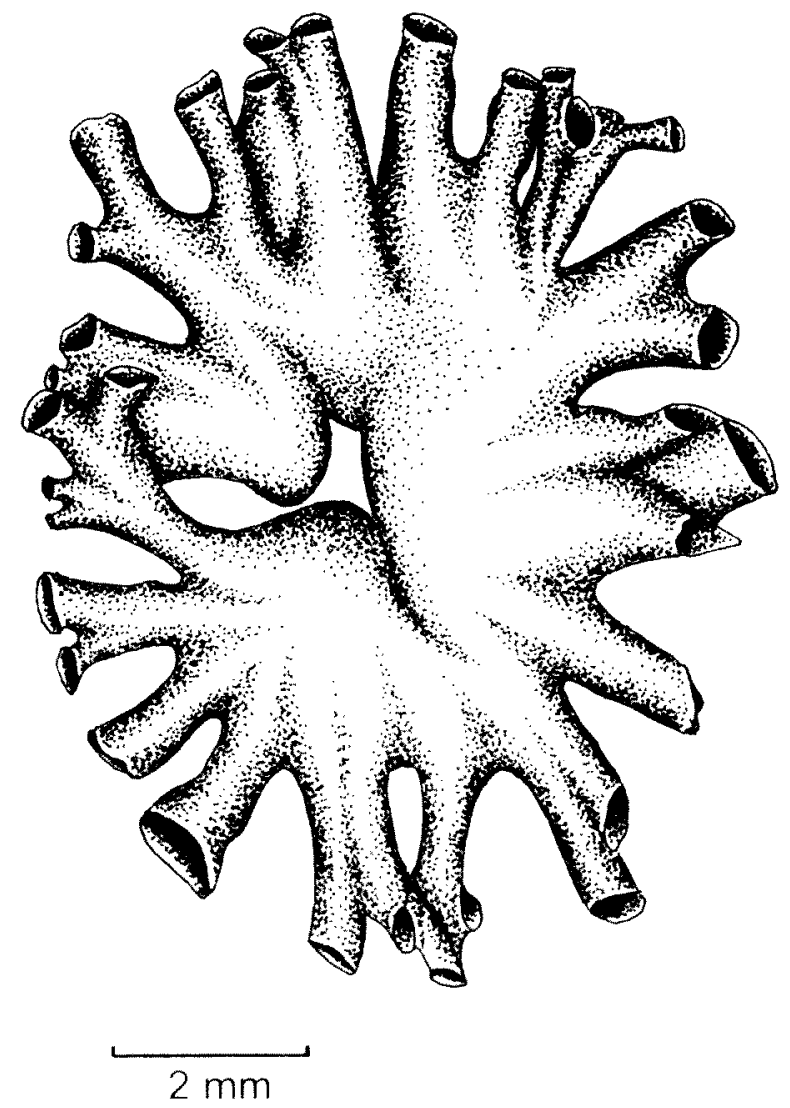

Figure 17 Stirpulina coronata. An anterior view of the watering pot (redrawn after Morton, 2006b). 
Function and origin of the penicillid adventitious tube

Morton (2002a) showed that interstitial water is pumped into the watering pot end of the endobenthic Brechites vaginiferus (Penicillidae), in contrast to the views of earlier authors (Purchon, 1956, 1960; Carter, 1978) that it is pumped out of it to effect either reburial following disinterment or recessing (with growth) by liquifying the sediment. Although Purchon (1956) believed this, he illustrated (fig.1) the first specimen of Brechites (= Penicillus) penis he found lying on its side on the sand and with growth of the adventitious tube upwards. Clearly, the animal could not re-burrow and must have been lying in such a position for a long time. Purchon (1960) later suggested that the function of pedal disc contractions was to pump interstitial water out of the mantle cavity. Savazzi (1982a) tested the reburial hypothesis by connecting the posterior end of a partially buried adventitious tube of Brechites penis to a water source by a flexible tube. At low water pressures, complete burial was attained in a few seconds. Notwithstanding this, Savazzi (1982a, p. 291) asserted, 'If the anterior part of crypt becomes exposed ...... the mollusc apparently is unable to rebury itself.' Morton (2002a, 2004a) has shown experimentally for $B$. vaginiferus and Foegia novaezelandiae, respectively, that neither can re- burrow and that the prime function of the pedal disc is to bring interstitial water into the mantle cavity.

The relationship between the pedal disc and watering pot of Brechites vaginiferus is, moreover, more complex than either the collection of interstitial nutrients, or the aeration and/or detoxification of the burrow heading since in this amyarian species there is no mechanism to extend the siphons (once retracted) other than by the hydraulic interplay of interstitial and supernatant water. Such pressure changes created inside the mantle cavity are transferred to the pallial haemocoels which, in turn, effect the pumping of blood between the various organ systems, for example, the siphons, and hence their extension. Body expansion in Kendrickiana veitchi (Morton, 2004 c, figure 18) is similarly by hydraulic means although this species has weak siphonal retractor muscles, as in Penicillus philippinensis (Morton, 2006c), so that siphonal retraction is to only a short distance $(\sim 20 \%)$ down the tube in both species. Brechites vaginiferus, however, can retract into at least the bottom $85 \%$ of the total adventitious tube length, and this is probably a defensive reaction. That is, the tube of all penicillids, like the crypt of clavagellids, is probably also protective, replacing in terms of one function, the greatly reduced shell
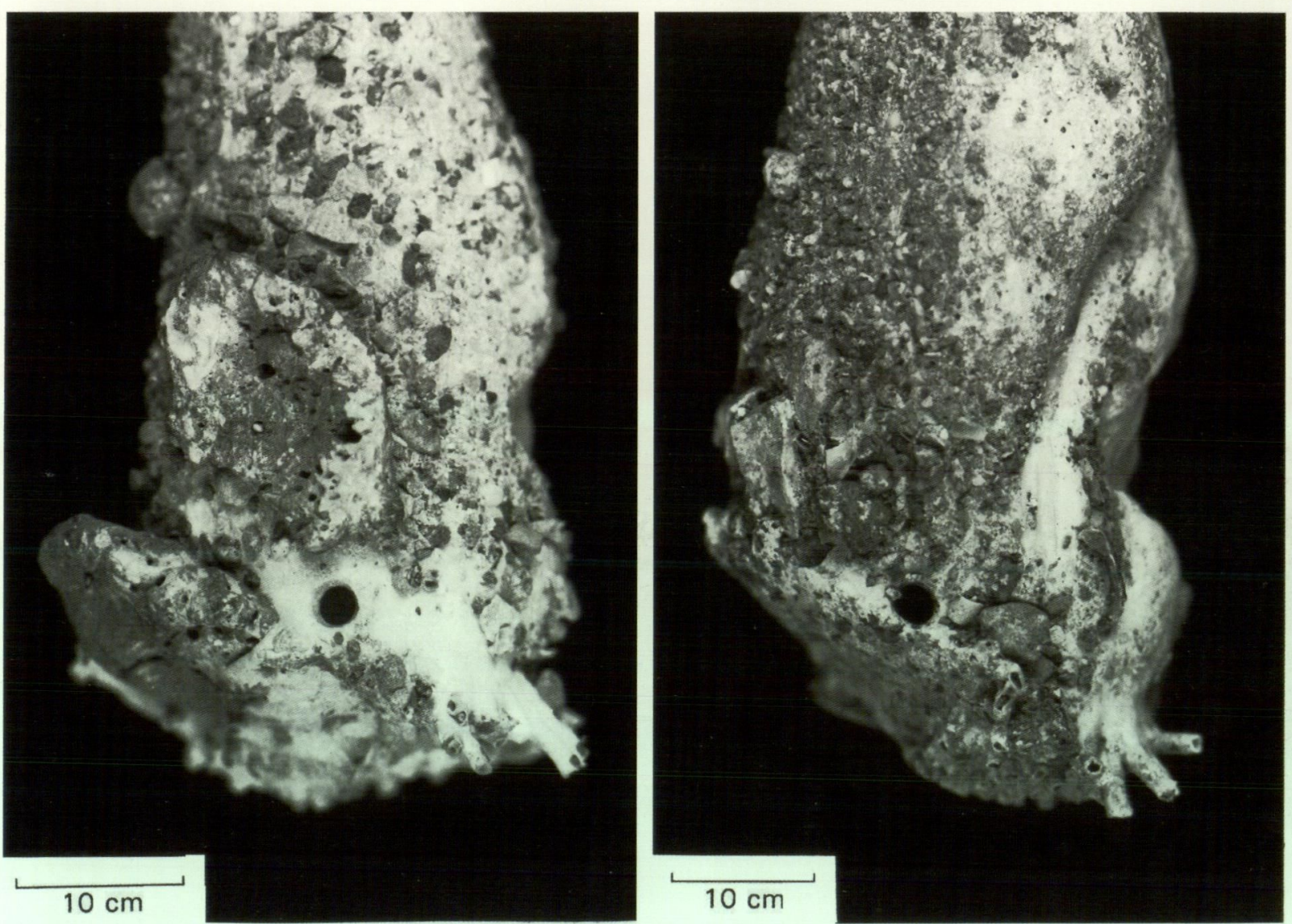

Figure 18 Brechites vaginiferus. Naticid boreholes in two adventitious tubes from Western Australia, close to the "watering pot" and thus some $10 \mathrm{~cm}$ beneath the sediment surface. 
valves. Brechites vaginiferus is nevertheless attacked by an unidentified drilling naticid in its natural habit in Western Australia, the holes always being evident at the base of the tube into which the animal has retracted (Figure 18; also illustrated in Morton, 2002a, figure 3C). Savazzi (1990, figure 3E; 1999, figure 17: 14C) also illustrated several repaired naticid boreholes near the posterior extremity of a Pliocene Stirpulina.

\section{(i) Function of the adventitious tube}

The adventitious tubes of penicillids can thus be considered to fulfil a number of functions. These are:

(a). Protection of the contained animal, in the absence of an adult shell.

(b). Creating the rigid external skeleton (again in the absence of a functional adult shell) against which the pedal disc can pump interstitial water into and out of the mantle cavity to generate the hydrodynamic pressures necessary in the pallial haemocoels to extend the siphons following retraction.

(c). The same pumping action may supply the animal with interstitial bacteria and dissolved organic and mineral salts from the burrow heading and which probably act as sources of nutrients accessory to the material collected by siphonal suspension feeding.

(d). Aeration of the interstitial water may be achieved by pumping mantle cavity water obtained from the sea above via the siphons into the burrow heading.

(e). Possible detoxification of interstitial water, by burrow aeration.

(f). In Foegia novaezelandiae that, unlike other penicillids (Morton, 2004a), lives in anoxic sediments, the periostracum covering the external surface of the pedal disc is coated with an organic floss containing rod-shaped bacteria. Morton (2004a) speculated that such bacteria might be chemoautotrophic.

\section{(ii) Formation of the adventitious tube}

Harper and Morton (2004) describe how the adventitious tube of Brechites vaginiferus is formed. This is illustrated in Figure 19. The pre-tube juvenile is surrounded by a layer of periostracum (P) secreted by the general mantle surface (E) marginal to the shell and saddle. Previously, the juvenile had enlarged itself to its full size within its burrow, so that the periostracum is secreted as a flexible sheet against the template of the burrow wall (B) (Figure 19(a)). Subsequently, the calcareous tube $(\mathrm{T})$ is secreted from the same general mantle surface, similar to a structurally ordered shell, and its external surface acquires the wrinkled form of the, now, overlying periostracum (Figure 19(b)). Once the tube is formed, the mantle beneath again secretes periostracum (P) such that the animal is now encased protectively within three layers of periostracum, tube and periostracum (Figure 19(c)). Extension of the tube posteriorly or the mending of any breaks involves dissolution of the inner layer of periostracum and secretion by the mantle of new calcareous material, as illustrated for $B$. vaginiferus by Harper and Morton (2004, figure 12).

The mechanism of tube formation in the Penicillidae is thus different from that described for the clavagellid Stirpulina (Savazzi, 1982a, 2005; Morton, 2006a, 2006b). In clavagellids only the left valve is united into the final structure of the crypt/ adventitious tube and a $\Omega$-shaped watering pot is produced. Conversely, in the Penicillidae, secretions unite both valves into its final structure and the watering pot when seen from the anterior,

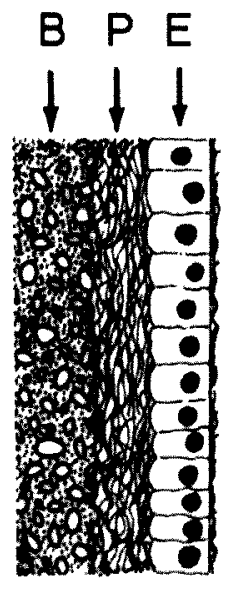

(a)

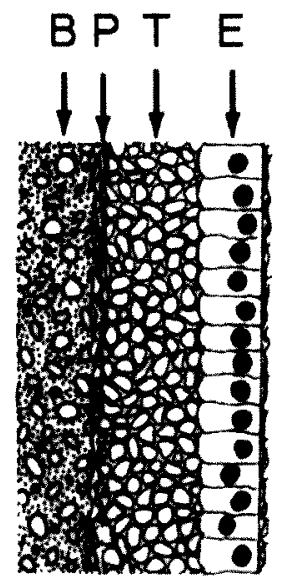

(b)

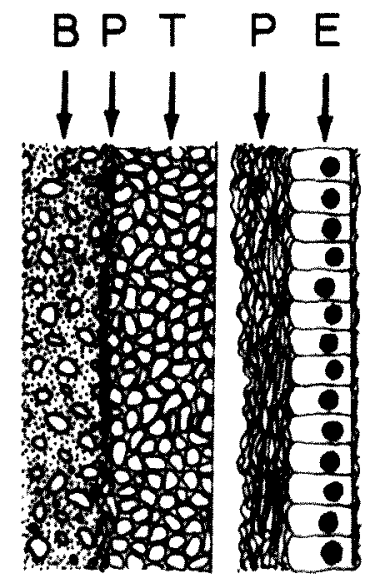

(c)

Figure 19 Brechites vaginiferus. Three transverse sections $(a-c)$ through the burrow wall and adventitious tube showing how the latter is formed by sequential secretion of A, periostracum; B, the calcium tube itself and C, a second layer of periostracum, all from the general mantle surface.

\section{B Burrow wall \\ P Periostracum \\ E Mantle epithelium \\ $T$ Adventitious tube}

\section{The 19}



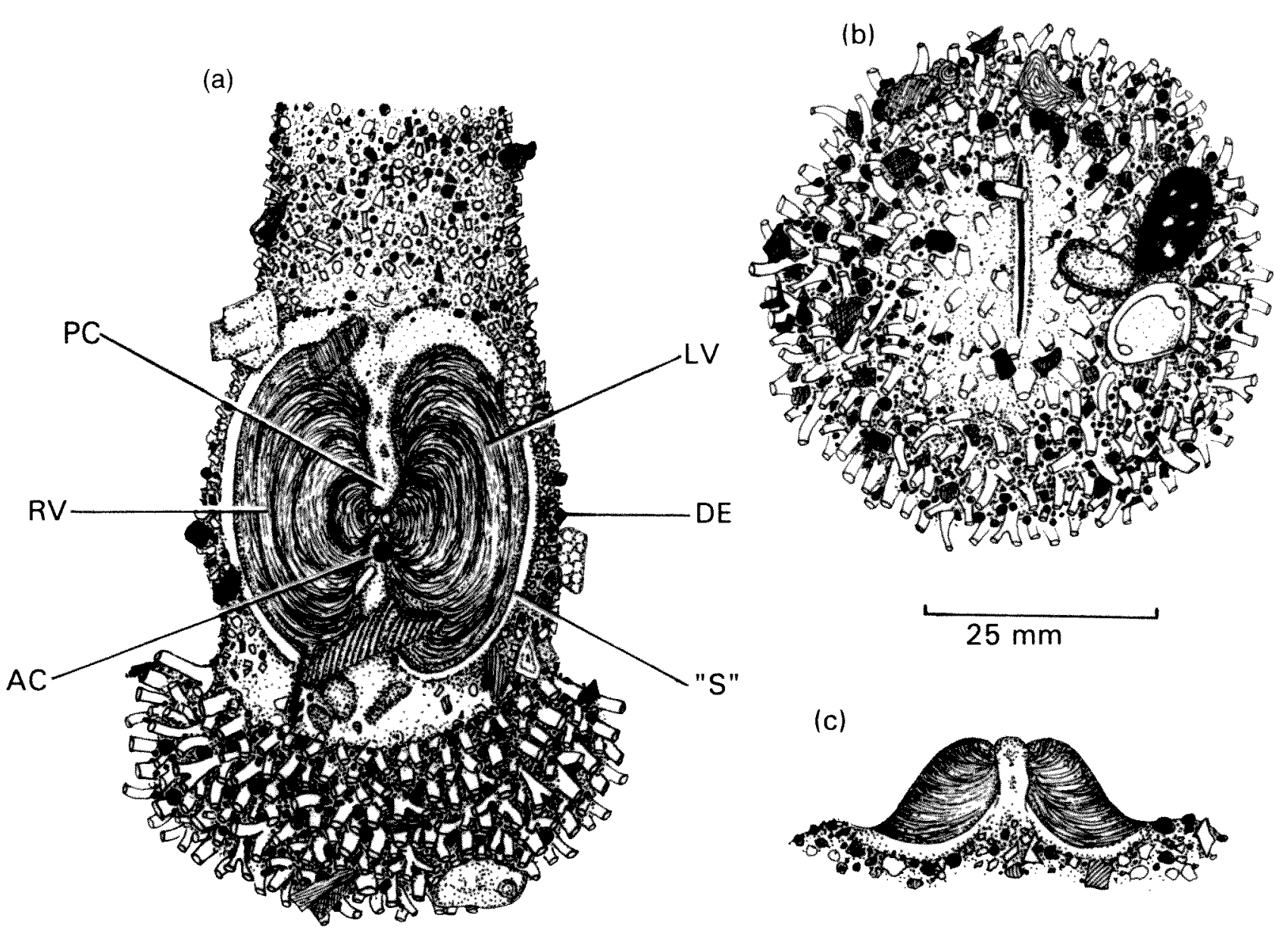

\section{$25 \mathrm{~mm}$}

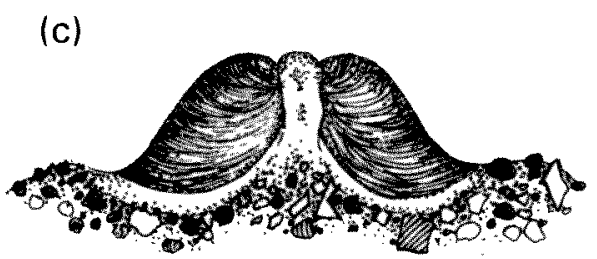

Figure 20 Nipponoclava gigantea. a, A dorsal view of the adventitious tube; $b$, the watering pot as seen from the anterior aspect and $c$, the elevated shell valves as seen from the posterior aspect (redrawn after Morton, 2004b). (For abbreviations see Appendix).

as described for Nipponoclava gigantea by Morton (2004b, figure $3 b$ ), is not folded but approximately bilaterally symmetrical.

An important feature of the shell of Nipponoclava gigantea relates not just to its relatively large size (Figure 20(a), LV, RV) in relation to the width of the surrounding, saddle (SA), debris covered (DE) adventitious tube and watering pot (Figure 20(b)) but also to the fact that the valves are splayed by only about $80^{\circ}$ to each other and thus stand proud of the tube (Figure 20(c)) although they are partly hidden by anterior (AC) and posterior (PC) calcareous concretions. Such a situation is very different from other penicillids identified by generic names only in Figure 21 wherein the shell valves are splayed at an angle of $\sim 180^{\circ}$ to each other but are also only $\sim 3 \mathrm{~mm}$ in height. The shells of all penicillids are each defined by a saddle of homogeneous shelly material secreted before the tube itself is manufactured. Figure 21 demonstrates the relationship between shell height (including saddle width) and adventitious tube diameter. The five genera of endobenthic penicillids studied to date can be put in a sequence of decreasing shell height and saddle width relative to tube diameter.
The shell and saddle of $N$. gigantea is the widest followed by $B$. vaginiferus that has a wide saddle in relation to its shell (Morton, 2004b). The other genera have yet smaller shells and saddles. Similarly, the angle of valve splay increases from $80^{\circ}$ in $N$. gigantea to $180^{\circ}$ in the others. Such a generalization seems to fit in approximately with a sequence of an increasing degree of muscle loss, or trend towards amyarianism, in the same penicillid genera resulting in the amyarian Foegia novaezelandiae (see Table 4).

It is here argued that just as the retention of the juvenile byssus into adult life in various lineages of the Bivalvia can be regarded as examples of paedomorphosis, or neoteny (Yonge, 1962), so the process of tube dwelling in the Penicillidae can be considered to represent a case of heterochrony. That is, at one time an otherwise "typical", , albeit neotenous, bivalve, possibly similar to animals like Panomya ampla and Panope generosa illustrated by Yonge (1971, figs 16 and 23, respectively), with very little of the mantle (and contained body) and siphons capable of being protected by withdrawal into the shell, produced a tube to protect such tissues. Over time, natural selection has favoured 
Table 4 A revised classification of the extant watering pot shells of the Clavagellidae and Penicillidae, with each family's representative genera, type species and the species reviewed in this paper also identified.

\section{Superfamily Clavagelloidea d'Orbigny, 1843}

Family Clavagellidae d'Orbigny, 1843

(= Aspergillidae Gray, 1858)

Genus Clavagella Lamarck, 1818 [Extinct]

Clavagella lamarck, 1818, H. N. Anim. sans Vert., 5, 430.

Type species: Clavagella echinata Lamark, 1818 (S.D.: Children, 1823)

Genus Dacosta Grav, 1858

Dacosta Gray, 1858, Proc. Zool. Soc. Lond. 26, 315.

Type species: Clavagella australis Sowerby, 1829, (Monotypy).

Dacosta australis (Sowerby, 1829)

Genus Bryopa Gray, 1847

Bryopa Gray, 1840. Syn. Cont. Brit. Mus, 42, 150 (n.n.): 1847.

Type species: Clavagella aperta Sowerby, 1823 (O.D.).

Bryopa lata (Broderip, 1834)

Bryopa aperta (Sowerby, 1823)

Bryopa aligamenta Morton, 2005

Genus Dianadema Morton, 2002

Dianadema Morton, 2002. J. Zool, Lond. 259, 391

Type species: Clavagella multangularis (Tate, 1887).

Dianadema multangularis (Tate, 1887)

Dianadema torresi (Smith, 1885)

Dianadema mascaranensis (Oliver and Holmes, 2004)

Genus Stirpulina Stoliczka, 1870

Stirpulina Stoliczka, 1870. Mem. Geol. Surv. India. Palaeont. Indica, 3, 27

Type species: Clavagella coronata Deshayes, 1824. (O.D.).

Stirpulina ramosa Dunker, 1882

Family Penicillidae Bruguière, 1789

Genus Penicillus Bruguiere, 1789

Penicillus Bruguiere, 1789. Enc. Method. (Vers). 1, 126.

Type species: Serpula aquaria Burrow, 1815 = Serpula penis Linnaeus, 1758: (S.D. - Stoliczka, 1871). Penicillus penis Linnaeus, 1758

Penicillus philippinensis (Chenu, 1843)

Genus Brechites Guettard, 1770

Brechites Guettard, 1770, Mem. diff. Sci., 3, 154.

Type species: Aspergillum vaginiterum Lamarck, 1818. (S.D.: Stolickka, 1871)

Brechites vaginiterus (Lamarck, 1818)

Genus Foegia Gray, 1847

Foegia Gray, 1847, Proc. Zool. Soc, Lond. 15, 188.

Type species: Aspergillum noraezelandiae Lamarck, 1818 = Penicillus novaezelandiae Bruguiere, 1789 (Monotypy). Foegia nowatelandiae Bruguiere, 1789

Genus Nipponodava B.J. Smith, 1976

Nipponoclava B.J. Smith, 1976, 1. Malac. Soc. Aust. 3, 197.

Type species: Aspergillum giganteum Sowerby, 1888.

Nipponoclava gigantea Sowerby, 1888

Genus Kendrickima Morton, 2004

Kendrickiana Morton, 2004, Invert. Biol. 123 (3), 245-246.

Type spectes: Brechite's weitchi B.J. Smith, 1971

Kendrickiana veitchi B.I. Smith, 1971

Genus Humphrevia Gray, 1858

Humphrevia Gray, 1858, Proc. Zool. Soc. Lond. 26, 317.

Type species: Aspergillum strangei A. Adams 1852 (Monotypy).

Humphrevia stranger (A. Adams, 1854) 


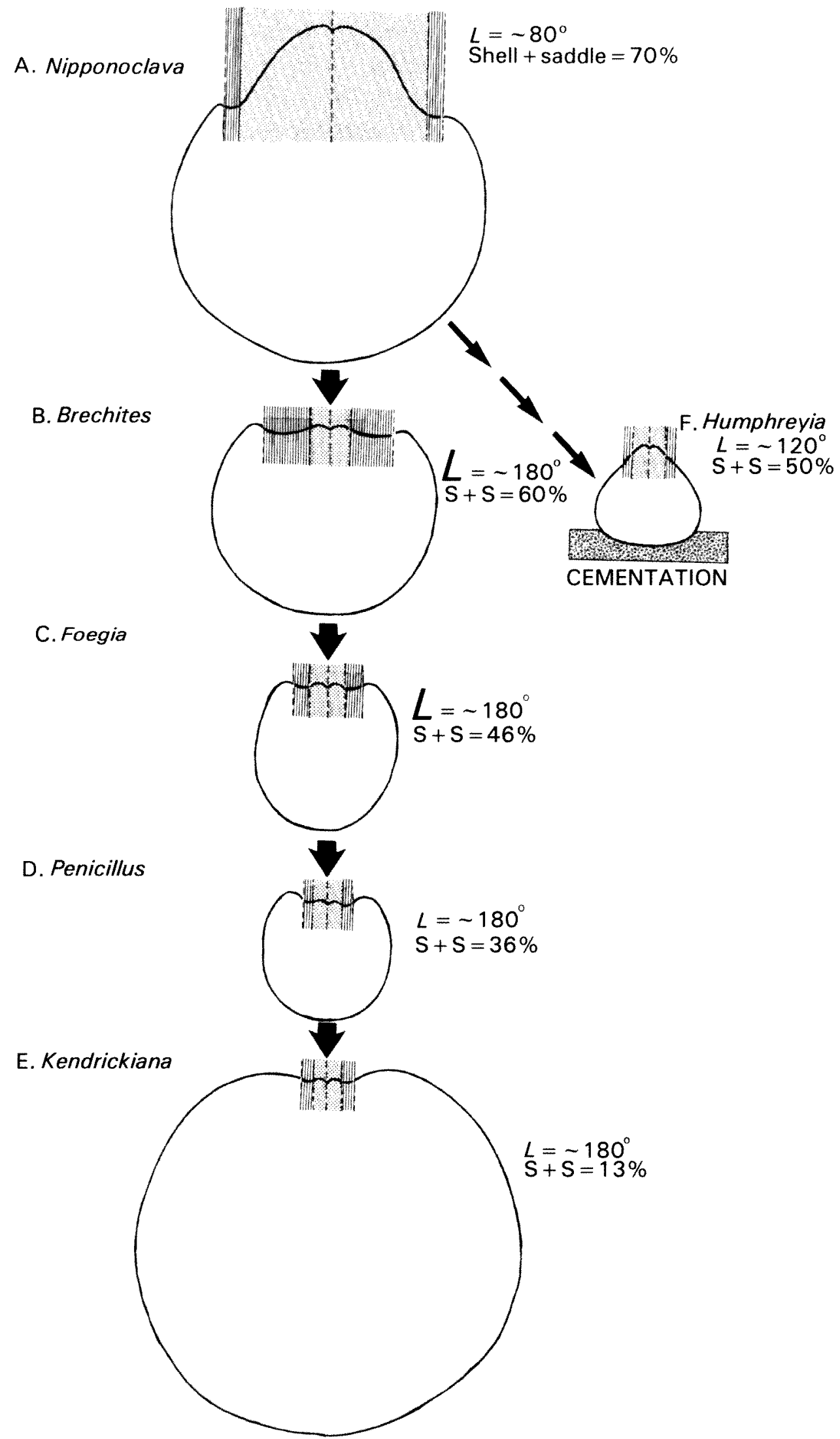

Figure 21 Generalised transverse sections through the true shells, saddles and adventitious tubes of various representatives of the Penicillidae. A, Nipponoclava gigantea; B, Brechites vaginiferus; C, Foegia novaezelandiae; D, Penicillus philippinensis; E, Kendrickiana veitchi and F, Humphreyia strangei. All drawn to the same scale. Central hatching, shell height; vertical lines, saddle width; $L$, angle of shell valve splay; $S+S($ as \%), total width of splayed valves plus saddle in relation to adventitious tube width (redrawn after Morton, 2004b). 
such a lifestyle and the adventitious tube has assumed, in addition to protection, another of the major functions of the shell, that is, to act as an exoskeletal attachment site for the albeit reduced adductor and pedal musculature. But this functions also in quite another way from the typical bivalve In more specialized penicillids, such as the

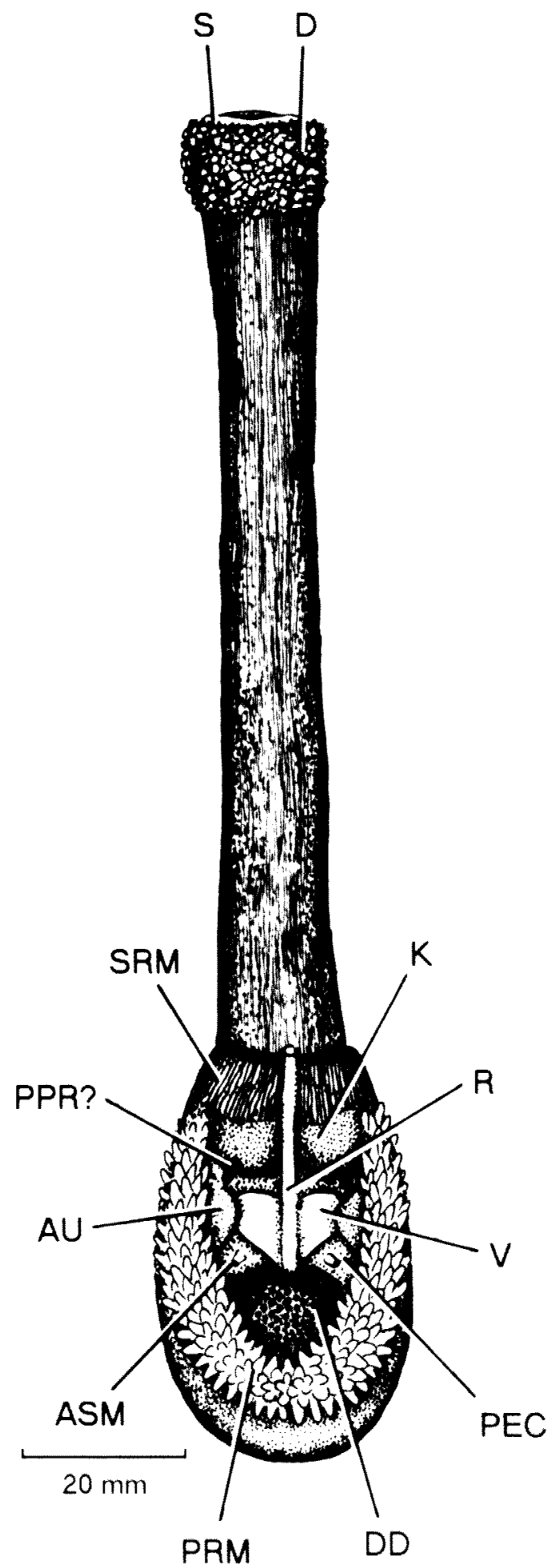

Figure 22 Kendrickiana veitchi. A dorsal view of the animal, showing the horseshoe shaped array of muscular papillae (redrawn after Morton, 2004c). (For abbreviations see Appendix). amyarian Foegia novaezelandiae, the functions of the shell and adductor muscles have been taken over by the tube and pallial musculature, respectively. Siphonal extension in penicillids is by hydraulic means (as in all bivalves) but the result of the interplay of hydrostatic forces created by the pumping actions of the pedal disc not by the conventional closing and opening of the shell valves by the interplay of adductor muscles and ligament. This has been explained and illustrated by Morton $(2004 \mathrm{c}$, figure 18$)$ for Kendrickiana veitchi that is attached to its tube (in the absence of adductor muscles) by an unique, horseshoe-shaped array of dorsal muscular, pallial papillae. This is seen in dorsal view in Figure 22 (PRM) and which surrounds the pericardium (PEC) and contained structures, that is, kidneys (K), rectum (R), heart with central ventricle (V) and auricles (AU), digestive diverticula (DD) and minute posterior pedal retractor (PPR?) and accessory suspensory muscles (ASM). In other respects $K$. veitchi is similar to other penicillids with a long siphonal tube (S), camouflaged by adhering debris (D). There are long siphonal retractor muscles (SRM)

Of all penicillids, Penicillus philippinensis (Figure 23(a)) is structurally most similar (Morton, 2006c) to Kendrickiana veitchi (Morton, 2004c) (Figure $23(\mathrm{~b})$ ). This similarity relates to the occurrence in them both of either a saddle or a horseshoe-shaped array of muscular papillae (PRM (2)) that connect each animal to its adventitious tube dorso-laterally. No other watering pot shell possesses such an array of muscular pallial papillae. The situation in $K$. veitchi seems to have evolved from that in $P$. philippinensis by the rotation dorsally of the papillate area of mantle and the movement too of the pedal gape ( $\mathrm{PG}$ ) to a more antero-ventral as opposed to a more anterior position. This accounts also for the radial symmetry of the watering pot of $P$. philippinensis and the dorso-ventrally asymmetrical one of $K$. veitchi. There are, moreover, other differences between the two species. In many ways the simple tiny papillae of $P$. philippinensis foreshadow the situation seen in $K$. veitchi. The papillae of the latter are large and find deep muscular attachment within pits in the adventitious tube whereas in the former they are but lightly attached via the intermediary of an epithelium to the calcareous concretion that covers the interior surface of its tube beneath and anterior to the positions of the true shell valves. Kendrickiana veitchi also possesses a distinct pair of accessory suspensory muscles (Figure 23(b), ASM) attaching the visceral mass dorsally to the adventitious tube. There is a similar but less distinct pair of such muscles in P. philippinensis (Morton, 2006c). Morton (2003b) showed, moreover, that such muscles are also possessed by the deep-water lyonsiellid Bentholyonsia teramachii. Runnegar 

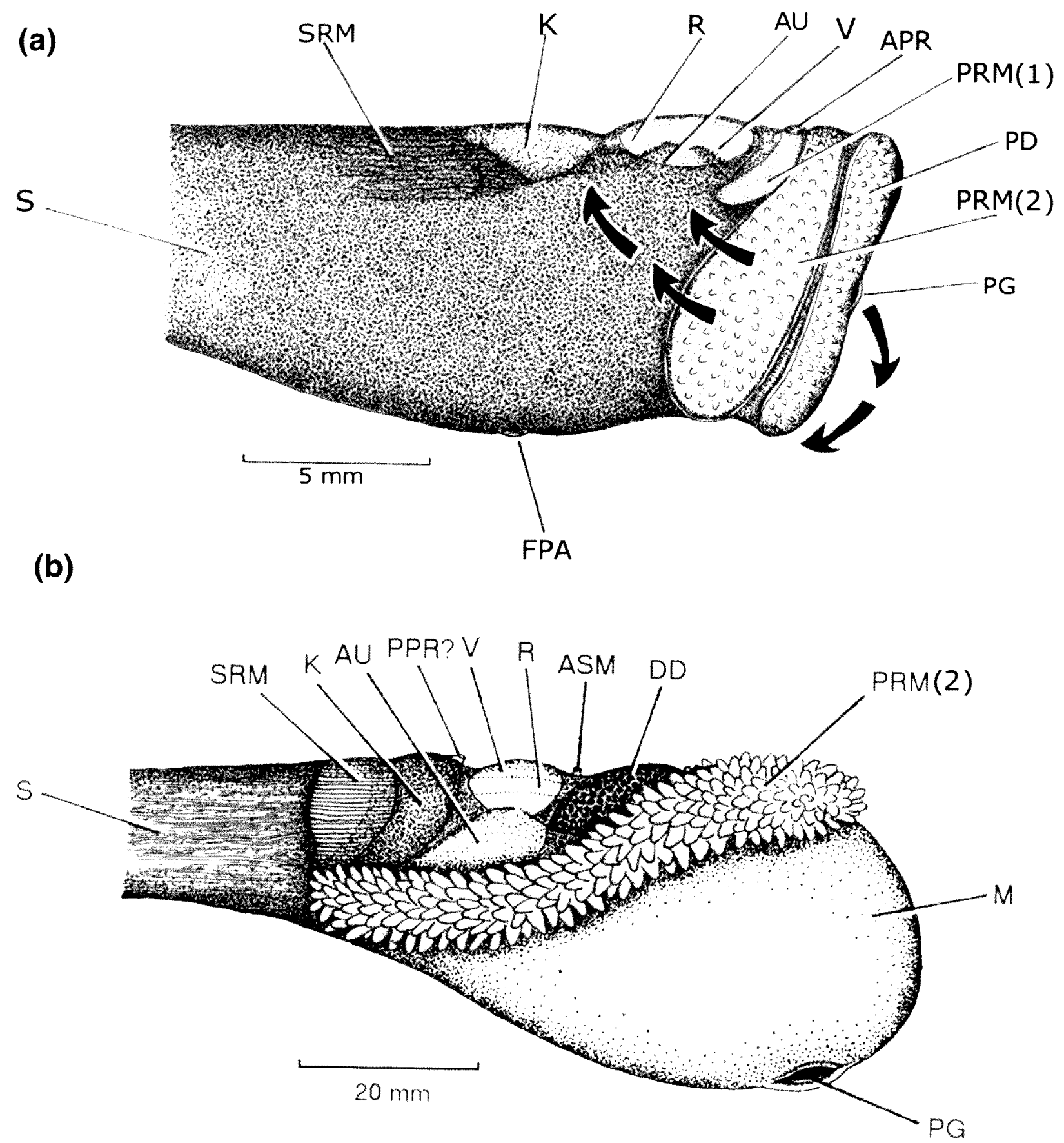

Figure 23 Penicillus philippinensis. a, Stucture of the mantle below the saddle and how it previses the situation, $b$, in Kendrickiana veitchi (redrawn after Morton, 2006c). (For abbreviations see Appendix).

(1972) also identified such muscle scars in various representatives of the Palaeozoic Pholadomyidae, including Pholadomya, Wilkingia and Homomya. Such an unusual and distinctive muscle might help to establish a connection between the most ancient pholadomyoids and some of the most modern lyonsiellid predators and representatives of the equally modern Penicillidae. Morton (1980) suggested that the pholadomyid Pholadomya candida pumped interstitial burrow water (plus contained nutrients) into its mantle cavity via the pedal gape. Such behaviour is clearly very similar to the situation in the endobenthic watering pot shells herein discussed lending support to the contention, again of Morton (1980) but also of Pojeta and Sohl (1987), of a common ancestry in the two lineages.

The peculiar dorsal horseshoe-shaped crescent of muscular papillae in Kendrickiana veitchi obviously facilitates secure attachment and can be considered to represent a neomorph, that is, a secondarily derived structure replacing the lost adductor muscles and serving to attach the animal securely to its tube and not shell valves. As such, it does not serve to close the shell valves, since these are tiny and immovably fused into the fabric of the 
adventitious tube but does re-create one of their functions, that is, to generate the forces which effect exchange with the water column above and interstitial waters in the burrow heading below. How this might be achieved is illustrated in Figure 24. In Figure 24(a), the animal is in hydraulic and muscular tonicity with its environment. Water is moved into and out of the mantle cavity via the siphons and the watering pot and pedal gape certainly by ciliary currents engendered by the ctenidia in the case of the former but at least also by the contractions and relaxations of the anterior mantle facilitated by the muscularized dorsal papillae. In Figure 24(b), a stimulus has caused the siphons to contract. But they can do so only a little, unlike in other penicillids, for example $B$ vaginiferus (Morton, 2002a, figure 10) where the siphons can be retracted to approximately one-fifth their expanded size. This contraction causes water to be pushed out of the tube, but since it cannot do so posteriorly at the siphons, it must be expelled anteriorly out of the pedal gape and into the interstitial spaces of the burrow heading external to the base of the tube. Extension of the siphons again, however (Figure 24(c)), must be effected by the anterior mantle being contracted upward, bringing interstitial water into the tube and thence into the mantle cavity. By repeating this process (Figure 24(d and e)), the siphons are extended further and further until the stable state of ambient tonicity is re-achieved (Figure 24(f))). This process is similar to that envisaged for other penicillids, for example, $B$. vaginiferus (Morton, 2002a) except that in this species, the siphons are highly muscular and their retraction is deep into the tube. Their extension is made possible by the pumping movements of the pedal disc acting agonistically and in concert with the siphonal muscles to move blood between haemocoels. In Kendrickiana veitchi, the siphons are poorly muscularized and so all movements must be controlled by the contraction of the horseshoe-shaped array of muscular mantle papillae - hence its large size and significance. In these two species, therefore, the "pumps" which create the hydraulic forces in the mantle cavity necessary to effect movement are the pedal disc in $B$. vaginiferus and the pallial muscles in $K$. veitchi. Foegia novaezelandiae is more like $B$. vaginiferus in this respect (Morton, 2004a).

It is important to realize however that the pressures generated in the mantle cavity by contraction of the pedal disc or muscular mantle papillae must act first on the blood vascular system to achieve movements of, for example, the foot but, especially, the siphons. In the highly hydraulic environment of the tube of Kendrickiana veitchi, therefore, there is a need to monitor body tonus. Over-inflation of the mantle and siphons may be

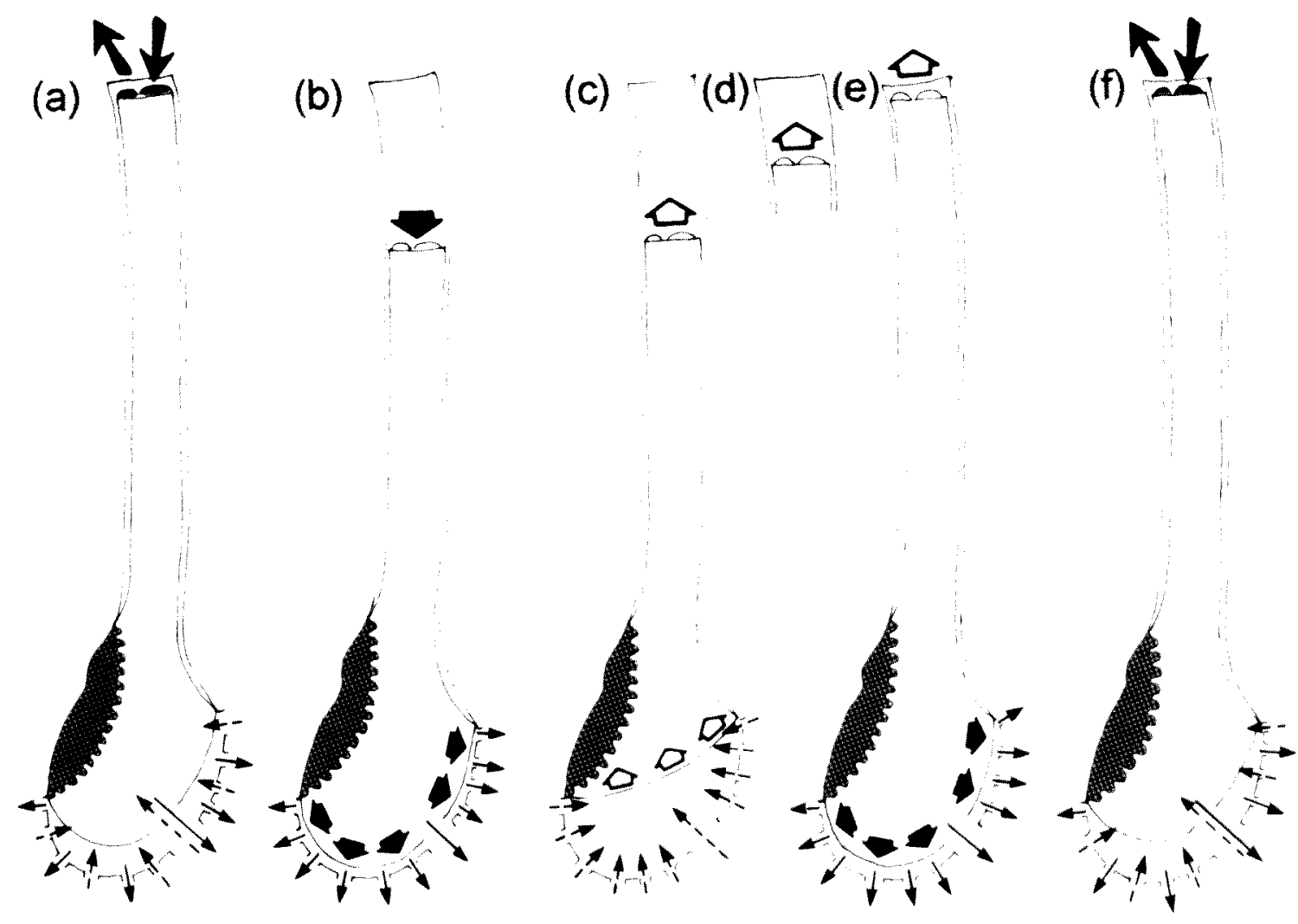

Figure 24 Kendrickiana veitchi. Generalized illustrations of longitudinal sections through the adventitous tube showing the postulated method of siphonal extension. For an explanation see page 53 . (redrawn after Morton, 2004c). 
restricted by the thick surrounding periostracum and adventitious tube but the reception of the state of tonicity is possibly the function of the paired, simple proprioreceptors based around the vestigial posterior pedal retractor muscles and their connection with the visceral ganglia. Such muscles are also retained in other members of the Penicillidae, for example, Humphreyia strangei, but also occur in the clavagellid Dianadema multangularis (Morton, 2002b, 2003a). Both of these are cemented, epibenthic species in which the pericardial proprioreceptors are much more sophisticated especially in the former. Where posterior pedal retractor muscles are either lost, for example in Brechites vaginiferus, or vestigial, as in Foegia novaezelandiae (Morton, 2002a, 2004a), there are no pericardial proprioreceptors. It is also significant that the blood vessels and pallial haemocoels of all penicillids are huge in comparison with those of representatives of the Clavagellidae.

\section{(iii) Growth in Humphreyia}

Savazzi (1982a, p. 84-85) considered that 'The genus Humphreyia Gray, 1858, represents an intermediate morphological state ...... Nevertheless, there are reasons to believe that Humphreyia is not an evolutionary intermediate between Clavagella and Penicillus (see L.A. Smith, 1962 [p.16; fig.1]): it represents more likely a secondary adaptation to cementation, and is a Recent offshoot of Clavagella'. B.J. Smith (1976), also, in erecting the sub-genus Nipponoclava, placed $N$. gigantea in the genus Humphreyia (Gray, 1858). Such an unexplained decision was possibly based upon the fact that the true shell valves of $H$. strangei are not splayed at $180^{\circ}$ to each other, but at an angle of $\sim 120^{\circ}$, that is, they stand proud of the adventitious tube and thereby resemble $N$. gigantea (Figure 21). Humphreyia strangei is clearly very different from the other endobenthic representatives of the Penicillidae in that it lives epibenthically cemented to stones and empty shells.

As postulated for Brechites vaginiferus, Humphreyia strangei probably undergoes a number of stages in its life history that are illustrated in Figure 25. First, there is probably an undescribed planktonic larva, followed by a settling pediveliger stage. This settles to produce, second, an active juvenile (Figure 25(a)) that has been described by Morton (1984b) and herein. Importantly, this possesses a normal pair of adductor muscles that means that the animal functions like a typical bivalve and must be able to close its shell valves, at least partially. Once a habitat is chosen by the juvenile for permanent occupation (Figure 25(b)), further growth occurs, the saddle is produced, and the mantle cavity is greatly expanded beyond the margins of the shell valves so that they become oriented at an angle of $\sim 120^{\circ}$ to each other. The adductor muscles presumably degenerate at this stage. The animal thus occupies a bag-like mantle covered mostly by periostracum. The third, cemented, adult stage (Figure 25(c)) is formed when the anterior watering pot is produced, possibly in two stages, the first uncemented, the second so attached. The fourth adult stage develops an (a)

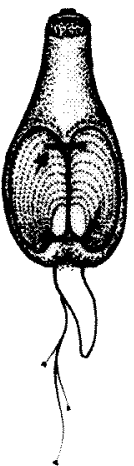

(b)

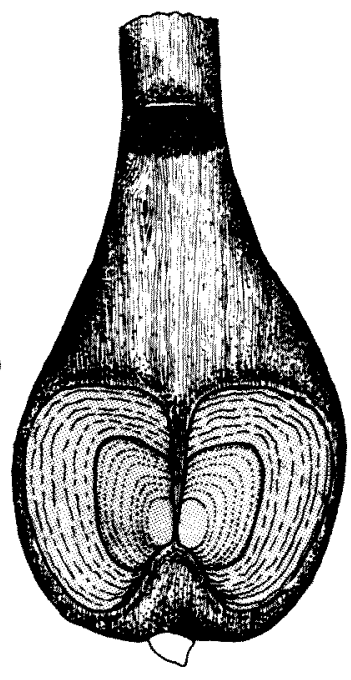

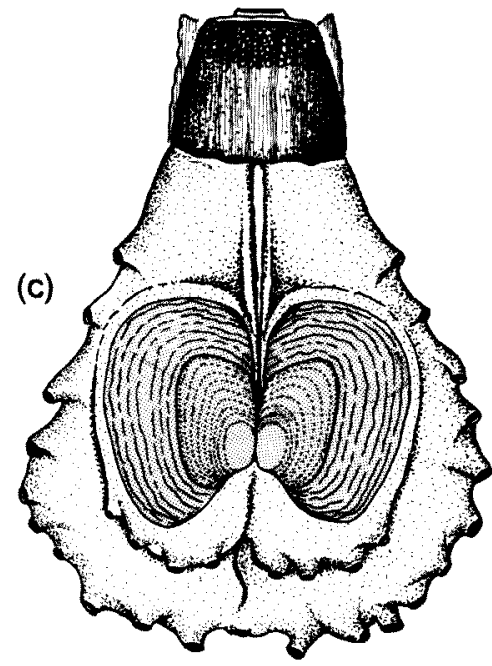

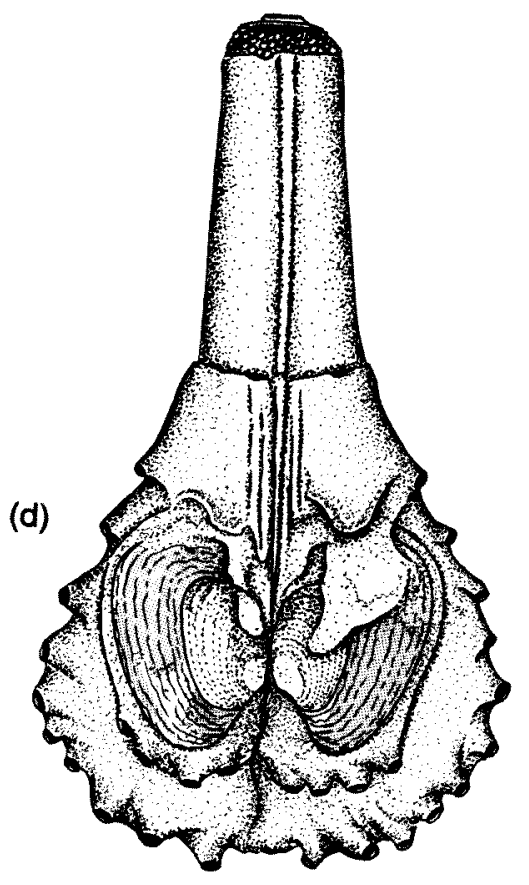

Figure 25 Humphreyia strangei. Postulated stages (a-d) in the growth from a juvenile to an adult. For an explanation see pages 54-55. (redrawn after Morton, 2002b). 
adventitious tube posteriorly to house the now greatly enlarged siphons (Figure $25(\mathrm{~d})$ ) and this, only, can be elongated as further growth occurs in this direction but, again, not anteriorly. Humphreyia strangei is, thus, first, a free-living juvenile, then an epifaunal, initially byssallyattached bivalve that subsequently cements to a substratum, and finally becomes a mature Brechiteslike watering pot shell, albeit with occluded pedal gape and tubules.

Like Nipponoclava gigantea, the juvenile of Humphreyia strangei has both adductor muscles present (Morton, 2002b) further supporting the argument that modern, functionally amyarian penicillids (Foegia is actually amyarian) arose from a more "typical" bivalve, probably a lyonsiid ancestor (Dreyer et al., 2003), by (i), the secretion of an adventitious tube for the protection of a body no longer encased largely within shell valves and (ii), progressive reduction in the size of the shell through processes of neoteny and heterochrony, in which the animal produces its adventitious tube at progressively earlier and earlier developmental stages such that the valves become actually and relatively smaller and smaller and, hence, more splayed. The large shell of $N$. gigantea, with internally a set of pallial and adductor muscle scars, forms a link, which Harper and Morton (2004) postulated must exist, between a more or less typical endobenthic lyonsiid bivalve and the more highly derived other representatives of the Penicillidae.

\section{Evolution}

Representatives of the Clavagellidae with their origins in the Upper Cretaceous are characterised by a shell with an internal ligament, the left valve uniting marginally with an adventitious crypt, the right valve free inside it. There are, moreover, large anterior and posterior adductor muscles, anterior pedal retractor muscles (in Clavagella) and no anterior muscular pedal disc. Conversely, representatives of the Penicillidae with their origins in the Oligocene possess a tiny shell with an external ligament, and both valves are marginally united with the adventitious tube. Penicillids are, moreover, virtually amyarian except for vestigial, either anterior (Brechites) or posterior (Humphreyia), pedal retractor muscles and all, save Kendrickiana veitchi, possess a muscular pedal disc. Thus, representatives of the two newly recognised families constitute a remarkable example of convergent evolution in terms of (i), the adoption of the epibenthic tube-dwelling mode of life in Brechites and its allies (Penicillidae) and Stirpulina (Clavagellidae) and (ii), cementation in Humphreyia and Dianadema.

An interesting point about Humphrevia strangei is that ontogenetic metamorphosis occurs at the end of the juvenile phase and is associated with a loss of mobility and adoption of the cemented mode of life. As far as is known, such a change, unlike cementation in other bivalves, including the anomalodesmatans Myochama and Cleidothaerus (although juveniles of these are also unknown), where the setting pediveliger transforms into the cemented juvenile which then grows into the adult, appears to be unique to Humphreyia. Although it has been argued that such a metamorphosis also occurs, for example, in Brechites vaginiferus (Harper and Morton, 2004) and probably other endobenthic penicillids. Morton (2002a) has shown that in some habitats, $B$. vaginiferus cements itself to stones and rocks. Cementation has thus evolved relatively recently in the Penicillidae, probably from a Brechites-like ancestor, possibly similar to Nipponoclava (B.J. Smith, 1976). Conversely, in representatives of the Clavagellidae there is no juvenile to adult metamorphosis. That is, for example, in Bryopa, there is a juvenile with a typical shell (Palazzi and Villari, 2004) that settles into a crevice and progressively grows, like any other bivalve, into an adult albeit with an admittedly strange form (Savazzi, 2000; Morton, 2005), but without a metamorphic phase. More similarly to Humphreyia, however, is the cemented Dianadema, but this too constitutes a juvenile that grows in the usual manner until a cemented crypt occupied by the adult is produced.

Harper and Morton (2000) and Morton and Harper (2001) have shown that cementation in the Anomalodesmata has evolved in two additional phylogenies, that is, the Myochamidae and Cleidothaeridae, and again in both, relatively recently. Thus, although the Anomalodesmata has a long history, especially the Pholadomyidae (Morton, 1980), stemming from the Palaeozoic to the Recent, cementation in the sub-class is a modern phenomenon and has, hence, evolved quite independently in the Myochamidae, Cleidothaeridae, Clavagellidae and Penicillidae. Dianadema (Clavagellidae) and Humphreyia (Penicillidae) are thus convergently similar, cementation in the former arising in approximately the Eocene of the Indo-West Pacific and Australia and the latter in the Pliocene of Australia. Convergent evolution in Humphreyia and Dianadema has resulted in some quite surprising analogies. For example, Morton (2002b, 2002c) showed that both have evolved a unique pair of pericardial proprioreceptors in the kidneys, possibly to prevent overfilling of the rectum or to monitor body tonus. Some other penicillids also possess such, typically simple, proprioreceptors but they are only present when the posterior pedal retractor muscles are not lost.

In addition to the extraordinarily wide range of morphological diversity seen in the representatives 
of anomalodesmatan families (Morton, 1981, 1985a), the more species that are examined, the wider becomes the total spectrum of adaptive radiation exhibited by the sub-class. For example, the cemented habit in the various lineages of the Anomalodesmata, that is, Myochama and Cleidothaerus (Harper and Morton, 2000; Morton and Harper, 2001) and now the Australian Humphreyia and Dianadema (Morton, 2002b, 2003a) seems restricted to the southern hemisphere islands of New Zealand and Australia. What factors drove the evolution of the cemented habit in these four families of the Anomalodesmata in southern hemisphere waters is, however, unknown [but needs to be addressed]. Similarly, Harper et al. (2000) showed that, cladistically, representatives of the Clavagelloidea appear more closely related to the various deep-water representatives of the predatory septibranch families. In these bivalves too there is pumping of water into and out of the mantle cavity, albeit to capture prey, by means other than the adductor muscles (Yonge, 1928).

The Anomalodesmata is hence a truly amazing example of adaptive radiation, with two families of watering pot shells in shallow waters competing, in terms of bizarreness, with four families of deepwater predators and an even greater variety of other strange bivalves last reviewed by Morton (1985a).

\section{A revised taxonomy of the watering pot shells}

Surprisingly, in what is perhaps one of the most important analyses of the evolutionary history of the fossil Anomalodesmata, Runnegar (1974) made no attempt to review the Clavagelloidea, beyond recognising it as one superfamilial entity. Similarly, L.A. Smith (1962a, 1962b) and B.J. Smith (1971, $1976,1998)$ considered all watering pot shells to comprise but one superfamily and family - the Clavagellidae.

Gray (1858a) considered that his family Aspergillidae comprised two subfamilies, that is, the Penicillina, encompassing the genera Warnea, Aspergillum, Penicillus, Clepsydra, Arytene and Foegia, and the Clavagellina, including Clavagella, Bryopa and Dacosta. Humphreyia was placed in its own family - the Humphreyiadae. Starobogatov (1992) considered that the most primitive component of his Order Pholadomyiformes was the Suborder Laternuloidei, and from which was derived two other suborders, that is, the Pholadomyoidei and Clavagelloidei. Starobogatov (1992) also considered his suborder Clavagelloidei to comprise two superfamilies, that is, the Penicilloidea Scarlato and Starobogatov, 1971 and the Clavagelloidea d'Orbigny, 1843. A somewhat similar view was held by Morton (1985a), who thought that the Clavagelloidea was most closely linked to the Laternulidae and, both, back in time, with the Pholadomyidae considered by Runnegar
(1974) and this author (Morton, 1980) to contain the oldest anomalodesmatans. Savazzi (1999) considered that the Clavagella and Brechites lineages represented a case of parallel evolution. It was only after a comparison of Brechites vaginiferus and Humphreyia strangei (Morton, 2002a, 2002b), that Morton (2002c) could agree with this view and therein suggested separation of Savazzi's two "lineages". This study formalizes this view. That is, watering pot shells are divisible on the basis of many criteria into the Clavagellidae d'Orbigny, 1843, with the name Aspergillidae Gray, 1858 as a junior synonym (Habe, 1977), and Penicillidae Bruguière, 1789. There is a time difference of at least 40 million years between when the two families arose, both, however, probably from lyonsiid ancestors.

The proposed taxonomic classification of the watering pot shells is presented in Table 4 . The two identified families - the Clavagellidae and Penicillidae - each contain a number of genera and representative species that are recognized and discussed herein.

\section{A revision of the watering pot clades and a remarkable example of convergent evolution}

Figure 26 provides a comparison of the currently recognized extant genera of the Clavagellidae and Penicillidae. A comparison with Stirpulina is hampered by a lack of information on the genus, the only living species, $S$. ramosa, never having been examined anatomically, although Morton, (2006a) has studied the shell and tube and shown how the latter is formed. There is clearly a range in lifestyles in the Clavagellidae, from the endobenthic Stirpulina (Savazzi, 1982a, 1982b), to the small, cemented, epibenthic Dianadema (Morton, 2003a) and the endolithic, either nestling (Dacosta) or boring (Bryopa) (Morton, 1984b; Savazzi, 2000). All are united by the fact that only the left valve is incorporated into the fabric of either the crypt or adventitious tube, but it is probable that ligament form is also related to lifestyle. All clavagelloids possess periostracal calcareous spinules on their shells, particularly posteriorly, as have been reported for a number of anomalodesmatans (Harper et al., 2000). Of importance is that no clavagellid possesses a pedal disc and in this context too it is important that in them all, the pedal retractor muscles are either vestigial (Dacosta and Dianadema) or absent (Bryopa) and the foot is also always small. There is, however, a pedal gape in representatives of all genera except Stirpulina (Morton, 2006a, 2006b) and, similarly, anterior tubules are present in all genera except Bryopa. None of the genera possesses a fourth pallial aperture, but radial mantle glands are present in the siphons of Clavagella and Dianadema the resulting in the presence of sand grains and other detritus 


RECENT
PLEISTOCENE

PLIOCENE

MIOCENE

OLIGOCENE

Stirpulina

\section{PALAEOCENE}

U. CRETACEOUS

\section{CRETACEOUS}
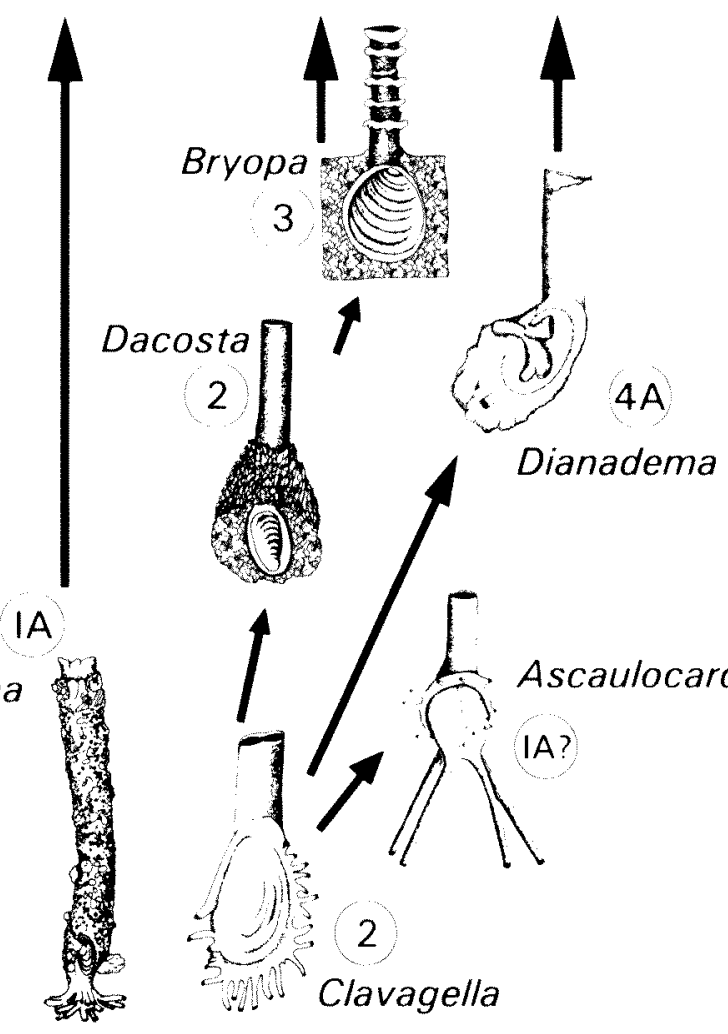

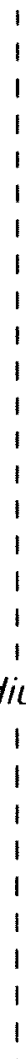

IB

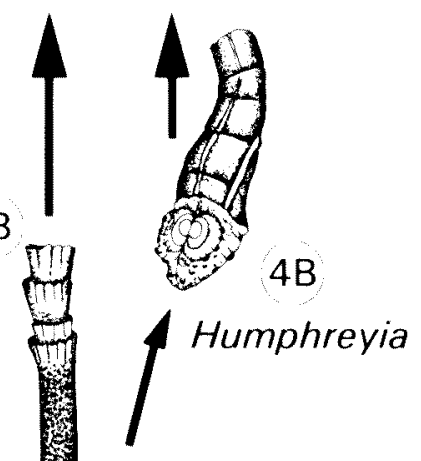

Brechites

+ Penicillus

Aspergillum

Warnea

Foegia

Pseudobrechites

Nipponoclava

\section{CLAVAGELLIDAE}

PENICILLIDAE

Figure 26 An illustration of watering pot evolution showing the remarkable pattern of parallel evolution between the Clavagellidae and Penicillidae, albeit over two time-scales, that is, Mesozoic and Cenozoic. 1-4 represent functional clades: $1 \mathrm{~A}$ and $1 \mathrm{~B}$ [endobenthic] and $4 \mathrm{~A}$ and $4 \mathrm{~B}$ [cemented endobenthic] and constitute the most striking examples of parallel evolution between the two phylogenies.

adhering to the siphonal tips, probably to camouflage them. Anatomically, all representatives are similar, for example in the degree of mantle fusion (Type C; Yonge 1982), with a two-layered periostracum, a ctenidial ciliation of Type $E$ (Atkins, 1937), a ctenidial/labial palp junction of Category III (Stasek, 1963) and statocysts of Type B3 (Morton, $1985 \mathrm{c}$ ). These characters, however, are typical of most anomalodesmatans (Harper et al., 2000).

There are two penicillid clades. The first is the endobenthic, adventitious tube-dwelling genera Penicillus, Brechites, Foegia, Kendrickiana and Nipponoclava with the last named showing how the former have evolved through a process of heterochrony (Morton, 2004b). The second is the cemented Humphreyia, possibly also evolved from a common ancestor with Nipponoclava. Associated with greater and greater specialization for occupation of an adventitious tube, endobenthic genera show a progressive loss of anterior and posterior adductor and pedal retractor muscles, culminating with the amyarian Foegia novaezelandiae (Morton, 2004a). Where posterior pedal retractor muscles survive as remnants, they, like their clavagellid counterparts, have evolved a pair of pericardial proprioreceptors. The foot is always present, but very reduced. There is, a pedal gape in representatives of all genera and, similarly, anterior tubules are present in all genera. All the genera possess a fourth pallial aperture and radial mantle glands are present in the siphonal apices of all genera, except Kendrickiana and Penicillus, and to them sand grains and other detritus presumably to camouflage them.

The shells of all representatives of both families resemble those of lyonsiid anomalodesmatans; a suggestion substantiated by genetic determination of a close affinity, at least between Lyonsia norwegica Gmelin, 1791 and Brechites vaginiferus (Dreyer et al., 2003). It is thus argued that the two families evolved at different times, possibly both from lyonsiid ancestors, and that the various representatives of both constitute an extraordinary example of convergent evolution 


\section{CONCLUSIONS}

As herein discussed, it is suggested the Clavagelloidea, as currently defined, comprises two families - the Clavagellidae and Penicillidae.

1. Representatives of the constituent genera of the two families are similar in terms of the shell structure and the organization and functioning of the organs of the mantle cavity and visceral mass in part accounting for why they have been considered to be representative of one phylogeny. Such characters are, however, largely "anomalodesmatan", more specifically, "lyonsiid".

2. Differences between the major genera of the Clavagelloidea have, however, progressively become recognized and in this the juvenile of Humphreyia strangei is most significant. The hinges of adult Brechites vaginiferus and its allies are obscured by internal and, in some, external calcifications that fuse juvenile shell, saddle and adventitious tube. The ligament of Humphreyia, however, is external and has a lithodesma whereas that of Dacosta is internal with no lithodesma. On other grounds too, Humphreyia can be allied to Brechites (Morton, $2002 \mathrm{~b}$ ) and not Clavagella, as previously thought (L.A. Smith, 1962a). Thus, cemented Humphreyia, and Brechites and the latter's endobenthic allies are separate from Clavagella and its allies, but the significance of this has hitherto escaped formal attention. Further, Clavagella, Dacosta and Bryopa have two large adductor muscles, no pedal retractor muscles, and a pallial sinus (both absent in adult Humphreyia, and Brechites and most of its allies), no pedal disc (present in Brechites and Humphreyia). Most important, however, the left valve only of Dacosta is united with its crypt or adventitious tube (Stirpulina), the right being free inside it. Conversely, in Brechites and its allies, including Humphreyia, both valves are united marginally with the adventitious tube.

3. The patterns of tube formation expressed by the endobenthic Brechites and its allies (Penicillidae) and Stirpulina (Clavagellidae) are also fundamentally different, though both are secreted from the mantle overlying the body. As a consequence, the watering pot of Brechites and Stirpulina are bi-laterally symmetrical and $\Omega$-shaped, respectively.

4. It is thus proposed that Clavagella and its left fused - valve allies be referred to the Clavagellidae (d'Orbigny, 1843) that appeared in the Mesozoic and Humphreyia, and Brechites and its allies to the Penicillidae Bruguiére, 1789 that appeared in the Cenozoic. This latter name is chosen based on it being (a), the oldest available and (b), that used by Gray (1858a) for his subfamily Penicillina (distinguishing it from the Clavagellina) and Starobogatov (1992) for his Penicilloidea (distinguishing it from the Clavagelloidea). In formalizing this taxonomic proposal, a familial compromise between the two taxonomic views of Gray and Starobogatov is adopted.

5. It is suggested, however that the Clavagellidae and Penicillidae as herein defined have both evolved from lyonsiid ancestors (albeit at different times of approximately 40 million years between such convergent evolutionary events), accounting for their genetic similarity (Dreyer et al., 2003). Finally, however, it is important to realize that the infaunal tube building and the cemented watering pot lifestyles have both evolved independently in the two families at different times, and thus constitute two remarkable examples of convergent evolution. This is illustrated in Figure 26 (partly after L.A. Smith, 1962a), with the clades of the Upper Cretaceous Clavagellidae identified by their constituent genera, that is, the endobenthic Stirpulina (1A) (and possibly Ascaulocardium [1A?]), the nestling / boring endolithic Clavagella and Dacosta (2), the endolithic, live coral boring Bryopa (3), and the cemented Dianadema (4A). The endobenthic and cemented clades of the Clavagellidae (1A and $4 \mathrm{~A}$ ) have penicillid analogues in Oligocene Brechites (1B) and its allies, and Plio-Pleistocene Humphreyia (4B), respectively. There is no penicillid analogue of Dacosta and Bryopa, however.

6. In the Clavagellidae, the occupation of a cemented crypt in Dianadema or an adventitious tube in Stirpulina is possibly the consequence of pre-adaptation (exaption). That is, the adoption of an endolithic life style (Dacosta, Bryopa) wherein the burrow is lined with relocated calcium carbonate and the formation of a protective tube for the siphons possibly foreshadows the situation in Dianadema and Stirpulina. However, no such endolithic precursor is known for the Penicillidae that probably, therefore, have evolved from a burrowing ancestor.

7. The Clavagellidae and Penicillidae thus provide us with perhaps one of the best, most remarkable, and hitherto unappreciated examples of convergent evolution in the Bivalvia. Harper et al. (2000) have suggested that the Anomalodesmata today comprises about one sixth of all bivalve families and has done since the Palaeozoic. With the discovery that the Clavagelloidea comprises not one but two families, this extraordinary adaptive radiation at the supra-generic level is now known to be yet more diverse and complex than 
hitherto appreciated. In the Palaeozoic, the Anomalodesmata comprised a diverse group of bivalves (Runnegar, 1974), albeit largely contained within one superfamily - the Pholadomyoidea (Moesch, 1875; Morton, 1980, 1981, 1985a, 1995). Today, however, as with the watering pot shells discussed herein, and generally in the Anomalodesmata as a whole, both pholadomyoid families are represented by but one or two genera and these often by but one or two species. The adaptive radiation of the Anomalodesmata, therefore, is remarkable and is nowhere better illustrated than in the extraordinary pattern of convergent evolution expressed by the Clavagellidae and Penicillidae.

8. It is, however, clear that the endobenthic lifestyle has not been a successful evolutionary development in the Clavagellidae, only Stirpulina ramosa surviving to the present day but leaving behind a rich array of such Mesozoic watering pot fossils virtually worldwide. Conversely, however, there are few fossils of the endobenthic Caenozoic Penicillidae, but these watering pot shells have radiated and evolved in the Indo-West Pacific into some of the most amazing bivalves ever seen. This raises the question of: why did endobenthic clavagellids fail, but their penicillid counterparts survive?

9. Finally, however, the remarkable example of convergent evolution described herein for the Clavagellidae and Penicillidae is matched by another example between these two families and unrelated representatives of the Gastrochaenidae that also possess boring (Gastrochaena), crypt- (Cucurbitula) and tubedwelling (Eufistulana) representatives.

\section{ACKNOWLEDGEMENTS}

Some of this research was conducted during the tenure of a Research Associateship at the Western Australian Museum, Perth, Western Australia, and while appointed as a Research Associate in the Department of Zoology, The Natural History Museum, London. I am grateful to the Executive Director of the Western Australian Museum for use of the facilities and to G.W. Kendrick (Department of Earth and Planetary Sciences), and S. Slack-Smith (Department of Aquatic Sciences) for kind help. Similarly, I am grateful to the Keeper of Zoology of the Natural History Museum and Dr J.D. Taylor and Ms Kathie Way of the Malacology Section for help in various ways. The work was also supported by a Royal Society grant to undertake research at the University of Cambridge. I am grateful to the Society and the University for the opportunity to undertake part of this research there and to Dr E.M.
Harper (Department of Earth Sciences) for the benefit of many discussions.

\section{REFERENCES}

Aller, R.C. (1974). Prefabrication of shell ornament in the bivalve Laternula. Lethaia 7: 43-56.

Appukuttan, K.K. (1974). Rediscovery of Clavagella (Bryopa) lata (Clavagellidae: Bivalvia) from the Gulf of Mannar, southeast coast of India. Journal of the Malacological Society of Australia 3: 19-24.

Atkins, D. (1937). On the ciliary mechanisms and interrelationships of lamellibranchs. Part III. Types of lamellibranch gills and their food currents. Quarterly Journal of Microscopical Science 79: 375-421.

Beu, A.G. and Maxwell, P.A. (1990). Cenozoic Mollusca of New Zealand. New Zealand Geological Survey and Paleontological Bulletin 58: 1-518.

Brocchi, G. (1814). Conchiologica fossile subapennina con osservazioni geologiche sugli Apennini e sul suolo adiacente. Stamperia Reale: Milan. 1-240 + 241-712, plates I-XVI.

Broderip, W.J. (1834). On Clavagella. Proceedings of the Zoological Society of London (1833-1834) 2: 115-117.

Broderip, W.J. (1835). On Clavagella. Transactions of the Zoological Society of London 1, 261-268, plates 1-35.

Bruguière, M. (1789). Encyclopédie Méthodique; Histoire Naturelle des Vers, Vol.1 (XV), 126-130, genus 33. Panckoucke: Paris.

Carter, J.G. (1978). Ecology and evolution of the Gastrochaenacea (Mollusca: Bivalvia) with notes on the evolution of the endolithic habit. Bulletin of the Peabody Museum 41: 1-92.

Carter, J.G. and Aller, R.C. (1975). Calcification of the bivalve periostracum. Lethaia 8: 315-320.

Chenu, M. (1843a). Clavagella. Clavagella. Illustration de Conchyliologie ou Description et Figures de toutes les Coquilles Connues, Vivants et Fossile 1: 1-4, plates 12. Paris: Masson.

Chenu, M. (1843b). Aspergillum. Arrosoir. Illustration de Conchyliologie ou Description et Figures de toutes les Coquilles Connues, Vivantes et Fossile 1: 1-4, plates 3-4. Masson: Paris.

Cossmann, M. and Pissarro, G. (1904-1913). Iconographie complète des coquilles fossils de l'Eocéne des environs de Paris. Atlas. 110 plates. Levrault: Paris

Cotton, B.C. (1952). Appendix IV. The Mollusca of the Adelaidean Stage. In: Miles, K. R. editor. Geology and Underground Water Resources of the Adelaide Plains Area Geological Survey of South Australia Bulletin No. 27: 239-243.

Cotton, B.C. (1961). South Australian Mollusca. Pelecypoda. South Australian Government Printer: Adelaide.

Darragh, T.A. (1970). Catalogue of Australian Tertiary Mollusca (except chitons). Memoirs of the National Museum of Victoria 31: 125-212.

Darragh, T.A. (1985). Molluscan biogeography and biostratigraphy of the Tertiary of southeastern Australia. Alcheringa 9: 83-116.

Darragh, T.A. and Kendrick, G.W. (1980). Eocene 
bivalves from the Pallinup Siltstone near Walpole, Western Australia. Journal of the Royal Society of Western Australia 63: 5-20.

Darragh, T.A. and Kendrick, G.W. (2000). Eocene bivalves and gastropods from the Pallinup Siltstone, Western Australia, with new records from the Eocene and Oligocene of southeastern Australia. Proceedings of the Royal Society of Victoria 112: 17-58.

Deshayes, G.-P. (1824). Description des Coquilles Fossiles des Environs de Paris. Tome Premiere. Conchifères. Paris.

Dharma, B. (1992). Indonesian Shells. Hemmen: Wiesbaden.

Dixon, F. (1878). The Geology of Sussex; or the Geology and Fossils of the Tertiary and Cretaceous Formations of Sussex. W.J. Smith: Brighton.

Dreyer, H., Steiner, G. and Harper, E. M. (2003). Molecular phylogeny of Anomalodesmata (Mollusca: Bivalvia) inferred from 18S rRNA sequences. Zooogical Journal of the Linnean Society 139: 229246.

Dunker, G. (1882). Index Molluscorum Maris Japonica. Cassellis Cattorum. 301 pp.

Eames, F.E. (1957). Eocene Mollusca from Nigeria (a revision). Bulletin of the British Museum (Natural History), Geology 3 (2): 1-70, plates 1-10.

Fischer, P. (1887). Manuel de Conchyliologie 1-1369, plates 1-23.

Forbes, E. (1846). Report on the fossil Invertebrata from southern India, collected by Mr. Kaye and $\mathrm{Mr}$. Cunliffe. Transactions of the Geological Society. Series 2. VII, 97-174 + unpaginated map, plates VII-IX.

Gammon, P.R., James, N.P., Clarke, J.D.A. and Bone, Y. (2000). Sedimentology and lithostratigraphy of Upper Eocene sponge-rich sediments, southwestern Western Australia. Australian Journal of Earth Sciences 47: 1087-1103.

Garner, R. (1860). Figures Illustrating the Structure of Various Invertebrate Animals, (Molluscs and Articulata). John van Voorst: London.

Gravely, F.H. (1941). Shells and other animal remains found on the Madras Beach. Bulletin of the Madras Government Museum, New Series, Natural History Section 5 (1): 66.

Gray, J.E. (1852). On the structure of Humphreyia, an anomalous bivalve shell, hitherto confused with Aspergillum. Annals and Magazine of Natural History, Series 3, 2: 16-20.

Gray, J.E. (1847). A list of the genera of Recent Mollusca, their synonyma and types. Proceedings of the Zoological Society of London 15: 129-219.

Gray, J.E. (1858a). On the families of Aspergillidae, Gastrochaenidae and Humphreyiadae. Proceedings of the Zoological Society of London 26: 307-318.

Gray, J.E. (1858b). On the development of the shell and tube in Aspergillum. Annals and Magazine of Natural History 1: 423-426.

Habe, T. (1951). Genera of Japanese Shells, Pelecypoda and Scaphopoda. Kyoto, Japan. 96 pp.

Habe, T. (1977). Systematics of Mollusca in Japan. Bivalvia and Scaphopoda. Hokururyu-kan: Tokyo. 372 pp.
Habe, T. (1981). A catalogue of molluscs of Wakayama Prefecture, the Province of Kii. I. Bivalvia, Scaphopoda and Cephalopoda. Publications of the Seto Marine Biological Laboratory Special Publication Series VII: 1-301.

Harper, E.M. and Morton, B. (2000). Biology and functional morphology of Myochama anomioides Stutchbury, 1830 (Bivalvia: Anomalodesmata: Pandoroidea) with reference to cementation. Journal of Molluscan Studies 66: 403-416.

Harper, E.M. and Morton, B. (2004). Tube construction in the watering pot shell Brechites vaginiferus (Bivalvia, Anomalodesmata, Clavagelloidea). Acta Zoologica (Stockholm) 85: 149-161.

Harper, E.M., Hide, E.A. and Morton, B. (2000). Relationships between the extant Anomalodesmata: a cladistic test. In: Harper E. M., Crame J. A. and Taylor, J. D. editors. The Evolutionary Biology of the Bivalvia. Geological Society, London, Special Publications 177: 129-143.

Hornell, J. (1921). Common molluscs of India. Madras Fishery Bulletin (2), 14: 197.

Jones, D.S. and Nicol, D. 1989. Eocene clavagelloids (Mollusca: Pelecypoda) from Florida: the first documented occurrence in the Cenozoic of the western hemisphere. Journal of Paleontology 63: 320323.

Jousseaume, E. (1888). Descriptions des mollusques recueillis par M. Le Dr. Faurot dans la Mer Rouge et Le Golfe D'Aden. Mémoirs de la Societie Zoologie, France 1: 165-223.

Keen, M. and Smith, L.A. (1969). Superfamily Clavagellacea d'Orbigny, 1844. In: Moore, R. C. editor. Treatise on Invertebrate Paleontology, Part N, Vol. 2: Mollusca 6, Bivalvia). pp. N857-N859. Geological Society of America and University of Kansas Press, Lawrence, Kansas. 951 pp.

Kemp, E.M. (1978). Tertiary climatic evolution and vegetation history in the Southeast Indian Ocean Region. Palaeogeography, Palaeoclimatology, Palaeoecology 24: 169-208.

Kilburn, R.N. (1974). A new species of Clavagella s.s. (Bivalvia: Clavagellidae) from Natal, South Africa. Journal de Conchyliologie 111 (3-4): 89-92.

Kossmatt, F. (1897). The Cretaceous deposits of Pondicherri (translated by A. H. Foord and A.H. Foord). Records of the Geological Survey of India 2: 51-110, pls 6-10.

Kuroda, T. and Habe, T. (1971). Sea Shells of Sagami Bay. Japan: Tokyo.

Lacaze-Duthiers, H. (1870). Sur l'organization de l'Arrosoir, Aspergillum javanicum. Compte rendu hebdomadaire des Séances de l'Academie des Sciences, Paris 70: 268-271.

Lacaze-Duthiers, H. (1883). Anatomie de $1^{\prime}$ Arrosoir (Aspergillum dichotomum, L. Reeve). Archives de Zoologie et Experimentale Generale 2: 1-68.

Lamarck, M. (1818). Histoire Naturelle des Animaux sans Vertèbres. Volume 5. Paris.

Lamprell, K. and Healy, J. (1998). Bivalves of Australia. Vol.2. Backhuys Publishers: Leiden. 288 pp.

Lamy, E. (1923). Les Clavagelles et Arrosoirs de la Mer 
Rouge ( $d$ 'apres les materioux recueillis par le Dr. Jousseaume). Bulletin du Muséum National d'Histoire Naturelle, Paris 19: 104-107.

Little, C. (2005). Mysterious fossils. Palaeontology Newsletter 59: 66-67.

Lukoviæ, M.T. (1922). The Eocene molluscan fauna from the area between the Aral Sea and Lake Chalkar and its importance. Annales Géologiques de la Péninsule Balkanique 8: 22-82.

Magne, A. (1941). De l'existence dans le Miocène de l'Aquitane du Brechites (Pseudobrechites) leognanum Hoeinghaus. Journal de Conchyliologie 38: 55-57.

Majima, R. (1991). Redescription and mode of occurrence of Nipponoclava yokoyamai (Shikama, 1954) (Clavagellidae: Bivalvia) from the Plio-Pleistocene warm-water fauna in Japan. Proceedings of the Paleontological Society of Japan 162: 781-793.

Maxwell, P.A. (1978). Taxonomic and nomenclatural notes on some New Zealand Cenozoic Mollusca, with descriptions of new taxa. New Zealand Journal of Zoology 5: 15-46.

Mayoral, E. (1990). Bivalvia Clavagellacea (Stirpulina pliocenica nov. sp.) del Neogeno superior de la Cuenca del Bajo Guad alquivar. Trebells Museum de Geologia, Barcelona 1: 117-134.

Michelotti, G. (1861). Études sur le Miocène Inférieur de l'Italie septentrionale. Hollandsche Maatschapij der Wetenschappen, Haarlam, Natuurkundige Verhandelingen, Series 2 15: 1-184.

Moesch, C. (1875). Monographie der Pholadomyen. Abhandlungen der schweizerischen paläontologischen Gesellschaft 1 (2): 1-125, plates 144.

Morton, B. (1974). Some aspects of the biology and functional morphology of Cleidothaerus maorianus Finlay (Bivalvia: Anomalodesmata: Pandoracea). Proceedings of the Malacological Society of London 41: 201-222.

Morton, B. (1980). The anatomy of the "living fossil" Pholadomya candida Sowerby, 1823 (Mollusca: Bivalvia: Anomalodesmata). Videnskabelige Meddelelser fra Dansk naturhistorik Forening $i$ Kjobenhavn 142: 7-102.

Morton, B. (1981). The Anomalodesmata. Malacologia 21: 35-60.

Morton, B. (1982). Pallial specializations in Gastrochaena (Cucurbitula) cymbium Spengler, 1783 (Bivalvia: Gastrochaenacea). In: Morton, B. and Tseng, C. K. editors. The Marine Flora and Fauna of Hong Kong and Southern China, Proceedings of the First International Marine Biological Workshop: the Marine Flora and Fauna of Hong Kong and Southern China, Hong Kong 1980. pp. 859-873. Hong Kong: Hong Kong University Press.

Morton, B. (1983). The biology and functional morphology of Eufistulana mumia (Bivalvia: Gastrochaenacea). Journal of Zoology, London 200: 381-404.

Morton, B. (1984a). The biology and functional morphology of Clavagella australis (Bivalvia: Anomalodesmata). Journal of Zoology, London 202: 489-511.
Morton, B. (1984b). Adventitious tube construction in Brechites vaginiferus (Bivalvia: Anomalodesmata: Clavagellacea) with an investigation of the juvenile of "Humphreyia strangei". Journal of Zoology, London 203: 461-484.

Morton, B. (1985a). Adaptive radiation in the Anomalodesmata. In: Trueman, E. R. and Clark, M. R. editors. The Mollusca, Vol. 10, Evolution. pp. 405459. Academic Press: New York.

Morton, B. (1985b). Tube formation in the Bivalvia. Soosiana 13: 11-26.

Morton, B. (1985c). Statocyst structure in the Anomalodesmata (Bivalvia). Journal of Zoology, London 206: 23-34.

Morton, B. (1987). The mantle margin and radial mantle glands of Entodesma saxicola and E. inflata (Bivalvia: Anomalodesmata: Lyonsiidae). Journal of Molluscan Studies. 53: 139-151.

Morton, B. (1990). Corals and their bivalve borers: the evolution of a symbiosis. In: Morton, B. editor. The Bivalvia. Proceedings of a Memorial Conference in Honour of Sir Charles Maurice Yonge, Edinburgh 1986. pp. 11-46. Hong Kong University Press: Hong Kong.

Morton, B. (1995). The evolutionary history of the Bivalvia. In: Taylor, J.D. (ed.), The Origin and Evolutionary Radiation of the Mollusca. pp. 337-359. Oxford University Press: Oxford.

Morton, B. (2002a). Biology and functional morphology of the watering pot shell Brechites vaginiferus (Bivalvia: Anomalodesmata: Clavagellidae). Journal of Zoology, London 257: 545-562.

Morton, B. (2002b). The biology and functional morphology of Humphreyia strangei (Bivalvia: Anomalodesmata: Clavagellidae): an Australian cemented watering pot shell. Journal of Zoology, London 258: 11-25

Morton, B. (2003a). The biology and functional morphology of Dianadema gen. nov. multangularis (Bivalvia: Anomalodesmata: Clavagellidae). Journal of Zoology, London 259: 389-401.

Morton, B. (2003b). The biology and functional morphology of Bentholyonsia teramachii (Bivalvia: Lyonsiellidae): clues to the origin of predation in the deep water Anomalodesmata. Journal of Zooogy, London 261: 363-380.

Morton, B. (2004a). The biology and functional morphology of Foegia novaezelandiae (Bivalvia: Anomalodesmata: Clavagelloidea) from Western Australia. Malacologia 46: 37-55.

Morton, B. (2004b). The biology and functional morphology of Nipponoclava gigantea: clues to the evolution of tube dwelling in the Penicillidae (Bivalvia: Anomalodesmata: Clavagelloidea). Journal of Zoology, London 264: 1-15.

Morton, B. (2004c). Biology and functional morphology of Kendrickiana gen. nov. veitchi (Bivalvia: Anomalodesmata: Clavagelloidea) from southern Australia. Invertebrate Biology 123: 244-259.

Morton, B. (2005). The biology and functional morphology of a new species of endolithic Bryopa (Bivalvia: Anomalodesmata: Clavagelloidea) from 
Japan and a comparison with the Eocene fossil Stirpulina coronata and other members of the Clavagellidae. Invertebrate Biology 124: 202-219.

Morton, B. (2006a). The structure and formation of the adventitious tube of the Japanese watering pot shell Stirpulina ramosa (Bivalvia: Anomalodesmata: Clavagellidae) and a comparison with that of the Penicillidae. Invertebrate Biology 125: 233-249.

Morton, B. (2006b). A new species and first record of the endobenthic clavagellid Stirpulina (Bivalvia: Anomalodesmata: Clavagellidae) from the Late Eocene of southern Western Australia. Alcheringa 30: 101-108.

Morton, B. (2006c). The functional morphology of Penicillus philippinensis (Anomalodesmata: Clavagelloidea) and the evolution of a unique muscular system in the Bivalvia. Records of the Western Australian Museum 23: 175-192.

Morton, B. and Harper, E.M. (2001). Cementation in Cleidothaerus albidus (Lamarck, 1819) (Bivalvia: Anomalodesmata: Pandoroidea). Molluscan Research 21: 1-15.

Morton, B. and Scott, P.J.B. (1980). Morphological and functional specializations of the shell, musculature and pallial glands in the Lithophaginae (Mollusca: Bivalvia). Journal of Zoology, London 192: 179-204.

Nakamine, T. and Habe, T. (1980). Three bivalve species collected from Okinawa, new to Japan. Chirobotan 11 (3): $38-40$.

Nicol, D. (1968). A new Meiocardia (Pelecypoda, Glossidae) from the Eocene of Florida. Nautilus 81: 89-93.

Oliver, P.G. and Holmes, A.M. (2004). Cryptic bivalves with descriptions of new species from the Rodrigues lagoon. Journal of Natural History 38: 3175-3227.

Omura, K. (1969). Fossil Penicillus from Ishikawa and Kagoshima Prefectures, Japan. Annals of Science, Kanazawa University College of Liberal Arts Part 2, 6: 25-39.

Orbigny, A.D.d'. (1843-1847). Terrains Crétacés. Vol. 3, Lamellibranches. Victor Massin: Paris. 807 pp.

Owen, R. (1835). On the anatomy of Clavagella Lam.. Transactions of the Zoological Society of London 1: 269-274.

Palazzi, S. and Villari, A. (2000). Mollusks and brachiopods from the submarine caves of Taormina, Sicily. La Conchiglia, Supplement No. 297: 1-56.

Pelseneer, P. (1911). Les lamellibranches de l'expedition du Siboga. Siboga-Expeditie Monographs 53a: 1-125, plates XXVI.

Pojeta, J., Jr. and Johnson, R. (1995). Parastirpulina sohli: a new Cretaceous clavagellid pelecypod. Geological Association of New Jersey 12: 14-23.

Pojeta, J., Jr. and Sohl, N.F. (1987). Ascaulocardium armatum (Morton, 1833), new genus (Late Cretaceous): the ultimate variation on the bivalve paradigm. Paleontological Society Memoirs 24: 1-77.

Pojeta, J., Jr. and Sohl, N.F. (1988). Eocene clavagellids from Florida. Journal of Paleontology 62: 8-26.

Prezant, R.S. (1979a). Shell spinules of the bivalve Lyonsia hyalina. Nautilus 93: 93-95.

Prezant, R.S. (1979b). The structure and function of the radial mantle glands of Lyonsia hyalina (Bivalvia: Anomalodesmata). Journal of Zoology, London 187: 505-516.

Purchon, R.D. (1956). A note on the biology of Brechites penis (L.). Lamellibranchia. Zoological Journal of the Linnean Society 43: 43-54.

Purchon, R.D. (1958a). The stomach in the Eulamellibranchia: Stomach Type IV. Proceedings of the Zoological Society of London 131: 487-525.

Purchon, R.D. (1958b). Phylogeny in the Lamellibranchia. Proceedings of the Centenary Congress of Biology, Singapore 1958. 69-82.

Purchon, R.D. (1960). A further note on the biology of Brechites penis (L). Lamellibranchia. Proceedings of the Malacological Society of London 34: 19-23.

Purchon, R.D. (1968). The biology of the Mollusca. Oxford: Pergamon Press. 560 pp.

Reeve, L. (1860). Aspergillum. Conchologia Iconica 12: plate 1.

Reeve, L. (1873). Clavagella. Conchologia Iconica 18: plates 1-8.

Runnegar, B. (1972). Anatomy of Pholadomya candida (Bivalvia) and the origin of the Pholadomyidae. Proceedings of the Malacological Society of London 40: 45-50.

Runnegar, B. (1974). Evolutionary history of the bivalve subclass Anomalodesmata. Journal of Paleontology 48: $904-939$.

Sacco, F. (1901). I Molluschi dei terreni terziarii del Piemonte e della Liguria. Parte XXIX. C. Clausen: Torino.

Satyamurti, S.T. (1956). The Mollusca of Krusadi Island (in Gulf of Mannar). Scaphopoda, Pelecypoda and Cephalopoda. Bulletin of the Madras Government Museum, New Series, Naural History Section 1 (2): part 7, 1-202.

Savazzi, E. (1982a). Adaptations to tube dwelling in the Bivalvia. Lethaia 15: 275-297.

Savazzi, E. (1982b). Clavagellacea (Bivalvia) from the Tertiary of the Venetian region, NE Italy. Acta Geologica Polonica 32: 83-91, plates 1-2.

Savazzi, E. (1990). Biological aspects of theoretical shell morphology. Lethaia 23: 195-212.

Savazzi, E. (1999). Boring, nestling and tube-dwelling bivalves. In: Savazzi, E. (ed.), Functional Morphology of the Invertebrate Skeleton. pp. 205-237. John Wiley: Chichester.

Savazzi, E. (2000). Morphodynamics of Bryopa and the evolution of clavagellids. In: Harper, E.M., Taylor, J.D and Crame, J.A. (eds), The Evolutionary Biology of the Bivalvia. pp. 313-327. Geological Society, London, Special Publications 177.

Savazzi, E. (2005). The function and evolution of lateral asymmetry in boring endolithic bivalves. Paleontological Research 9: 169-187.

Shackleton, N.J. and Kennett, J.P. (1975). Palaeotemperature history of the Cenozoic and the initiation of Antarctic glaciation: oxygen and carbon isotope analyses in DSDP sites 277, 279, 281. Initial Reports of the Deep Sea Drilling Project 29: 743-755.

Shikama, T. (1954). Clavagellid fossils from Japan. 
Scientific Reports, Yokohama National University Section II. 3: 63-65.

Smith, B.J. (1971). A revision of the family Clavagellidae (Pelecypoda Mollusca) from Australia with descriptions of two new species. 2: 135-161.

Smith, B.J. (1976). Revision of the recent species of the family Clavagellidae (Mollusca: Bivalvia). Journal of the Malacological Society of Australia 3: 187-209.

Smith, B.J. (1978). Further notes on the Clavagellidae, with speculation on the process of tube growth. Journal of the Malacological Society of Australia 4: 77-79.

Smith, B.J. (1998). Superfamily Clavagelloidea. In: Beesley, P. L., Ross, G. J. B. and Wells, A. (eds), Mollusca: the Southern Synthesis. Fauna of Australia. Vol. 5, Part A. pp. 412-415. Melbourne: CSIRO Publishing.

Smith, E.A. (1909). Note on the very young stage of the genus Humphreyia. Proceedings of the Malacological Society of London 9: 23-25.

Smith, L.A. (1962a). Historical zoogeographic study of the Clavagellacea. Veliger 5: 15-19.

Smith, L.A. (1962b). Revision of the Clavagellacea. The Veliger 4: 167-174.

Soliman, G.N. (1971). On a new clavagellid bivalve from the Red Sea. Proceedings of the Malacological Society of London 39: 389-397.

Sowerby, G.B. (1888). Description of a gigantic new species of Aspergillum from Japan. Proceedings of the Zoological Society of London 1888: 290.

Stallwood, R.B. (1995). A Turonian clavagellid (Bivalvia) from the Ladd Formation of southern California. Journal of Paleontology 69: 84-88.

Starobogatov, Y.I. (1992). Morphological basis for phylogeny and classification of Bivalvia. Ruthenica 2: $1-25$.

Stasek, C.R. (1963). Synopsis and discussion of the association of ctenidia and labial palps in the bivalved Mollusca. The Veliger 6: 91-97

Stoliczka, F. (1870-1871). The Cretaceous fauna of southern India III. The Pelecypoda with a review of all known genera of this class, fossil and Recent. Memoirs of the Geological Society of India 3: 1-538.

Sundaram, R., Henderson, R.A., Ayyasami, K. and Stilwell, J.D. (2001). A lithostratigraphic revision and palaeoenvironmental assessment of the Cretaceous System exposed in the offshore Cauvery Basin, southern India. Cretaceous Research 22: 743-762.

Swennen, C., Moolenbeek, R.G., Ruttanadukal, N., Hobbelink, H., Dekker, H. and Hajisamae, S. (2001). The Molluscs of the Southern Gulf of Thailand. Biodiversity Research and Training Program, Bangkok.

Tate, R. (1887a). Descriptions of some new species of South Australian marine freshwater Mollusca. Transactions of the Royal Society of South Australia 9: 62-75, plates 4-5.

Tate, R. (1887b). The Lamellibranchia of the Older Tertiary of Australia (Part II). Transactions of the Royal Society of South Australia 9: 142-189, plates 14-20.
Taylor, J.D., Kennedy, W.J. and Hall, A. (1969). The shell structure and mineralogy of the Bivalvia. Introduction. Nuculacea-Trigonacea. Bulletin of the British Museum (Natural History), Zoology Supplement 3: 1-125.

Taylor, J.D., Kennedy, W.J. and Hall, A. (1973). The shell structure and mineralogy of the Bivalvia. II. Lucinacea - Clavagellacea. Conclusions. Bulletin of the British Museum (Natural History), Zoology 22: 255-294.

Taylor, J.D., Glover, E.A. and Braithwaite, C.J.R. (1999). Bivalves with 'concrete overcoats': Granicorium and Samarangia. Acta Zoologica 80: 285-300.

Turner, R.D. (1966). A Survey and Illustrated Catalogue of the Teredinidae (Mollusca: Bivalvia). Harvard University: Cambridge, Massachusetts.

Vaught, K.C. (1989). Abbott, R. T. and Boss, K. J. editors. A Classification of the Living Mollusca. American Malacologists Inc.: Melbourne, Florida.

Vokes, H.E. (1980). Genera of the Bivalvia: a Systematic and Bibliographic Catalogue (Revised and Updated). Palaeontological Research Institution: Ithaca, New York. 307 pp.

Wallace, A.R. (1869). The Malay Archipelago. Macmillan \& Co.: London.

Yonge, C.M. (1928). Structure and function of the organs of feeding and digestion in the septibranchs, Cuspidaria and Poromya. Philosophical Transactions of the Royal Society of London, Series B 216: 221-263.

Yonge, C.M. (1962). On the primitive significance of the byssus in the Bivalvia and its effects in evolution. Journal of the Marine Biological Association of the United Kingdom 42: 113-125.

Yonge, C.M. (1971). On functional morphology and adaptive radiation in the bivalve superfamily Saxicavacea (Hiatella (=Saxicava), Saxicavella, Panomya, Panope, Cyrtodaria). Malacologia 11: 1-44.

Yonge, C.M. (1978a). Significance of the ligament in the classification of the Bivalvia. Proceedings of the Royal Society of London, Series B 202: 231-248.

Yonge, C.M. (1978b). On the monomyarian, Acostaea rivoli and evolution in the family Etheriidae (Bivalvia: Unionacea). Journal of Zoology, London 184: 429-448.

Yonge, C.M. (1982). Mantle margins with a revision of siphonal types in the Bivalvia. Journal of Molluscan Studies 48: 102-103.

Yonge, C.M. and Morton, B. (1980). Ligament and lithodesma in the Pandoracea and the Poromyacea with a discussion on evolutionary history in the Anomalodesmata. Journal of Zoology, London 191: 263-292.

Manuscript accepted 3 May 2007 


\section{APPENDIX}

Abbreviations used in the figures

AA Anterior adductor muscle (or scar)

$A C$ Anterior crest

AGI Anterior growth increment

APR Anterior pedal retractor muscle

ASM Anterior suspensory muscle

AT Anterior tubules

AU Auricle (of heart)

C Chondrophore

C-P-V-CONN Cerebro-pleural-visceral connective

CR Crypt

CT Crown of tubules

CTE Ctenidia

DD Digestive diverticula

DE Debris

DP Disc papilla

EAT End of primary adventitious tube

ES Exhalant siphon

ESWP Posterior extension of secondary watering pot

EU Eroded umbo

FP Fused periostracum

FPA Fourth pallial aperture

$\mathrm{H}$ Heart

HP Hinge plate

HT? Hinge tooth

IBC Infra-branchial chamber

IGI Internal growth increment

IS Inhalant siphon

K Kidney

LI Lithodesma

LP Lateral papilla

LR Lateral ridge

LV Left shell valve

M Mantle

MM Mantle margin

NL Nacreous layer of shell

OLP Outer labial palp

PA Posterior adductor muscle (or scar)

PC Posterior crest
PE Periostracum

PEC Pericardium

PEP Perforate watering pot

PG Pedal gape

PL Pallial line

PM Proprioreceptor muscle

PPR? Posterior pedal retractor muscle

PR Prodissoconch

PRG Proprioreceptor ganglion

PRL Primary ligament

PRM Pallial retractor muscle

PRM1 Pallial retractor muscle (component 1)

PRM2 Pallial retractor muscle (papillate component 2)

PS Pallial sinus

PSS Proprioreceptor sensory sac

PWP Primary watering pot

$\mathrm{R}$ Rectum

RAT Right anterior tubules

RE Repair in adventitious tube

RV Right shell valve

$S$ Siphons

SA Saddle area of shell valve

SAG Sand grains

SBC Supra-branchial chamber

SC Siphonal channel

SRM Siphonal retractor muscles

STG Subsequent tube growth

SV Shell valve

SWP Secondary watering pot

T Adventitious tube

TJ Triple junction

TU Watering pot tubules

U Umbo

UBW Unlined burrow wall

$\checkmark$ Ventricle

VM Ventral mantle

VT Ventral tubules

WF Wood fibres 